\title{
GRAPTOLITOS DEL TREMADOCIENSE (ORDOVÍCICO INFERIOR) DE LA FORMACIÓN VOLCANCITO, SISTEMA DE FAMATINA (LA RIOJA, ARGENTINA)
}

\author{
Juan Carlos GUTIÉRREZ-MARCO ${ }^{1}$ y Susana B. \\ ESTEBAN ${ }^{2}$
}

${ }^{1}$ Instituto de Geología Económica (CSIC-UCM), Facultad de Ciencias Geológicas, 28040 Madrid, España, y Academia Nacional de Ciencias, Av. Vélez Sarsfield 229, Casilla de Correo 36, 5000 Córdoba, Argentina. c/e: jcgrapto@geo.ucm.es ${ }^{2}$ Instituto Superior de Correlación Geológica (CONICET-Universidad Nacional de Tucumán), Facultad de Ciencias Naturales e IML, Miguel Lillo 205, 4000 Tucumán, Argentina. c/e: susana_esteban@yahoo.com.ar

Gutiérrez-Marco, J.C. \& Esteban, S. B. 2005. Graptolitos del Tremadociense (Ordovícico Inferior) de la Formación Volcancito, Sistema de Famatina (La Rioja, Argentina). [Tremadocian (Lower Ordovician) graptolites from the Volcancito Formation, Famatina System (La Rioja, Argentina).] Revista Española de Paleontología, 20 (1), 65-118. ISSN 0213-6937.

\begin{abstract}
Tremadocian graptolites from the Famatina System (NW Argentina) occurred mainly in the black shales that characterized the Peña Negra Member of the Volcancito Formation. Bed-by-bed collecting of graptolites through the $400 \mathrm{~m}$ thick sequence of the Peña Negra and Volcancito river sections, resulted in a complete taxonomic and biostratigraphic reappraisal of the abundant graptolite record, which is merited by recent review and correlation of the Tremadocian chronozones and global graptolite assemblages. The two sections are not exactly time equivalent as there were considered largely until the present study, reaching younger beds in Volcancito river. The oldest Ordovician graptolites occur in the upper part of the Filo Azul Member of the Volcancito Formation, with an assemblage probably representative of the Early Tremadocian Rhabdinopora flabelliformis parabola chronozone, placed slightly above the Cambrian-Ordovician boundary as indicated by trilobite and conodont distributions. Graptolite assemblages from the lower part of the Peña Negra Member of the Volcancito Formation are correlated with the Anisograptus matanensis and $R$. f. anglica graptolite chronozones of the upper Lower Tremadocian. Above the respective biozones, the remaining upper two thirds of the formation probably correlate with the lowest Upper Tremadocian ?Adelograptus Zone, in absence of batipelagic assemblages of delicate adelograptids or the epipelagic warm-water genus Psigraptus. This data agrees with the occurrence of Upper Tremadocian conodonts and graptolites, namely the Paltodus deltifer conodont biozone and the graptolitic "Assemblage 4", in the overlying Bordo Atravesado Formation. The black graptolite shales of the Volcancito Formation were deposited under anoxic conditions in an outer shelf to basin plain along the margings of western Gondwana, before the origination and emersion of the Famatinian Volcanic Arch. The anoxic conditions probably developed under a restricted upwelling area with high productivity that was a favourable habitat for some endemic holopelagic and mesopelagic rhabdinoporinids. From a paleontological point of view, the identified and described forms are Rhabdinopora flabelliformis flabelliformis, $R$. f. anglica, $R$. f. socialis, $R$. f. ?bryograptoides, $R$. cf. enigma, Anisograptus matanensis and ?Bryograptus sp. The bad characterized form Rhabdinopora flabelliformis famatinensis is here restricted to the holotype. Two new taxa, Rhabdinopora turneri sp. nov. and $R$. flabelliformis acenolazai subsp. nov., are respectively reminiscent of $R$. praeparabola and $R$. f. parabola, both global elements of the earliest Tremadocian graptolite "Assemblage 1". However the record of the new Famatinian forms, besides different average morphology and measurements, is rather younger and clearly postdate the appearance of rhabdosomes with triradiate development, being distributed in the A. matanensis and $R$. $f$. anglica zones. Together with the planktic graptolites, some transported remains of rooted (benthic) dendroids are recorded from some levels and described as Dendrograptus sp., Dictyonema sp. nov. 1, Aspidograptus cuerdai sp. nov., ?Pseudocallograptus sp. and ?Airograptus guillermoi sp. nov.. The first occurrence of a remarkable benthic graptolite (?Dictyonema sp. cf. D. cordillerensis) in the Tremadocian Bordo Atravesado Formation is also reported.
\end{abstract}

Key words: Graptolites, Anisograptidae, Dendrograptidae, biostratigraphy, Ordovician, Tremadocian, Famatina, Argentina. 


\section{RESUMEN}

El Miembro Peña Negra de la Formación Volcancito (Tremadociense) del Sistema de Famatina (noroeste argentino) consta de pizarras negras graptolíticas, que se investigaron paleontológicamente, capa a capa, a lo largo de 400 m de sucesión en las secciones complementarias de Peña Negra y río Volcancito, la segunda de las cuales incluye los niveles más modernos. Los resultados bioestratigráficos permiten una correlación precisa con las asociaciones evolutivas y cronozonas globales de graptolitos del Tremadociense, y la reevaluación de todas las dataciones e identificaciones previas de la unidad. Los graptolitos más antiguos se localizan en el Miembro Filo Azul de la formación (Cámbrico Superior-Tremadociense) y se adscriben muy probablemente a la cronozona de Rhabdinopora flabelliformis parabola de la base del Ordovícico, lo que concuerda con los datos suministrados por los trilobites y conodontos. Las asociaciones graptolíticas de la parte baja del Miembro Peña Negra pertenecen a las cronozonas de Anisograptus matanensis and $R$. $f$. anglica, indicativas del Tremadociense superior tardío. Los dos tercios restantes del Miembro Peña Negra se correlacionan probablemente con el Tremadociense superior temprano (cronozona de Adelograptus?), en ausencia de asociaciones batipelágicas típicas con adelográptidos delicados, o formas epipelágicas de aguas cálidas como Psigraptus. Esta posible atribución se apoya también en el registro de conodontos y graptolitos del Tremadociense superior en la Formación Bordo Atravesado suprayacente. Las pizarras negras graptolíticas de la Formación Volcancito se depositaron en fondos anóxicos profundos (de plataforma externa a planicie cuencal) en el margen de Gondwana occidental, previamente al nacimiento y emersión del Arco Volcánico Famatinense. El desarrollo de condiciones anóxicas tuvo que ver con la aparición de un área de afloramiento oceánica con elevada productividad orgánica, que constituyó el hábitat favorable para los rhabdinoporínidos holo- y mesopelágicos, donde se desarrollaron algunas formas endémicas. Desde el punto de vista paleontológico, se identifican y describen Rhabdinopora flabelliformis flabelliformis, $R$. $f$. anglica, $R$. $f$. socialis, $R$. f. bryograptoides?, R. cf. enigma, Anisograptus matanensis y Bryograptus? sp. La forma Rhabdinopora flabelliformis famatinensis se propone restringirla al holotipo para obviar su mala caracterización taxonómica. Las nuevas formas Rhabdinopora turneri sp. nov. y R. flabelliformis acenolazai subsp. nov., guardan ciertas similitudes con los graptolitos planctónicos primitivos $R$. praeparabola y $R$. flabelliformis parabola, respectivamente. Sin embargo, los nuevos taxones del Famatina coexisten en horizontes más modernos de las cronozonas de A. matanensis y R.f. anglica, que claramente postdatan la aparición del desarrollo proximal trirradiado. Además de las formas planctónicas, se describen algunos restos transportados de graptolitos bentónicos como Dendrograptus sp., Dictyonema sp. nov. 1, Aspidograptus cuerdai sp. nov., Pseudocallograptus? sp. y Airograptus? guillermoi sp. nov.. Otro graptolito bentónico notable, Dictyonema? sp. cf. D. cordillerensis, se cita por vez primera en la Formación Bordo Atravesado del Tremadociense superior.

\section{Palabras clave: Graptolitos, Anisograptidae, Dendrograptidae, biostratigrafía, Ordovícico, Tremadociense, Famatina, Argentina.}

\section{INTRODUCCIÓN}

El Sistema de Famatina (provincias de Catamarca y La Rioja, Argentina) comprende importantes afloramientos fosilíferos del Cámbrico Superior y Ordovícico Inferior, conocidos desde el siglo XIX (Stelzner, 1872). Las unidades del Tremadociense y Arenigiense están formadas principalmente por pizarras negras, en las que se localizan niveles ricos en graptolitos, que han sido descritos en las localidades de Cuchilla Negra (Formación Portezuelo de las Minitas: Lavandaio, 1971, 1973; Aceñolaza \& Gutiérrez-Marco, 2000), río La Alumbrera (Formación La Alumbrera: Aceñolaza et al., 1976; Toro, 1997) y Peña Negra-río Volcancito (Formación Volcancito: Turner, 1960; Aceñolaza \& Durand, 1984; Esteban \& Gutiérrez-Marco, 1997; Tortello \& Esteban, 1999), ubicadas en ambos flancos del Sistema de Famatina (Fig. 1).

En este trabajo se estudian los graptolitos del Miembro Peña Negra de la Formación Volcancito, en parte descritos por Turner (1960) y Aceñolaza \& Durand (1984), presentándose un análisis bioestratigráfico y una taxonomía actualizada a la luz de la moderna revisión de los graptolitos del Tremadociense hecha por Cooper et al. (1998), Wang et al. (1998) y Cooper (1999).

El término Tremadociense se utiliza aquí como Piso/ Edad, en el sentido global aprobado oficialmente (Gradstein et al., 2003; Gradstein \& Ogg, 2004; Ogg, 2004; IUGS, 2004), que adapta el nombre de la serie Tremadoc de la escala regional británica (Fortey et al., 1995, con referencias previas). El Tremadociense constituye la división más antigua de la Serie / Época Ordovícico Inferior, adoptada formalmente con rango global (Webby, 1998; IUGS, 2004) y cuyo estratotipo de límite está situado en Terranova (Canadá), en vez de en las áreas topotípicas del Tremadoc británico (Cooper et al., 2001). Dentro del Tremadociense, los niveles estudiados corresponderían a la "porción de tiempo" 1a tardía y $1 \mathrm{~b}$ temprana (Time Slices de Webby et al., 2004). 


\section{MARCO GEOLÓGICO}

Los depósitos ordovícicos de la Cuenca del Famatina comprenden sedimentos epiclásticos (Cámbrico Superior alto-Tremadociense) y volcaniclásticos (Arenigiense/ Darriwiliense) expuestos en distintas localidades de las provincias de Catamarca y La Rioja, en el Noroeste de Argentina (Fig. 1a y 1b). Estos sedimentos, que se acumularon en una cuenca relacionada esencialmente con un arco volcánico existente para esta época en el oeste de Gondwana (Aceñolaza \& Toselli, 1988; Mángano \& Buatois, 1996; Mannheim, 1993; Aceñolaza et al., 1996; Astini, 1999), han sido reunidos bajo la denominación de Grupo Cachiyuyo (Aceñolaza \& Toselli, 1981). La Formación Volcancito constituye la unidad basal del mismo, y alcanza un espesor aproximado de $590 \mathrm{~m}$. Desde el punto de vista litoestratigráfico, la Formación Volcancito comprende dos miembros (Turner, 1964), modernamente asignados al Cámbrico Superior-Tremadociense temprano (Miembro Filo Azul) y al Tremadociense temprano (Miembro Peña Negra), respectivamente. La formalización de ambos miembros se debe a Albanesi et al. (2005). Esteban (1999a) había propuesto un tercer miembro terminal para la Formación Volcancito, el cual fue erigido recientemente como una formación independiente (Formación Bordo Atravesado: Esteban, 2002, 2003, con prioridad sobre la homónima de Astini, 2003).

La asociación de graptolitos estudiada en este trabajo, proviene del Miembro Peña Negra de la formación, aflorante en dos localidades del flanco oriental de la sierra de Famatina que distan 4 km entre sí: río Volcancito y Peña Negra (Fig. 1c). Ambos lugares se circunscriben a un área definida por los paralelos de $28^{\circ} 51^{\prime}$ y $28^{\circ} 53^{\prime}$ de latitud sur y los meridianos de $67^{\circ} 45^{\prime}$ y $67^{\circ} 46^{\prime}$ de longitud oeste.

Desde el punto de vista estratigráfico, los dos afloramientos se caracterizan por la presencia casi exclusiva de lutitas negras a gris oscuras, finamente laminadas y con marcada fisilidad, que sobreyacen a calcilutitas y margas oscuras con delgadas intercalaciones de calcarenitas, lumaquelas calcáreas y raras megabrechas tabulares, asignadas al Miembro Filo Azul de la Formación Volcancito (Fig. $3)$. En este último se registran variadas asociaciones de trilobites, braquiópodos y conodontos, que han permitido situar el límite Cámbrico-Ordovícico dentro del Miembro Filo Azul de la formación (Tortello \& Esteban, 1997, 1998, 1999; Tortello, 2003; Albanesi et al., 1999). Otros fósiles frecuentes son ciertas "algas" calcáreas, restos de pelmatozoos y, en menor medida, algunos ostrácodos, gasterópodos y poríferos por el momento indeterminados (Astini et al., 2000; Astini, 2001a y b).

En la sección de río Volcancito (Figs. 1c, 2a y 2b), el Miembro Peña Negra de la formación homónima alcanza un espesor aproximado de $180 \mathrm{~m}$. En la parte inferior se han observado abundantes horizontes con graptolitos, en los que se concentran y superponen numerosas colonias, algunas de ellas de gran tamaño. No obstante, el denso diaclasamiento que presentan estas rocas dificulta mucho la obtención de rabdosomas en buenas condiciones de estudio.

Por su parte en la sección de Peña Negra (Figs. 1c, 2c y 3), el espesor alcanzado es de $260 \mathrm{~m}$ y se han localizado numerosos niveles con graptolitos, así como con algunos restos de filocáridos y de esponjas hexactinélidas (Protospongia spp.: Esteban \& Rigby, 1998), y es de donde proviene la mayor parte del material paleontológico aquí descrito.

Finalmente, la Formación Volcancito da paso a más de $160 \mathrm{~m}$ de limolitas arcillosas masivas con intercalaciones de areniscas, antes consideradas como un tercer miembro de dicha formación, pero actualmente integradas en la nueva Formación Bordo Atravesado (Esteban, 2002, 2003). Su registro fósil comprende esencialmente trilobites (Esteban, 1992, 1996b, 1999b; Tortello \& Esteban, 1995, 2003b; Tortello et al., 2002) y filocáridos (Aceñolaza \& Esteban, 1996) del Tremadociense superior, a los que hay que añadir raros conodontos y graptolitos (Albanesi et al., 2000b, 2001, 2005) más algunos braquiópodos linguliformes (aún por estudiar) y ciertas estructuras biogénicas (Esteban, 1993, 2001).

En el presente trabajo no contemplamos los afloramientos supuestamente correlacionables con el Miembro Peña Negra de la Formación Volcancito en la Sierra de Narváez, de donde proceden algunos graptolitos mal conservados de la asociación Rhabdinopora-Anisograptus (Rubiolo et al., 2002), cuya revisión queda supeditada a la obtención de datos significativos.

\section{ANTECEDENTES}

Los primeros graptolitos del Famatina fueron descubiertos por Bodenbender (1911, 1912, 1916, 1922). Dicho autor reconoció la existencia de Dictyonema flabelliforme y Staurograptus dichotomus en los "esquistos negros" de la localidad de Peña Negra (curso alto del río Achavil), atribuyéndolos al "Cambriano superior-Siluriano inferior". Años más tarde, Harrington (en Harrington \& Leanza, 1957) define la Formación Volcancito en la sección del río homónimo, donde encontró abundantes graptolitos. Éstos fueron identificados por Turner en un informe inédito de 1951 (en Harrington \& Leanza, 1957: 15) como Dictyomena flabelliforme, Dictyonema sp., Callograptus sp. cf. $C$. salteri, Aspidograptus sp. cf. A. implicatus, Aspidograptus sp. cf. A. minor, Anisograptus sp. cf. A. flexuosus y Anisograptus sp. cf. A. richardsoni. Además, hace mención a un segundo afloramiento coincidente con el de Peña Negra, que se ubica $4 \mathrm{~km}$ al norte del río Volcancito. El mismo suministró numerosos restos de graptolitos atribuidos al Tremadociense inferior, correspondientes a las mismas especies antes citadas. 
Con posterioridad, Turner (1960) publica el material original de los dos trabajos precedentes, perteneciente a las colecciones Bodenbender, Flossdorf y Harrington (números 14 a 16 de su catálogo), depositadas en la Universidad de Buenos Aires. Discrimina la relación de especies identificadas en cada colección, e ilustra y describe: Aspidograptus cf. implicatus, Aspidograptus? cf. minor, Callograptus cf. salteri, Dictyonema flabelliforme var. famatinense nov., Dictyonema sp. b, Anisograptus cf. richardsoni y Anisograptus cf. flexuosus.

Turner (1964) vuelve a citar los mismos graptolitos con motivo del levantamiento cartográfico a escala 1:200.000 de la zona (Hoja 15c: Vinchina), indicando por vez primera que las asociaciones registradas en río Volcancito y Peña Negra podrían no ser idénticas, con una mayor diversidad relativa en Peña Negra, dado que Anisograptus flexuosus, Dictyonema sp. b y Aspidograptus? cf. minor faltan en el río Volcancito. Ello implicaría una cierta mezcla de elementos provenientes de ambas localidades en las tres colecciones publicadas con anterioridad.

Respecto al contexto estratigráfico de los horizontes con graptolitos, Harrington (en Harrington \& Leanza, 1957) los adscribe a la parte inferior de un tramo de 100 $\mathrm{m}$ de pizarras negras que sobreyace a una sucesión de pizarras silíceas y calizas margosas de $250 \mathrm{~m}$ de potencia, las cuales libraron a $60 \mathrm{~m}$ del techo abundantes restos de trilobites, braquiópodos y moluscos pertenecientes a la Zona de Parabolina argentina del Tremadociense temprano. De acuerdo con su posición estratigráfica y atendiendo a la presencia de ciertas especies de graptolitos dendroideos y Anisograptus, conocidos respectivamente en Gran Bretaña y Canadá, Turner \& Harrington (en Harrington \& Leanza, 1957: 26) asignan la asociación graptolítica al Tremadociense inferior alto, aproximadamente equivalen-

Figura 1. Localización de los afloramientos estudiados. a, ubicación del sector en el noroeste argentino (provincias de Catamarca y La Rioja). b, Esquema de la constitución geológica del Sistema de Famatina, señalando los principales afloramientos de rocas sedimentarias ordovícicas: A, Sierra de las Planchadas; B, Chaschuil; C, Cerro Negro de Rodríguez; D, Río La Alumbrera; E, Morro de Las Planchadas; F, Cerro El Pintado; G, Río Cachiyuyo; H, Río Volcancito-Peña Negra; I, Cuchilla Negra; J, Bordo Atravesado. Símbolos: 1, materiales post-paleozoicos; 2, Ordovícico sedimentario; 3, basamento paleozoico; 4, límite provincial. c, Detalle del área de estudio, con situación de las secciones fosilíferas de Río Volcancito y Peña Negra.

Location of the studied area. $\boldsymbol{a}$, Map of South America showing in black the placement of next figure in the NW of Argentina (Catamarca and La Rioja provinces). b, Geological scheme of the Famatina System, with the main outcrops of sedimentary Ordovician rocks: A, Sierra de las Planchadas; B, Chaschuil; C, Cerro Negro de Rodríguez; D, La Alumbrera river; E, Morro de Las Planchadas; F, Cerro El Pintado; G, Cachiyuyo river; H, Volcancito river-Peña Negra; I, Cuchilla Negra; J, Bordo Atravesado. Symbols: 1, post-Paleozoic rocks; 2, Ordovician sedimentary rocks; 3, other Paleozoic rocks; 4, provincial administrative border. $\boldsymbol{c}$, Detail of the area west of the Famatina city, showing the location of the graptolite localities and fossiliferous sections of Peña Negra and Volcancito river.
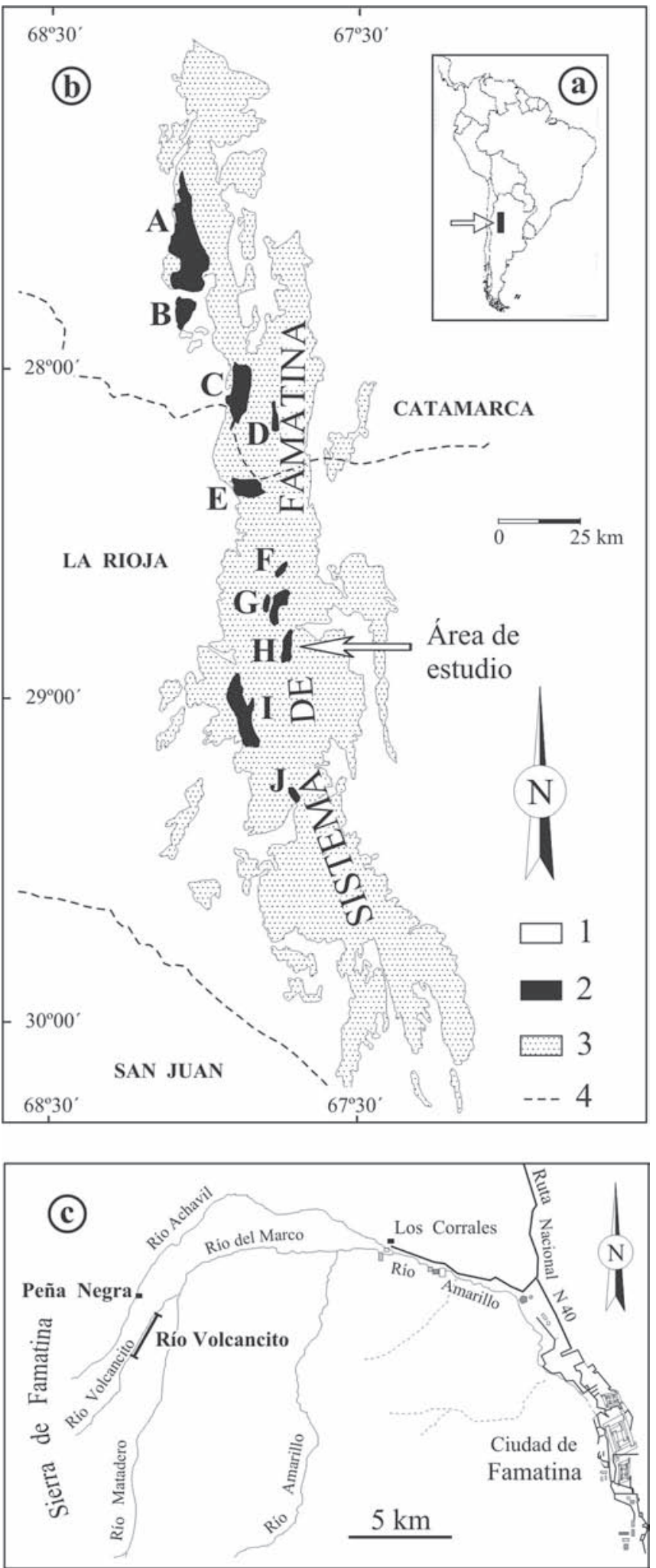
te en edad y posición a la Zona de Kainella meridionalis. Sin embargo, Turner (1960) correlaciona los niveles graptolíticos del Famatina con la parte media de la Zona de Dictyonema flabelliforme de otras áreas mundiales, considerándolos equivalentes a la parte superior de la Zona de Parabolina argentina.

Toselli $(1975,1977)$ reemprende el estudio de los graptolitos del Ordovícico Inferior del Famatina con motivo de su trabajo de tesis doctoral en geología regional. El autor describe e ilustra en 1975, como provenientes de Puesto Volcancito: Dictyonema flabelliforme var. famatinense, Anisograptus cf. richardsoni, Aspidograptus cf. implicatus y Aspidograptus sp. De forma paralela, en Peña Negra, las tres primeras especies se hallan acompañadas por Callograptus sp. y Clonograptus sp., género que se cita por vez
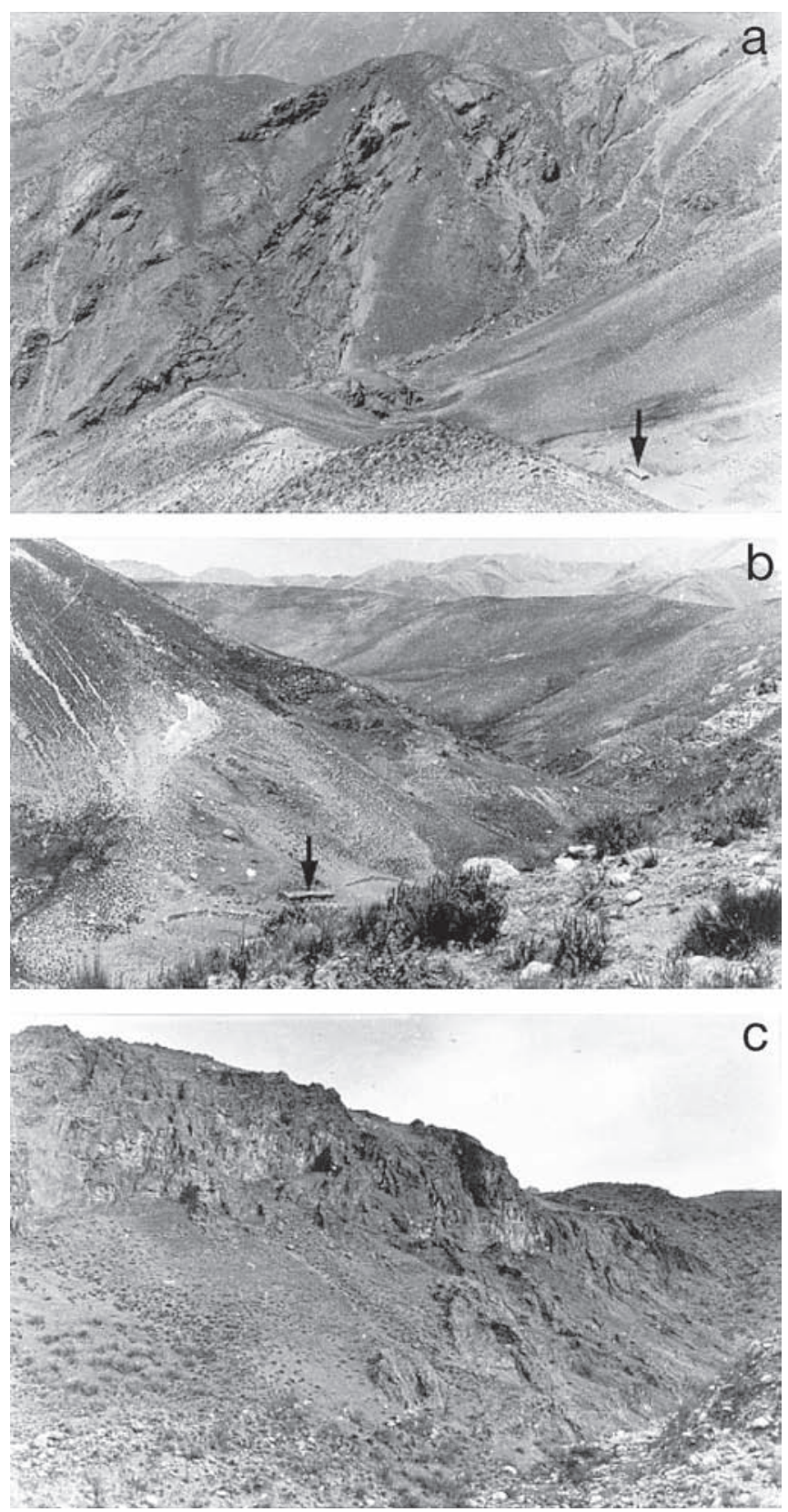

primera en estos niveles. La asociación en su conjunto fue asignada a la Zona de Dictyonema flabelliforme del Tremadociense inferior (espesor calculado: $380 \mathrm{~m}$ ), que aquí se situaría por encima de la Zona de Parabolina argentina - Kainella meridionalis.

La asociación encabezada por Dictyonema famatinense (sic) fue integrada por Erdtmann (1982a) en el grupo de "dictyonémidos de tipo Matane" (trirradiado), contrapuesto al grupo de D. flabelliforme, y que caracterizarían áreas profundas de cuencas de tipo geosinclinal o de retroarco. Los afloramientos graptolíticos de la Formación Volcancito fueron considerados "alóctonos" y comparados con la zona $\mathrm{F}$ (Tremadociense inferior tardío) a posiblemente la C (Tremadociense inferior pleno) de su cuadro de correlación (Erdtmann, 1982a: 11). El mismo autor (Erdtmann, 1982b) cita paralelamente, en otro trabajo, al taxón creado por Turner como Rhabdinopora flabelliformis famatinensis (sic).

Aceñolaza \& Durand $(1983,1984)$ hacen una revisión de las secciones graptolíticas del Tremadociense de la sierra de Famatina, determinando por vez primera la presencia de Dictyonema flabelliforme forma typica, D. flabelliforme var. anglica $(=D$. flabelliforme var. famatinense fide Aceñolaza \& Durand), Dictyonema cf. D. scitulum y Bryograptus sp. afín a $B$. kjerulfi. La misma lámina, reproducida en ambos trabajos, ilustra también ejemplos de Callograptus sp., Anisograptus sp., Anisograptus cf. A. flexuosus y Clonograptus sp. Los autores concluyen una probable edad "parte alta del Tremadociano inferior" para

Figura 2. Fotografías de los afloramientos estudiados en el Miembro Peña Negra de la Formación Volcancito. a-b, sección del río Volcancito mostrando los niveles basales (a la izquierda en a), y el tramo más elevado del Miembro Peña Negra (centro-izquierda de la foto b). Las flechas señalan el Puesto Volcancito, que sirve de escala, ubicado hacia los $3450 \mathrm{~m}$ de altitud. Los relieves más occidentales (al fondo en b) corresponden al Granito Nuñorco (Ordovícico). c, sección de Peña Negra, en el curso alto del río Achavil. En primer término se observa el tramo basal del Miembro Peña Negra, y más al fondo (hacia el oeste) los niveles más elevados de la unidad.

Field photographs of the studied sections, Peña Negra Member of the Volcancito Formation. $\boldsymbol{a}$ - $\boldsymbol{b}$, Volcancito river section, showing basal beds of the member (to the left in a), and the upper beds of same (left from the center in B). The small house arrowed in both pictures is Puesto Volcancito, lying on about $3,450 \mathrm{~m}$ hight. The westernmost mountains (skyline in b) are built by the Nuñorco Granite (Ordovician). c, Peña Negra section, in the upper valley of the Achavil river, showing a continuous outcrop of the Peña Negra Member of the Volcancito Formation, from basal beds (front view) to the highest part of the sucession (rigth background). 
el conjunto de la sucesión graptolítica, y ponen en duda las relaciones estratigráficas de la misma con el tramo que contiene los trilobites de la Zona de Parabolina argentina, el cual había sido descrito como infrayacente (y por tanto más antiguo) en trabajos anteriores.

En la misma línea precedente, Moya et al. (1994) correlacionan los graptolitos del Famatina con la "Asociación Graptolítica IV" de la Cordillera Oriental, que representaría el "Tremadoc inferior cuspidal".

Tortello et al. (1996) sintetizan el conocimiento paleontológico del Ordovícico de Famatina y resumen las descripciones de Anisograptus cf. richardsoni, A. cf. flexuosus, Aspidograptus cf. implicatus, A.? cf. minor, Callograptus cf. salteri y Rhabdinopora flabelliforme, reproduciendo algunas ilustraciones tomadas de autores anteriores.

Esteban \& Gutiérrez-Marco (1997) realizan la segunda revisión taxonómica de las especies de Rhabdinopora representadas en el Miembro Peña Negra de la Formación Volcancito, antecedente directo de este estudio. Estos autores confirman la presencia de Rhabdinopora flabelliformis, $R$. socialis y $R$. patula; mencionan en nomenclatura abierta otras tres especies (Rhabdinopora n. sp. 1, 2 y 3), y citan Anisograptus richardsoni, A. flexuosus y graptolitos bentónicos transportados (Aspidograptus, Callograptus?). El conjunto de estas asociaciones se correlacionaría con la "parte media a relativamente tardía del Tremadoc inferior (Cressagiense)". Estos mismos datos paleontológicos y bioestratigráficos son reiterados por Esteban et al. (1999) en una reciente síntesis acerca del Famatina.

Tortello \& Esteban (1999) describen una asociación de graptolitos distinta de las precedentes, que por provenir de la parte alta del Miembro Filo Azul de la Formación Volcancito, representarían los graptolitos más antiguos de la región del Famatina. Estos fueron asignados a Rhabdinopora flabelliformis cf. socialis y $R$. $f$. cf. norvegica, pero bajo esta última denominación se incluyen también ejemplares revisados aquí como $R$. f. cf. parabola (Fig. 3).

Albanesi \& Ortega (2002) confirman la presencia de $R$. f. anglica entre los ejemplares estudiados por Bodenbender (1916) y Turner (1960) en la sección del río Volcancito, refiriéndose tal vez con ello a su posible sinonimia con R. f. famatinensis, ya expresada por Aceñolaza \& Durand (1983, 1984). Toro \& Brussa (2003) sumarizan también las menciones de graptolitos en la Formación Volcancito, dando por cierta la cita de Rhabdinopora f. flabelliformis, y haciéndose eco de las determinaciones de $R$. $f$. socialis y $R$. f. anglica aportadas por otros autores.

Rubiolo et al. (2002) dan cuenta del hallazgo de un posible equivalente de la Formación Volcancito en la Sierra de Narváez (extremidad septentrional del Sistema de Famatina), citando el registro de ejemplares de Rhabdinopora sp. y Anisograptus mal conservados (identificaciones de Gladys Ortega).

Por último, Gutiérrez-Marco \& Esteban (2003, 2004) anticiparon un pequeño avance bioestratigráfico del pre- sente trabajo en la Séptima Conferencia Internacional de Graptolitos y el Simposio Bodenbender, respectivamente. Sus datos para el Miembro Peña Negra fueron retomados por Albanesi et al. (2005), quienes ilustran sendos ejemplares de Rhabdinopora flabelliformis ssp. cf. R. f. parabola procedentes del Miembro Filo Azul de la Formación Volcancito.

\section{BIOESTRATIGRAFÍA Y CORRELACIÓN}

La sucesión estratigráfica de la Formación Volcancito constituye una sección muy completa y representativa de los materiales del Cámbrico Superior tardío y del Ordovícico Inferior temprano (Tremadociense inferior), tal y como habían señalado los distintos autores mencionados en el epígrafe de antecedentes. Sin embargo, con referencia a la sucesión graptolítica apenas se conocían mayores detalles que la atribución de todo el conjunto al Tremadociense inferior (presumiblemente tardío) a partir de los trabajos de Turner (en Harrington \& Leanza, 1957, y Turner, 1960). Turner (1964) fue también el primer autor en considerar que las asociaciones de graptolitos de los afloramientos de Peña Negra y del río Volcancito presentaban diferencias taxonómicas y por lo tanto podrían no ser directamente correlacionables, aunque nadie más avanzó luego en el tema y la sucesión estratigráfica del Miembro Peña Negra de la Formación Volcancito (lutitas negras graptolíticas) pasó a ser considerada como virtualmente idéntica en ambas secciones.

En el presente trabajo se aporta el primer estudio bioestratigráfico detallado del registro principal de graptolitos tremadocienses en la Formación Volcancito, evaluando su distribución a la luz de las cronozonas globales (Cooper, 1999) y de los acontecimientos evolutivos ocurridos entre los primitivos graptoloideos planctónicos, que sirven de fundamento biocronológico esencial para la zonación internacional (Cooper, 1979, 1999; Erdtmann, 1988b; Wang, 2000).

Los graptolitos ordovícicos más antiguos se localizan hacia la parte alta del Miembro Filo Azul de la formación en la sección del río Volcancito (Fig. 3), y fueron estudiados por Tortello \& Esteban (1999). A pesar de que la revisión de sus horizontes de procedencia no forma parte de los objetivos del presente trabajo (centrado en la sucesión plenamente graptolítica del Miembro Peña Negra de la unidad), hemos tenido oportunidad de acceder al material original de la publicación mencionada, confirmando la presencia de Rhabdinopora flabelliformis cf. parabola sugerida por Albanesi et al. (2005: lám. 2 fig. 2 y 4). Dicho taxón equivale a los ejemplares estratigráficamente más bajos del género Rhabdinopora, que habían sido referidos en parte a $R$. $f$. cf. norvegica por Tortello \& Esteban (1999). Rhabdinopora flabelliformis parabola define una cronozona próxima al inicio del Periodo Ordovícico, 
y el posible hallazgo de su taxón nominal en el Miembro Filo Azul de la Formación Volcancito, ha sido adoptado aquí como límite inferior tentativo de la correspondiente unidad crono- y bioestratigráfica (Fig. 3). La base de la biocronozona de $R$. f. parabola coincide con la aparición de una malla elaborada entre los rhabdinoporininos cuadrirradiados de la "Asociación 1" de Cooper (1979) y Erdtmann (1988b). Con anterioridad a su posible hallazgo en el Famatina, R. f. parabola había sido identificado en la sucesión cambro-ordovícica de la Formación Lampazar en la Sierra de Cajas, Cordillera Oriental argentina (Ortega \& Rao, 1995). La sección de la Quebrada Amarilla en esta última localidad, ofrece un marco excepcional para la correlación de las biozonas de conodontos, graptolitos y trilobites en torno al límite Cámbrico-Ordovícico (Ortega \& Rao, 1995; Rao, 1999). A ella se suma la sucesión representada por el Miembro Filo Azul de la Formación Volcancito, a la luz de los modernos trabajos de revisión bioestratigráfica de graptolitos y trilobites, por un lado (Tortello \& Esteban, 1999), y de conodontos, por otro (Albanesi et al., 1999, 2000a, 2000b).

La correlación bioestratigráfica entre los perfiles de río Volcancito y la Quebrada Amarilla ofrece, sin embargo, algunas discrepancias en cuanto a la integración de los datos biocronológicos derivados de los distintos grupos taxonómicos. La principal de todas ellas es que la aparición del olénido Jujuyaspis keideli, hasta ahora considerada como una isocrona para el reconocimiento aproximado del límite Cámbrico-Ordovícico en ausencia de graptolitos y conodontos (Chen et al., 1980b; Aceñolaza \& Aceñolaza, 1992; Miller \& Stitt, 1995; Shergold, 2000; Cooper et al., 2001), parece ocurrir aquí en horizontes muy distintos en términos de las biozonas de conodontos. Así, el primer registro de $J$. keideli se sitúa a $10 \mathrm{~m}$ por encima de la base de la Biozona de Cordylodus lindstromi en la Cordillera Oriental (Ortega \& Rao, 1995), en tanto que en el Famatina este mismo trilobites aparece en un horizonte

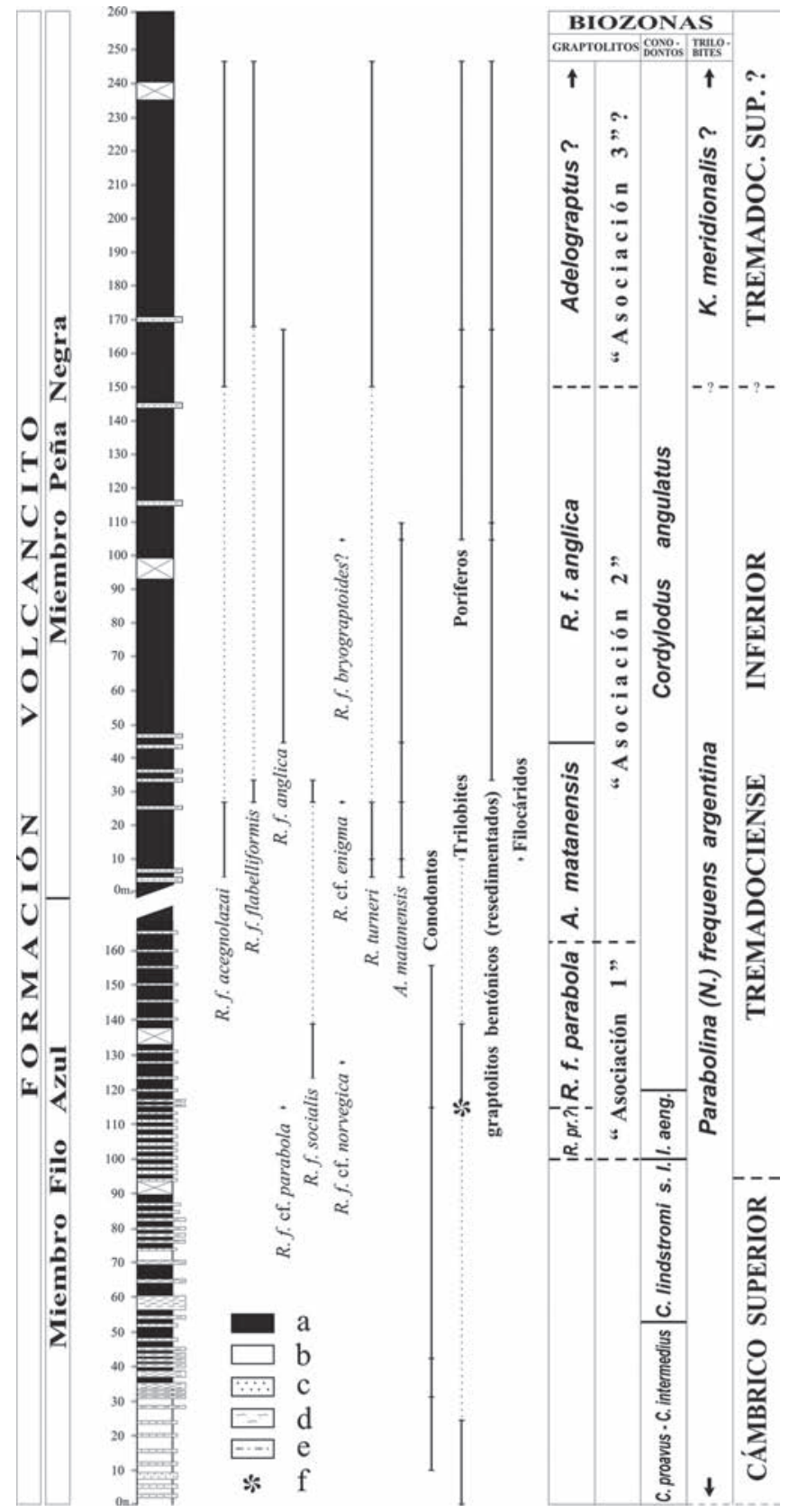

Figura 3. Esquema estratigráfico de los Miembros Filo Azul y Peña Negra de la Formación Volcancito en las secciones de Río Volcancito y Peña Negra, respectivamente, indicando la distribución vertical de los graptolitos estudiados en el Miembro Peña Negra, el registro general de otros grupos fósiles, y la extensión de las unidades bioestratigráficas. Litologías: a, pizarras negras; b, margas; c, areniscas de grano fino; d, lumaquelas calcáreas; e, pizarras grisáceas; f, primera aparición del trilobites Jujuyaspis. Abreviaturas taxonómicas y bioestratigráficas: A, Anisograptus; R., Rhabdinopora; R.f., Rhabdinopora flabelliformis; R. pr., Rhabdinopora praeparabola; C., Cordylodus; "Iapet.", Iapetognathus (biozona local definida por la aparición de I. aengensis); N., Neoparabolina; K., Kainella. Biozonación de conodontos según Albanesi et al. (1999, 2000a).

Stratigraphic column for the Filo Azul and Peña Negra Members of the Volcancito Formation (uppermost Cambrian to lower upper Tremadocian), according to the Volcancito river and Peña Negra sections, respectively. The vertical ranges of the studied graptolites and the general record of other fossil groups are indicated, as well as the correlation of some biostratigraphical and chronostratigraphical units based on graptolites, conodonts and trilobites. Younger upper Tremadocian graptolitic beds, from the Peña Negra Member of the formation at the Volcancito river section (with Rhabdinopora and ?Bryograptus) are not included in this scheme. Symbols: a, black shales; $b$, marls; $c$, fine sandstones; $d$, calcareous coquinas; e, grey shales; $f$, lowest stratigraphic record of the trilobite genus Jujuyaspis. Abbreviations: A, Anisograptus; R., Rhabdinopora; R.f., Rhabdinopora flabelliformis; R. pr., Rhabdinopora praeparabola; C., Cordylodus; "Iapet.", Iapetognathus (local biozone defined here by the FAD of I. aengensis); N., Neoparabolina; K., Kainella. Conodont biostratigraphy after Albanesi et al. (1999, 2000a). 
presumiblemente más tardío, localizado a unos $15 \mathrm{~m}$ por encima de la base de la Biozona local de Iapetognathus (definida por la aparición de Iapetognathus aengensis) y a $62 \mathrm{~m}$ sobre la base de la Biozona de Cordylodus lindstromi. En lo concerniente a los graptolitos, las primeras formas relacionadas con $R$. f. parabola postdatan al primer registro de Jujuyaspis en la Sierra de Cajas (16 m por encima), pero resultarían aproximadamente coetáneas con la aparición de Jujuyaspis tanto en el área vecina de El Aguilar (Tortello \& Esteban, 2003a), como en la sucesión del río Volcancito (horizonte de 115 m según Tortello \& Esteban, 1999; horizonte de $100 \mathrm{~m}$ para Albanesi et al., 1999; horizonte de 110 m para Albanesi et al., 2005). En función de estos datos y de los límites marcados por la base de $C$. angulatus en ambas secciones, parece claro que el registro de Jujuyaspis keideli en la Formación Volcancito no corresponde en realidad a la isocrona regional antes citada, sino que constituye un hallazgo puntual dentro del rango bioestratigráfico total de esta especie (véase Harrington \& Leanza, 1957: fig. 3).

Los restantes horizontes con graptolitos citados para el Miembro Filo Azul (Tortello \& Esteban, 1999) se adscriben provisionalmente a la Biocronozona de Rhabdinopora flabelliformis parabola por su antecedencia con respecto a los primeros niveles con graptolitos trirradiados, conocidos ya en la base del Miembro medio de la formación (Fig. 3). La presencia de $R$. $f$. socialis dentro del rango estratigráfico asignado a la Biocronozona de $R . f$. parabola (más exactamente hacia su parte superior) es un hecho conocido a nivel global (Cooper et al., 1998; Cooper, 1999). No así el registro de $R$. f. norvegica, que se inicia mundialmente hacia la base de la biocronozona siguiente (de Anisograptus matanensis). La leve precedencia en el registro de $R$.f. socialis en el Famatina frente al contexto internacional, unida al hallazgo de posibles rabdosomas relacionados con $R$. f. norvegica en niveles claramente más antiguos que los acreditados por dicha subespecie (Cooper et al., 1998; Cooper, 1999), puede deberse a varios factores. Por un lado, hay que considerar el propio carácter pionero asignado a los ecomorfotipos $R$. $f$. socialis y $R$. $f$. norvegica en la colonización temprana de los ambientes de plataforma interna, tras el Episodio Regresivo Acerocare, según el modelo ecoestratigráfico de Cooper (1999). En este sentido, el contexto marginal gondwánico de la Sierra de Famatina podría haber representado un área donde tal colonización se hubiera producido con alguna antelación frente a las pocas áreas mundiales con registro de graptolitos de la Biocronozona de R.f. parabola en ambientes de plataforma interna a intermedia (Norte de Estonia, Utah, Nuevo México...). Por otro lado, tampoco es descartable que la revisión de los horizontes graptolíticos conocidos hasta el momento en la parte alta del Miembro Filo Azul de la Formación Volcancito, se amplíe en el futuro con nuevos hallazgos que permitan reevaluar todas las identi- ficaciones previas. Buena prueba de ello es la reasignación efectuada por nosotros, a $R$. $f$. cf. parabola, de parte del material determinado previamente como $R$. f. cf. norvegica en el trabajo de Tortello \& Esteban (1999).

La siguiente Biocronozona de Anisograptus matanensis ha sido evidenciada por el registro de los primeros graptolitos trirradiados del taxón homónimo, el cual debuta hacia la base del Miembro Peña Negra de la Formación Volcancito en la sección de Peña Negra (Fig. 3). Debido a la falta de afloramientos de su contacto con el Miembro Filo Azul, consideramos justificado suponer que el límite inferior de la Biocronozona de A. matanensis pudiera haberse extendido a niveles previos a los estudiados, incluso dentro de la parte más elevada del Miembro Filo Azul de la formación. Ello resultaría especialmente patente por la ausencia de la forma cosmopolita $R$. $f$. canadensis en la base del Miembro Peña Negra, dado que la misma caracteriza a los niveles de tránsito entre las biocronozonas de $R$. f. parabola y de A. matanensis a nivel mundial, y cuya presencia merecería ser investigada en la parte más alta del Miembro Filo Azul de la Formación Volcancito, lo cual excede en principio a los objetivos de este trabajo.

La Biocronozona de Rhabdinopora flabelliformis anglica queda acreditada por el registro de la forma nominal, en la sección de Peña Negra, hacia el horizonte de 46,65 m. Su límite superior no ha podido establecerse con certeza, pero podría situarse por encima del posible registro de $R$. f. bryograptoides hacia los $105 \mathrm{~m}$. Esta última subespecie se encuentra restringida a la parte superior de la Biocronozona de R.f. anglica, y no supera el límite Tremadociense inferior / superior, coincidente a su vez con la aparición del desarrollo birradiado a escala global (Cooper et al., 1998; Cooper, 1999).

Tanto la Biocronozona de A. matanensis como la de R. f. anglica se adscriben a la "Asociación 2" (evolutiva y cronorregistrática) de Cooper (Cooper, 1979, 1999). Ésta materializa el "bioevento 3" de Wang (2000). De acuerdo con la escala global de las "porciones de tiempo" (time slices) de Webby et al. (2004), la Biocronozona de A. matanensis se equipara con el final de la TS $1 \mathrm{a}$, y la de $R$. f. anglica con el inicio de la TS 1b. Ambas serían correlacionables en su mayor parte con la Unidad de Tiempo 2, exceptuando la parte terminal de ésta, de acuerdo con la escala alternativa diferenciada para los graptolitos (Cooper et al., 2004).

En ausencia de formas auténticamente birradiadas en el Miembro Peña Negra de la Formación Volcancito (véase discusión a "Adelograptus"? sp.), cabe preguntarse si el resto de la sucesión en Peña Negra podría atribuirse ya al Tremadociense superior, o bien resultaría más prudente seguir relacionándola con "la parte alta del Tremadociense inferior", tal y como viene haciéndose desde los trabajos de Turner (en Harrington \& Leanza, 1957 y Turner, 1960). La cuestión no admite de momento una respuesta inequívoca, 
ante la ausencia aparente de especies características. Sin embargo, en este trabajo tendemos a considerar como muy probable que parte de la sucesión graptolítica del Miembro Peña Negra de la Formación Volcancito pertenezca ya al Tremadociense superior, merced a la concurrencia de diversas evidencias circunstanciales:

- La primera es el posible registro (ya comentado) de $R$. $f$. bryograptoides, que brindaría una proximidad inmediata al techo de la Biozona de R. f. anglica y base de la Biocronozona de Adelograptus (Cooper et al., 1998; Cooper, 1999) para sus niveles fosilíferos suprayacentes.

- La segunda circunstancia es el acotamiento impuesto por la presencia de conodontos de la parte inferior de la Biozona de Paltodus deltifer en el tercio bajo de la Formación Bordo Atravesado, y de raros hallazgos de graptolitos (Kiaerograptus spp., Paradelograptus spp.) en el tercio alto de la misma unidad (Albanesi et al., 2000b, 2001, 2005). Ambos registros concuerdan bien con una edad equivalente a la de la parte más baja de la "Asociación 4" de graptolitos (Cooper et al., 1998; Cooper, 1999), y por tanto permiten especular con una edad equivalente a la de la "Asociación 3" para los tramos infrayacentes: es decir, para la base de dicha formación y, posiblemente también, para la segunda mitad del Miembro Peña Negra de la Formación Volcancito.

- Una tercera circunstancia aplicable al caso es que las formas birradiadas más primitivas (Adelograptus, Bryograptus) nunca aparecen de manera explosiva en el registro mundial (Cooper \& Lindholm, 1990; Cooper, 1999), sino que se documentan en forma esporádica dentro de un intervalo muy mal conocido (la antedicha "Asociación 3" de Cooper, 1979, 1999; Cooper et al., 1998). Los graptolitos más característicos de este tramo (Psigraptus, Adelograptus tenellus, primeros Paratemnograptus?) se localizarían hacia la parte superior del mencionado intervalo en contextos paleotropicales, equiparables con el horizonte Lancefieldiense $1 \mathrm{~b}$ (antiguo La1.5) de la escala australoasiática. Pero la correlación del Lalb también admite interpretaciones y hay autores que integran a estos graptolitos en la Biozona de Aorograptus victoriae de contextos más boreales (Maletz \& Egenhoff, 2001, 2003; Egenhoff et al., 2004), que Cooper (1999: fig. 2) equiparaba con la parte baja de la "Asociación 4". Unos problemas de correlación semejantes ocurren entre la "Asociación 3" y la Biozona de Aorograptus asiaticus de China (la antigua biozona de Adelograptus asiaticus-Clonograptus minutus o, más generalizadamente, de Adelograptus-Clonograptus), que unas veces es asignada a la Biocronozona de Adelograptus (“Asociación 3": Cooper et al., 1998; Cooper, 1999), otras considerada como equivalente parcial (su parte inferior) de la Biocronozona de R.f. anglica ("Asociación 2", Feng \& Erdtmann, 1999: tabla 1) e, incluso, correlacionable en el noreste de China con niveles aún más elevados, en el tránsito de la "Asociación 3" a la "Asociación 4" (Jackson
\& Lenz, 2000: fig. 6). La revisión bioestratigráfica de las secuencias tremadocienses del norte y sur de China (Zhang et al., 2003, 2004) sitúa todos estos intervalos en el Tremadociense superior (aproximadamente en las biozonas de Aorograptus victoriae y Acanthograptus sinensis). En cualquier caso, las asociaciones del límite Tremadociense inferior a superior, se caracterizan en China por un predominio notable de restos transportados de dendroideos bentónicos (Dendrograptus, Aspidograptus, Callograptus, Pseudocallograptus, Dictyonema s. str. y Airograptus), semejantes a los registros que ocurren en una posición comparable dentro de la secuencia del Famatina (véase apartado taxonómico).

Además de los problemas de correlación expresados, lo que resulta indudable es que el conocimiento de las asociaciones graptolíticas de la base del Tremadociense superior es muy imperfecto todavía, y que casi todos los trabajos describen como "no investigados", "sin graptolitos" o "zonas aún por definir", a los niveles previos a la gran biodiversificación de los graptolitos planctónicos ocurrida hacia la base de la Biozona de Aorograptus victoriae y equivalentes (Williams \& Stevens, 1991; Maletz \& Egenhoff, 2001, con diversos ejemplos mundiales). El propio límite intra-tremadociense es situado por Maletz \& Egenhoff (2001: fig. 9) en la Biozona de R. f. anglica, en lugar de en la base de la Biozona de ?Adelograptus tenellus. Ello revela una vez más la incertidumbre bioestratigráfica y cronorregistrática existente en torno al tránsito Tremadociense inferior-superior, que en el Famatina no puede resolverse por ausencia de formas auténticamente birradiadas. De todos modos, conviene recordar que en la mayoría de las sucesiones mundiales, el registro de Rhabdinopora flabelliformis s. 1. persiste durante el Tremadociense superior temprano, incluyendo a $R$. f. anglica. Y que el rango total de esta última subespecie supera el límite Tremadociense inferior a superior, coincidiendo con una especiación endémica de Rhabdinopora (por ejemplo $R$. novosemelicum en Rusia o $R$. hunanensis en China), dentro de un género que hasta entonces permanecía prácticamente restringido a la especie $R$. flabelliformis. El mismo fenómeno podría ser asumible para la cuenca del Famatina, donde la forma endémica Rhabdinopora turneri y la más difundida $R$. $f$. acenolazai debutan en la Biocronozona de A. matanensis y prosiguen su representación en horizontes posteriores a los de la Biocronozona de $R$. f. anglica, junto con abundantes restos de $R$. flabelliformis ssp. y aún frecuentes de $R$. $f$. flabelliformis. En ausencia de otros graptolitos, Rhabdinopora flabelliformis acenolazai resulta fácil de confundir con $R$.f. parabola, una subespecie cuyo registro mundial culmina antes de la aparición del desarrollo trirradiado de Anisograptus o Triramograptus, y que en todo caso se extingue antes de la Biozona de Anisograptus matanensis (Cooper et al., 1998; Cooper, 1999). No obstante, en la Sierra del Famatina y en el sur de China (véase Zhang 
et al., 2004: fig. 7) el morfotipo "parabola" (s. l.) pervive acompañado por A. matanensis e incluso por Bryograptus o Kiaerograptus?, formas propias del Tremadociense superior. En nuestra opinión tales registros, desconocidos en las sucesiones graptolíticas del resto del mundo, deben imputarse a un taxón diferente de R.f. parabola, en lugar de atribuir al mismo una extensión vertical desmesurada y anómala, de carácter puntual, relacionada con factores ecológicos de difícil justificación (¿localidades refugio o apariciones "Lázaro" de orden tafonómico?). Es por ello que en el presente trabajo proponemos la creación de un nuevo taxón, $R$. $f$. acenolazai, que supone la reaparición del morfotipo "parabola" (s. l.) coincidente con la diversificación tardía del género en determinados contextos paleogeográficos ( $R$. turneri, $R$. hunanensis, $R$. novosemelicum, $R$. f. bryograptoides, etc).

Por último, debemos referirnos a la correlación del Miembro Peña Negra de la Formación Volcancito en las distintas secciones estudiadas. Turner (1964) había apuntado que las asociaciones de graptolitos obtenidas en Peña Negra y en río Volcancito podrían no ser idénticas, por la ausencia de tres especies en río Volcancito de las identificadas en Peña Negra. Los resultados obtenidos por nosotros confirman la mayor diversidad taxonómica existente en Peña Negra, pero implicarían una transposición o mezcla de colecciones en las listas originales de Harrington (identificaciones de Turner, 1951 fide Harrington \& Leanza, 1957) y Turner (1960) procedentes de ambas secciones.

De acuerdo con la reinvestigación de la sección de río Volcancito, en esta sucesión sólo hemos reconocido Rhabdinoporaf. flabelliformis y R.f. acenolazai junto a dudosos ejemplares de $R$. f. socialis, que alternativamente podrían representar variantes intraespecíficas o tafonómicas de $R$. flabelliformis s. str. Esta asociación coexiste en la parte baja de la sección estudiada, donde faltan aparentemente Anisograptus u otras formas comunes en el Tremadociense inferior, entre ellas R.f. anglica. Ello nos lleva a considerar la posibilidad de que toda la sucesión del Miembro Peña Negra de la formación en río Volcancito se adscriba ya al Tremadociense superior, lo cual se ve refrendado por una colonia única de Bryograptus? sp., recogida suelta hacia la parte baja de dicha sección. En este sentido, el género Bryograptus inicia su registro mundial en el Tremadociense superior (base de la Biocronozona de Paradelograptus antiquus o de la Biozona de Aorograptus victoriae), coincidiendo con el evento global de biodiversificación en el que se origina la "Asociación 4" (Cooper, 1979, 1999).

Desde el punto de vista litoestratigráfico, la revisión bioestratigráfica del Miembro Peña Negra de la Formación Volcancito permite incrementar por vez primera el espesor mínimo asignado al mismo, estimado hasta ahora en los poco más de 260 m medidos en la sección de Peña Negra. De ellos, los primeros $110 \mathrm{~m}$ son de edad Tremadociense inferior (Biocronozonas de Anisograptus matanensis y $R$. f. anglica, comprendiendo esta última el posible registro de $R$. f. bryograptoides hacia los $105 \mathrm{~m}$ ), en tanto que los $150 \mathrm{~m}$ superiores podrían ser ya del Tremadociense superior basal (Biocronozona de Adelograptus?). Por su parte, los aproximadamente $180 \mathrm{~m}$ de la sección de río Volcancito (con varios tramos cubiertos) parecen corresponder enteramente al Tremadociense superior (Biocronozonas de Adelograptus? en parte, P. antiquus? y Kiaerograptus? en parte), lo cual se enmarca en los posibles registros de Bryograptus hacia la parte inferior, y de Kiaerograptus y Paradelograptus en la Formación Bordo Atravesado suprayacente. Ello implica que una correlación posible, entre las dos secciones estudiadas del Miembro Peña Negra de la Formación Volcancito, debería sumar, a los 110 $\mathrm{m}$ de Tremadociense inferior representados en la sección de Peña Negra, los aproximadamente $180 \mathrm{~m}$ de posible Tremadociense superior de la sección de río Volcancito, correlacionables en principio con los $150 \mathrm{~m}$ asignados a la posible Biocronozona de Adelograptus? en Peña Negra. Pero como el registro de Rhabdinopora turneri y de algunos dendroideos bentónicos (Dendrograptus, Dictyonema sp. nov. 2), conocido en esta última unidad y localidad, no se extiende a la base de la sección de río Volcancito, en cuya parte inferior aparecen posibles horizontes más modernos con Bryograptus, podemos concluir presuponiendo que no existe un solapamiento bioestratigráfico importante entre ambas secciones. Se estima así un espesor mínimo en torno a los 400-440 m para el conjunto de pizarras negras graptolíticas que constituyen el Miembro Peña Negra de la Formación Volcancito, sin perjuicio de que la potencia pudiera ser todavía mayor al desconocerse con exactitud sus límites litoestratigráficos con el Miembro Filo Azul y con la Formación Bordo Atravesado, respectivamente. La extensión del Tremadociense superior a esta última unidad en su estratotipo de Bordo Atravesado (Esteban, 1999b; Tortello \& Esteban, 2003b; Albanesi et al., 2001, 2005) implica un espesor desmesurado, por comparación con otras áreas mundiales, para los materiales asignados a dicha edad en la cuenca del Famatina (alrededor de $450 \mathrm{~m}$ ). Sin embargo, el mismo entra dentro del rango de potencias del Tremadociense superior en el ámbito perigondwánico, tanto de la Cordillera Oriental argentino-boliviana ("Lutita 2-Arenisca 3" en Moya et al., 1994; formaciones Cieneguillas y Obispo en Erdtmann et al., 1995 y Egenhoff et al., 2004), como en el norte de África (por ejemplo la Formación de Fezouata Inferior: Destombes et al., 1985) y Europa central (por ejemplo el Grupo Phycodes de Turingia, Alemania: Linnemann et al., 2003, con síntesis de referencias previas).

\section{RASGOS PALEOECOLÓGICOS}

El Miembro Filo Azul de la Formación Volcancito representa ambientes de plataforma relativamente somera, 
afectada por tormentas y eventualmente también por el oleaje (Esteban, 1999a, 2002, 2003; Astini, 2001a y b; Mángano et al., 2002; Albanesi et al., 2005). En estas circunstancias tiene lugar la transgresión global del Tremadociense (Fortey, 1984), que profundiza notablemente el ambiente de sedimentación hacia la mitad o el tercio superior del Miembro Filo Azul de la formación, cambiando la sucesión de dominantemente calcárea (calcilutitas, margas y calcarenitas) a siliciclástica fina (lutitas y limolitas verdes). A partir de ese momento ingresan a la plataforma los primeros graptolitos planctónicos, representados por Rhabdinopora flabelliformis cf. parabola, R. $f$. socialis y $R$. $f$. cf. norvegica. Los dos últimos mencionados representan ecosubespecies características de la plataforma externa (Cooper, 1999). La ausencia de Staurograptus/ "Radiograptus" en la mitad inferior del rango atribuido a la Biozona de R.f. parabola, y de R.f. canadensis en la mitad superior del mismo intervalo, puede deberse tanto a deficiencias en los muestreos previos como, más probablemente, a que estos taxones se encuentran restringidos a ambientes todavía más profundos (talud inferior a llanura abisal: Erdtmann, 1988b; Cooper, 1999) y, secundariamente, de menor paleolatitud. Por su parte, las biofacies de conodontos encontradas en el Miembro Filo Azul serían las típicas de ambientes periféricos profundos, localizados entre la plataforma distal y el talud, y comparables con las secciones descritas en el oeste de Terranova o el noroeste de Canadá (Albanesi et al., 2000a), o más estrechamente con las de Asia Central (Albanesi et al., 2005). Los trilobites olénidos y agnóstidos que completan la asociación no aportan mayores precisiones.

El Miembro Peña Negra de la Formación Volcancito, representado por facies de pizarras negras con delgadas intercalaciones turbidíticas, ha sido interpretado esencialmente como depositado en un ambiente de planicie abisal (= "planicie de cuenca") y fondo anóxico (Esteban, 1994, 1999a; G.F. Aceñolaza et al., 1996; Albanesi et al., 2005). Otros autores eran algo más crípticos, aludiendo a un depocentro que genera "ambientes restringidos" en condiciones de columna de agua estratificada y fondos anóxicos (Astini, 1999; Mángano et al., 2002) o, más modernamente, una alternativa con depocentros restringidos a un contexto de plataforma externa y ambientes profundos (Astini, 2003; Astini \& Dávila, 2004).

Las asociaciones de graptolitos estudiadas en este trabajo permiten constatar el marco paleoecológico y sedimentario del Miembro Peña Negra, que se atribuye con gran probabilidad a depósitos del talud continental superior. Esto se deduce de la aplicación del modelo ecoestratigráfico introducido por Erdtmann (1982a) y perfeccionado por Cooper $(1998,1999)$ para las biofacies de graptolitos tremadocienses a escala global. Los datos más significativos resultan de la presencia, por un lado, de Anisogratus matanensis, que es una forma meso- a batipelágica, común en todo tipo de ambientes oceánicos y de talud. Por otra parte, $R$. f. anglica nunca ha sido identificada con certeza en depósitos puramente oceánicos como los de noroeste de Canadá y Australasia, sino que se presenta restringida al biotopo epipelágico de la plataforma y el talud (Cooper, 1999). La concurrencia de ambas formas (A. matanensis y $R$. f. anglica) en el Miembro medio de la Formación Volcancito, excluye la interpretación de estos sedimentos como depositados en una llanura abisal. La proximidad a la plataforma vendría indicada también por el registro de graptolitos bentónicos y de esponjas silíceas resedimentadas en distintos niveles de la sucesión, acarreadas por corrientes desde zonas vecinas antes de su completa disgregación o desarticulación.

Los restantes graptolitos planctónicos registrados en el Miembro Peña Negra, o bien son formas holopelágicas y estenotérmicas como R. f. flabelliformis, ampliamente difundidas en la plataforma y el talud, o bien son repetición de ecomorfotipos conocidos en ambientes de talud continental, como ocurre con $R$. turneri (similar a $R$. praeparabola) y con $R$.f. acenolazai (reminiscente de $R$. parabola). Estos dos últimos taxones prosiguen su representación en horizontes mucho más modernos que los de las formas a las que se asemejan superficialmente.

Erdtmann (1982a) encuadró a las asociaciones del Famatina entre los rhabdinoporininos del "tipo Matane", en alusión a la presencia de formas con nema dividido y asociadas a Anisograptus, características de biotopos profundos relacionados con zonas de alta productividad de fitoplancton. Nuestros resultados taxonómicos no permiten una comparación tan precisa de las asociaciones estudiadas con las del este de Canadá (Matane-Gaspé en Québec y Terranova occidental), pese a la presencia esporádica de $R$. f. acenolazai entre estas últimas, debido a sus mayores condiciones de profundidad en la parte media a baja del talud continental (Cooper, 1999: fig. 4). Sin embargo, el biotopo mesopelágico entre el borde de la plataforma y el talud continental superior, deducido para el Miembro Peña Negra de la Formación Volcancito, sí coincide, en los océanos actuales, con zonas de elevada productividad en fitoplancton. Éstas se relacionarían espacialmente con áreas de afloramiento (upwelling) de corrientes oceánicas profundas y disaeróbicas, muy ricas en nutrientes, influídas también por los vectores Ekman de flujo para corrientes oceánicas superficiales. En estas condiciones y ambientes se generan ingentes acúmulos de materia orgánica, origen de las pizarras negras sapropelíticas (Wilde et al., 1989; Cooper, 1998, 1999; todos con referencias previas).

El tránsito a la sucesión del Tremadociense superior, tentativamente asignada a la Biozona de Adelograptus?, se marca por un descenso brusco en la diversidad de los graptolitos planctónicos (excluyendo las formas holopelágicas y mesopelágicas endémicas), y también por la ausencia de formas características desde el punto de vista biocronológi- 
co. Ambos aspectos concuerdan con lo observado en otras secuencias mundiales, como por ejemplo en la sucesión báltica de Oslo, donde la Biozona de R. f. anglica (Tremadociense inferior) y la de Adelograptus del tipo tenellus (Tremadociense superior) están separadas por $3 \mathrm{~m}$ sin graptolitos (Bulman, 1954; Spjeldnaes 1986: fig. 1), o muchos lugares de Avalonia oriental donde los graptolitos llegan incluso a desaparecer (Erdtmann, 2001). A un intervalo equivalente (post-anglica y pre-tenellus) podría adscribirse la Biozona de Adelograptus? del Famatina, pues el biotopo del talud continental superior pudo ser colonizado en este caso con un cierto retraso por las primeras formas birradiadas (¿mediando controles paleolatitudinales?), frente al éxito experimentado por los adelográptidos en los biotopos epipelágicos de plataforma. En cualquier caso, el ambiente regional de depósito para la mitad superior del Miembro Peña Negra, no parece experimentar grandes variaciones de profundidad, y su evolución a medios más oceánicos se descarta en virtud de la ausencia de formas batipelágicas como ciertos adelográptidos de rabdosoma tenue.

Finalmente, en la Formación Bordo Atravesado suprayacente se localizan restos de Kiaerograptus spp. y Paradelograptus spp., además de unas biofacies de conodontos de baja abundancia y diversidad, dominadas por elementos de hábito pelágico en aguas profundas o frías del margen gondwánico (Albanesi et al., 2000b, 2001, 2005). La presencia de trilobites pelágicos como los ciclopígidos (Esteban, 1996b, 1999b; Tortello \& Esteban, 2003b), así como los tipos litológicos predominantes, refuerza la evolución del ambiente de sedimentación desde la parte superior del talud continental a la plataforma externa, e incluso a medios más someros bajo el influjo esporádico del oleaje de tormenta. Al registro de graptolitos planctónicos en esta formación, le sumamos aquí el descubrimiento del fragmento resedimentado de un graptolito bentónico, citado en el apartado taxonómico como Dictyonema? cf. D. cordillerensis (Fig. 12).

Tras la sedimentación de las formaciones Volcancito y Bordo Atravesado, la subducción famatiniana termina por generar un arco volcánico activo en el margen gondwánico. Éste se manifiesta por la emersión progresiva de los edificios volcánicos que pasan a delimitar una cuenca interna de retroarco, donde a lo largo del Arenigiense se acumulan importantes espesores de sedimentos fosilíferos.

\section{MARCO PALEOGEOGRÁFICO Y DISCUSIÓN}

La sedimentación de la Formación Volcancito tuvo lugar en el margen gondwánico protoandino con posterioridad al colapso extensional con el que finaliza la Orogenia Pampeana en el Cámbrico tardío, y contemporáneamente al inicio de la subducción famatiniana del Ordovícico. Esta última conduce, ya en el Arenigiense, al desarrollo de un vulcanismo calcoalcalino (arco magmático del Famatina) y a la génesis de una cuenca de retroarco que perdura hasta la fase compresiva oclóyica de la Orogenia Famatiniana (véase Rapela et al., 1998; Pankhurst \& Rapela, 1998; Sureda \& Omarini, 1999; Astini et al., 2003; Astini \& Dávila, 2004; para detalles sobre el marco geotectónico general, referencias previas y nomenclatura).

Hasta el presente se consideraba al Sistema de Famatina como un Terreno de origen gondwánico, acreccionado a su posición actual en el inicio del Ciclo Famatiniano, y que constituiría la cuenca de antepaís y arco magmático previa a la colisión del Terreno alóctono o para-autóctono de la Precordillera. El rango temporal y procedencia de la Precordillera, que forma parte del terreno compuesto de Cuyania (Ramos, 1999, y referencias allí citadas), es objeto de debate entre los que defienden su deriva desde Laurentia, con acrección efectiva a partir del Ordovícico Superior (por ejemplo Astini et al., 1995; Benedetto et al., 1999; VV.AA. in Ramos \& Keppie, 1999; Casquet et al., 2001; Astini \& Rapalini, 2003; Thomas \& Astini, 1996, 2003) o bien del Silúrico terminal (Keller, 1999 o Buggisch et al., 2000, entre otros trabajos); así como la hipótesis previa (recientemente rehabilitada) de traslación y colisión oblicua de la Precordillera desde otros sectores paleoecuatoriales del propio Gondwana (Aceñolaza \& Toselli, 2000; Aceñolaza et al., 2000, 2002, 2003). Una de las especulaciones más recientes calificaba incluso a la Precordillera como un microcontinente de origen lauréntico para el Cámbrico, que derivaba en solitario y colisionaba con Gondwana en el Ordovícico (Thomas et al., 2002).

Del conjunto de modelos así surgidos, el más actualizado y verosímil es el que considera un origen gondwánico para la Precordillera (no lauréntico ni microcontinental independiente), el cual ha tratado de demostrarse por geocronología de los circones detríticos heredados por las rocas del Cámbrico Inferior y Ordovícico Superior temprano de la Precordillera (Finney et al., 2003a, 2003b). No obstante, los datos publicados han de ser descartados provisionalmente por diversas deficiencias en la colecta e identificación de las muestras (Finney et al., 2004, con datos suplementarios), si bien las investigaciones en curso sobre circones detríticos de otras localidades en Precordillera, revelan claramente la ausencia de conexiones con Laurentia (Finney et al., 2005), puestas recientemente en duda por Thomas et al. (2004). Las modernas revisiones de los niveles de K-bentonitas del Ordovícico Inferior y Medio de la Precordillera, tampoco guardan relación alguna con las de Laurentia (son de diferentes edades), con posibilidad de tener su foco emisor dentro de Gondwana (Huff et al., 1998, 2003). En este sentido, Fanning et al. (2004) confirman que los volcanes del arco magmático del Famatina, en su fase explosiva ácida contemporánea de las K-bentonitas, fueron la fuente de las cenizas vol- 
cánicas acumuladas en el Ordovícico de la Precordillera. Ello implica que la acrección Precordillera-Famatina ya estaba casi completada en el Ordovícico Medio (Baldo et al., 2003; Fanning et al., 2004). Hay que tener en cuenta también que los núcleos precámbrico-paleozoicos de las Sierras Pampeanas Occidentales, hasta hora considerados como de afinidades laurénticas e integrantes del terreno exótico de la Precordillera, parecen ser de origen gondwánico autóctono o parautóctono (Galindo et al., 2004).

Hasta hace poco, Astini et al. (1995) y Ramos (2000) continuaban considerando a la Faja del Famatina como el posible vestigio de un arco-isla oceánico, acreccionado como un terreno independiente a Gondwana, antes de la supuesta colisión de la Precordillera. Esta idea ya había sido formulada por algunos autores previos, lo que explica que Erdtmann (1982a) calificase de "alóctonos" a los afloramientos graptolíticos de la Formación Volcancito. La renovación actual de esta hipótesis viene de la mano de algunos datos biogeográficos, en especial la caracterización de asociaciones de conodontos, trilobites y braquiópodos, interpretadas como de aguas cálidas a templadas, cuyas afinidades "celtas" implicarían conexiones con las faunas de la Precordillera y Apalaches-Avalonia occidental. Todo ello en un marco paleogeográfico periférico, aunque externo, a la plataforma continental de Gondwana (Benedetto, 1998, 2001).

A la discusión anterior han venido a sumarse recientes hallazgos paleontológicos, de pretendida relevancia paleogeográfica y paleoclimática, como son el hallazgo de las "algas calcáreas" Nuia y Girvanella en el Miembro Filo Azul de la Formación Volcancito (Astini \& Dávila, 2000; Astini et al., 2000; Astini, 2001a, 2001b, 2003). Según estos trabajos, la asociación sería típica de baja paleolatitud ("dentro de la faja periecuatorial", entre $0-25^{\circ}$ ) y comparable a otros registros de Precordillera y Gondwana oriental, planteando la sospecha de que el Famatina fuese un terreno exótico a Gondwana, o bien cuestionando la ubicación paleogeográfica admitida hasta la fecha para el Gondwana occidental (Astini, 2001a, 2001b, 2003; Astini \& Dávila, 2004).

Nuestra opinión es bien distinta de tales conclusiones, en primer lugar porque las asociaciones paleontológicas perigondwánicas de paleolatitudes altas a intermedias se conocen aún con un detalle insuficiente como para permitir cualquier comparación, fuera de algunos contextos clásicos europeos y latinoamericanos. Así, por ejemplo, Girvanella ha sido citada en el Cámbrico y Ordovícico del suroeste de Europa, en un contexto de paleolatitudes intermedias a elevadas, respectivamente (Hernández Sampelayo, 1915; Fernández Fernández \& Moro Benito, 1996; Álvaro et al., 2000; Perejón et al., 2000). La distribución de Girvanella es muy amplia, pero la permineralización de tales filamentos cianobacterianos ocurre de forma muy esporádica en los sedimentos siliciclásticos, donde cuentan además con muy bajo potencial de fosilización. El carácter cosmopolita de Girvanella, su diversidad de hábitats y su amplio registro estratigráfico, hace que su asociación con Nuia no sea particularmente significativa. Por otra parte, si aceptamos el origen orgánico de Nuia (discutido entre otros por Spincer, 1998), y su distribución paleotropical en el Cambro-Ordovícico, su presencia en el Famatina puede no deberse a factores estrictamente paleolatitudinales, al contrario de como hasta ahora se ha pretendido centrar la discusión. En este sentido, el desarrollo de corrientes cálidas de origen tropical que afectasen al margen occidental de Gondwana, podría haber sido decisivo para la dispersión de Nuia en torno al límite Cámbrico-Ordovícico en la región del Famatina. Pero el registro de Nuia (individual o en asociación con Girvanella) tampoco es demostrativo de ambientes con aguas cálidas permanentes como los que cabría esperar en una región paleotropical de bajas latitudes. Muy al contrario, las asociaciones de conodontos del Ordovícico basal de la Formación Volcancito no incluyen ninguno de los elementos característicos de la provincia del Continente Medio, propios de aguas cálidas y someras, si bien resultan comparables a las de otras localidades contemporáneas de la Cordillera Oriental (formaciones Lampazar y Cardonal), asignadas a los ambientes de "transición" (Transitional Faunal Realm) entre aguas frías y cálidas a lo largo del margen gondwánico (Albanesi et al., 2000a, 2000b, 2005).

La demostración de la llegada de corrientes cálidas al Famatina está acreditada para el Arenigiense medio, donde entre trilobites, moluscos y braquiópodos típicamente perigondwánicos, aparecen algunos trilobites epipelágicos como Carolinites genacinaca, considerado paleoecuatorial por McCormick \& Fortey (1999), cuyo registro se prolonga hasta el sur de Bolivia (G.F. Aceñolaza et al., 1999, con referencias previas). También por el braquiópodo Ahtiella, una forma de aguas templadas identificada recientemente en el Arenigiense de Famatina (Benedetto, 2003b) y Perú (Gutiérrez-Marco et al., 2004). No obstante, el registro de ciertos trilobites como Hungioides y Gogoella en el Arenigiense del Famatina, induce a la confusión de asignar la asociación a la "Provincia de Asaphopsis" de Gondwana oriental (Vaccari, 1995). A diferencia de Gogoella, Hungioides no puede ser considerado como un inmigrante australiano (fide Vaccari, 1995, y Benedetto, 1998), habida cuenta de su presencia frecuente en el Ordovícico de Europa y el suroeste de China (Rábano, 1983; Zhou et al., 1998: ambos con referencias previas).

Pese a que Astini (2003: 95) continúa insistiendo en que el reconocimiento de la asociación Nuia-Girvanella en el Miembro Filo Azul de la Formación Volcancito es significativa en términos paleoclimáticos y paleogeográficos, Benedetto (2003a: 102) admite otras posibilidades relacionadas con condiciones ambientales locales. La primera que menciona son aguas cálidas inducidas por su 
proximidad a áreas volcánicas (en esos momentos desconocidas a escala local), y la segunda la influencia de una posible corriente oceánica de aguas cálidas que circulase a lo largo del margen gondwánico, como la acreditada para el Silúrico-Devónico Inferior, pero que en nuestra opinión ya opera con seguridad en el Arenigiense.

En cualquier caso y retomando la discusión principal, el quimismo de las rocas ígneas revela que el arco magmático del Famatina tiene un origen claramente continental en el Ordovícico Inferior (Rapela et al., 1992) y no fue un arcoisla oceánico. Los autores que así lo interpretaban, situaron el relleno sedimentario y volcaniclástico registrado en la cuenca de intra- a retroarco entre el Tremadociense y el Darriwiliense (Astini et al., 1995; Rapela et al., 1998). En el mismo sentido, la Formación Volcancito llegó a figurar en algunos modelos paleogeográficos y esquemas secuenciales como el primer depósito acumulado en la cuenca del retroarco famatinense (por ejemplo, Astini et al., 1995: fig. 11c), lo cual no concuerda con las indicaciones ecoestratigráficas aportadas por los graptolitos estudiados en el presente trabajo. Éstos revelan que la sedimentación del Miembro Peña Negra de la Formación Volcancito tuvo lugar en un ambiente profundo y océanico, probablemente en la parte superior del talud continental o en el borde más externo de una plataforma de alto gradiente. Y ello dentro del contexto de una fase corta de margen pasivo en un marco netamente gondwánico, previo a la emersión del arco volcánico continental que definió la cuenca arenigiense (cf. Esteban, 1996a, 2002; Zimmermann \& Esteban, 2002; Esteban \& Zimmermann, 2002; Zimmermann et al., 2003; Astini, 2003; Astini \& Dávila, 2004). Este vulcanismo se inicia diacrónicamente en la Puna a partir del Tremadociense (Koukharsky et al., 1996), siendo en parte contemporáneo al principal periodo intrusivo granítico famatiniense. No obstante, la actividad volcánica en el arco Puna-Famatina es esencialmente arenigiense, y postdata en el área de estudio a una Formación Volcancito cuyo depósito tuvo lugar bajo el influjo oceánico directo del Iapetus (Japeto) sur, sin que mediasen los ambientes "restringidos" que anteriormente servían para interpretar sus facies graptolíticas.

\section{DESCRIPCIONES TAXONÓMICAS}

La taxonomía de los graptoloideos planctónicos primitivos adopta las revisiones modernas de Erdtmann (1982b) y Cooper et al. (1998). La clasificación supragenérica de los mismos considera únicamente a la familia Anisograptidae, coincidiendo con los criterios expresados por Fortey \& Cooper (1986) y Williams \& Stevens (1991), para no adscribir los taxones que siguen a las subfamilias Rhabdinoporinae, Anisograptinae (sensu Mu) o Adelograptinae. La distinción entre las familias Rhabdinoporidae y Anisograptidae (enmendadas ambas por Wang \& Wang,
2001), dentro de un supuesto suborden Graptodendroidina, no nos parece fundada en argumentos morfológicos o evolutivos convincentes.

La clasificación de los dendroideos bentónicos adopta las divisiones tradicionales, en tanto no se proceda a clarificar la elevación de las familias actuales a superfamilias, subórdenes e incluso órdenes independientes, tal y como se está considerando de cara a la tercera edición del volumen de graptolitos del Treatise (coordinado por C.E. Mitchell).

La nomenclatura abierta y las indicaciones añadidas a las listas de sinonimias siguen los criterios recopilados por Matthews (1973) y Bengtson (1988).

El material estudiado ha sido depositado en la colección paleontológica del Instituto Superior de Correlación Geológica e Instituto Miguel Lillo (sigla PIL), radicada en la Universidad Nacional de Tucumán (Argentina). Allí se consultó también el material original procedente de otros estudios previos sobre la Formación Volcancito del Famatina (Toselli, 1975, 1977; Aceñolaza \& Durand, 1983, 1984)

\section{Orden GRAPTOLOIDEA Lapworth \\ (in Hopkinson \& Lapworth, 1875) \\ Familia anisograptidae Bulman, 1950}

Género Rhabdinopora Eichwald, 1855

Especie tipo: Gorgonia flabelliformis Eichwald 1840, por designación original.

\section{Rhabdinopora flabelliformis flabelliformis (Eichwald, 1840) \\ Figs. 4a-b, 14a-c}

* 1840 Gorgonia flabelliformis nob.; Eichwald, 207.

? 1916 Dictyonema flabelliforme (Eichwald); Bodenbender, 142.

- 1927 Dictyonema flabelliforme (Eichwald); Bulman, 12-26, figs. $6 \mathrm{c}-\mathrm{d}, 12-14$, lám. 1 figs. 2 y 4 ; lám. 2 figs. $3-4$.

- 1954 Dictyonema flabelliforme flabelliforme (Eichwald); Bulman, 14-17, fig. 4a-d, lám. 2 figs. 1-5.

? 1960 Dictyonema flabelliforme (Eichwald) var. famatinense nov.; Turner, 36-38, lám 1 fig. 2.

- 1966 Dictyonema flabelliforme (Eichwald); Bulman, 407-413, fig. 1-3.

1973 Dictyonema flabelliforme patulum subsp. nov.; Bulman \& Rushton, 18-20, figs. 4a-b, lám. 2 figs. 1, 5, 6; lám. 3 figs. 1-2.

.p 1982b Rhabdinopora flabelliformis (Eichwald); Erdtmann, 129-136, lám. 2 figs. 4-7 [non lám. 2 figs. 3, 8-9 = $R$. f. norvegica (Kjerulf)]. Con sinonimia completa de la subespecie, de la que hay que excluir las referencias a $R$. $f$. socialis y $R$. $f$. norvegica.

p 1984 Dictyonema flabelliforme (Eichwald) forma typica 
Brögger; Aceñolaza \& Durand, 271-272, lám. 1 figs. $1,3,10$ ? (pp.= R. f. socialis).

1992 Rhabdinopora flabelliformis; Aceñolaza, 91.

? 1996 Rhabdinopora flabelliforme (Eichwald); Tortello et al., 128-129, lám. 10.2 fig. 2.

v 1997 Rhabdinopora flabelliformis (Eichwald); Esteban \& Gutiérrez-Marco, 60.

v 1997 Rhabdinopora patula (Bulman \& Rushton); Esteban \& Gutiérrez-Marco, 60.

v 1998 Rhabdinopora patula (Bulman \& Rushton); Esteban \& Rigby, 2.

- 1998 Rhabdinopora flabelliformis flabelliformis (Eichwald); Cooper et al., 12-13, figs. 6c y 7.

v 1999 Rhabdinopora f. flabelliformis; Esteban et al., 219.

v 1999 Rhabdinopora patula; Esteban et al., 219.

- 1999 Rhabdinopora flabelliformis (Eichwald); F.G. Aceñolaza et al., 178.

v 2002 Rhabdinopora flabelliformis flabelliformis; Esteban, 30 .

v 2003 Rhabdinopora flabelliformis flabelliformis (Eichwald); Gutiérrez-Marco \& Esteban, figs. 2 y $3 \mathrm{f}$.

p 2003 Rhabdinopora flabelliformis flabelliformis (Eichwald); Toro \& Brussa, 444 (su ejemplar de la lám. 1 fig. 1 procede de la Cordillera Oriental).

Material: Numerosos fragmentos de rabdosomas, incluyendo colonias juveniles y restos incompletos de rabdosomas adultos, PIL 13780-13793 y 14672-14678, encontrados en la parte inferior de la sección de río Volcancito y en el intervalo de 2,5 a 247 m de la sección de Peña Negra. Biozonas de Anisograptus matanensis, Rhabdinopora flabelliformis anglica y Adelograptus?: Tremadociense inferior a parte baja del Tremadociense superior.

Descripción: El rabdosoma es de tamaño medio a grande con una morfología comprendida entre las categorías 2a a 4a de Cooper et al. (1998), con predominio de esta última. La relación longitud/anchura varía entre 0,8 y 1,18. La sícula mide 1,2 $\mathrm{mm}$ y conserva vestigios muy cortos del nema $(0,19 \mathrm{~mm})$. La estructura proximal aparenta ser cuadrirradiada; las dicotomías posteriores a las primeras se suceden con cierta regularidad a intervalos situados a 1-1,5, 3-3,5, 6-8, 9-10, 10-15, 16-18, 21-25 y $27-29 \mathrm{~mm}$ de la sícula.

Las estipes son delgadas y aproximadamente rectilíneas, con una anchura lateral de 0,34-0,45 mm, y un ancho dorsoventral igual o superior a $0,72 \mathrm{~mm}$. Su número en $10 \mathrm{~mm}$ varía entre 7-9,5 (8-9 en los sectores maduros del rabdosoma). Las estipes aparecen unidas por disepimentos finos, cuya distribución e inserción varía para cada rabdosoma, observándose dos morfotipos bien definidos en función de las características de estas estructuras. En el primer caso, que corresponde a las formas típicas de la subespecie, los disepimentos se disponen de una forma bastante regular y en su mayoría están orientados de modo perpendicular a las estipes, alcanzando un diámetro de 0,07-0,1 mm en la parte central. El número de disepimentos en $10 \mathrm{~mm}$ oscila entre 7 y 10 (normalmente 7 a 8) dentro de un mismo rabdosoma de este primer grupo. Ocasionalmente presentan recrecimientos corticales, que afectan selectivamente a sus bases de fijación en la estipe, y que se manifiestan por un engrosamiento en el diámetro $(0,12-0,14 \mathrm{~mm}$ en la parte central y $0,27-0,36 \mathrm{~mm}$ en la unión con la estipe). Estos disepimentos suelen ser simples y rectilíneos, delimitando una malla regular con fenéstrulas rectangulares, cuadrangulares o tabulares, dependiendo del estado astogenético del rabdosoma. En contadas ocasiones se observa la divergencia de dos disepimentos desde un mismo punto de inserción en una de las estipes, pero las irregularidades en su espaciamiento no afectan más que a sectores concretos del rabdosoma.

En un segundo grupo de rabdosomas, los disepimentos presentan grandes variaciones en su morfología, orientación y espaciamiento, incluso dentro de una misma colonia (Fig. 4a). La mayoría de estas estructuras se insertan perpendiculares a la estipe y están adelgazadas en su porción central (anchura: 0,03-0,09 mm). Sin embargo, en los mismos sectores, existen también un

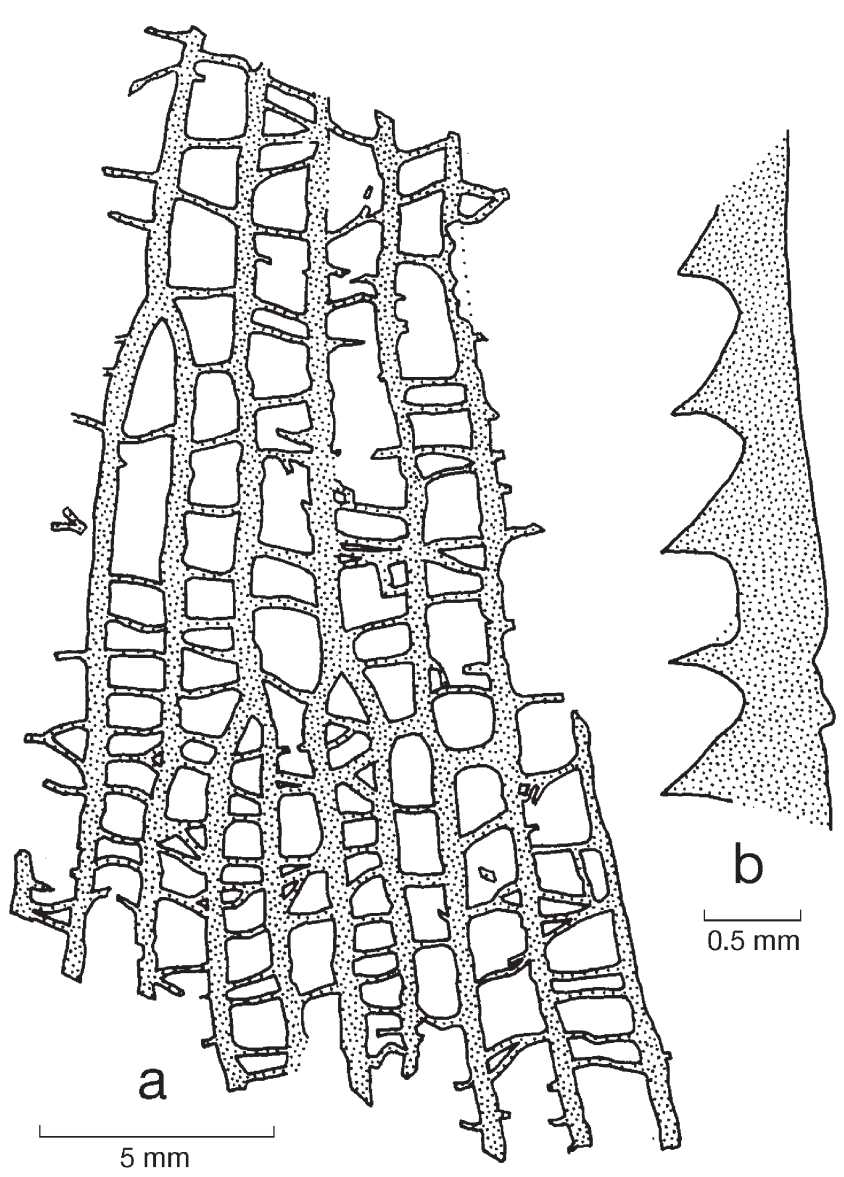

Figura 4. Rhabdinopora flabelliformis flabelliformis (Eichwald, 1840). a, detalle de la malla de la colonia PIL 13781, con fenéstrulas y disepimentos irregulares (morfotipo "patulum"). Horizonte de $168 \mathrm{~m}$ en la sección de Peña Negra. b, detalle de una estipe de PIL 13783a, en vista lateral, mostrando el perfil de las autotecas. Horizonte de 3,30 m en la sección del río Volcancito.

Rhabdinopora flabelliformis flabelliformis (Eichwald, 1840). a, detail of the mesh of the specimen PIL 13781, with irregular fenestrulae and disepiments ("patulum" morphotype). Peña Negra Member of the Volcancito Formation, horizon of $168 \mathrm{~m}$ above the local base of Peña Negra section. $\boldsymbol{b}$, detail of stipe in sample PIL 13783a, showing lateral profile of autothecae. Horizon of $3.30 \mathrm{~m}$ above the base ot outcrop in the Volcancito river section. 
gran número de disepimentos oblicuos, que frecuentemente se unen a una de las bases de inserción de otro disepimento normal. Raras veces se observa convergencia de tres disepimentos en un mismo punto de la estipe, o la unión de un disepimento oblicuo a la parte central de otro disepimento dispuestos entre dos estipes. En ocasiones, las anastomosis entre disepimentos implican ángulos elevados; la presencia de disepimentos incompletos ocurre también con cierta frecuencia, pero puede ser debido a deficiencias en la conservación. La existencia de espesamientos corticales se manifiesta en la base ensanchada o coalescente de muchos disepimentos, llegando a desembocar en la unión esporádica entre disepimentos contiguos, que pueden formar estructuras aisladas de grosor considerable $(0,28-0,36 \mathrm{~mm})$.

El espaciamiento longitudinal entre los disepimentos de los rabdosomas de este segundo morfotipo registra grandes irregularidades, contabilizándose un número variable entre 8-16 en $10 \mathrm{~mm}$ en diferentes regiones de una misma colonia, o incluso entre dos estipes concretas. El número más elevado de disepimentos se concentra normalmente en pequeños sectores del rabdosoma, sin estar asociado a procesos patológicos de regeneración de la malla.

Las autotecas han podido reconocerse en la región proximal de algunos rabdosomas, así como en las estipes laterales de las colonias adultas. Su margen ventral está inclinado $40^{\circ}$ con el eje de la estipe, y presentan dentículos aperturales. El número de autotecas varía entre 15 y 16 en $10 \mathrm{~mm}$. En vista dorsal, lo más que se distingue son los recorridos entrelazados y alternos de las protecas (de aspecto tubular) correspondientes a autotecas y bitecas sucesivas.

Observaciones: El registro de Rhabdinopora flabelliformis flabelliformis en las secciones estudiadas, comprende dos morfotipos bien diferenciados en cuanto a la distinta regularidad de la malla, condicionada por el modo de inserción y densidad de los disepimentos. El primero de estos morfotipos corresponde a la forma típica de la subespecie, con estipes rectilíneas y fenéstrulas rectangulares a cuadrangulares (Fig. 14c). Por su parte el segundo, con la malla mucho más irregular (Fig. 4a), se relaciona claramente con el morfotipo "patulum" (o "patula"), descrito como una subespecie de R. flabelliformis por Bulman \& Rushton (1973). Recientemente, Cooper et al. (1998) consideraron que el espaciamiento de los disepimentos y la morfología del rabdosoma son caracteres sujetos a un rango considerable de variación intraespecífica, por lo cual poseen un valor diagnóstico muy limitado. Rhabdinopora flabelliformis patula fue considerada, consecuentemente, como un sinónimo posterior de R. f. flabelliformis, dado que los caracteres distintivos de la primera carecen, en realidad, de valor diagnóstico.

En el Miembro Peña Negra de la Formación Volcancito, las formas típicas de $R$. f. flabelliformis predominan notablemente sobre el morfotipo "patula". Las poblaciones de este último se presentan bien separadas, estratigráficamente, en los horizontes de $27 \mathrm{~m}$ (Biozona de Anisograptus matanensis) y $167,5 \mathrm{~m}$ (Biozona de Rhabdinopora f. anglica), sin observarse su concurrencia con la forma típica. Por el contrario, en el nivel fosilífero superior de la parte baja del perfil del río Volcancito, ambos morfotipos coinciden en un mismo horizonte, con un predominio relativo de los rabdosomas de malla irregular (= "patula").

La presencia de R. f. flabelliformis en la Sierra de Famatina fue indicada por vez primera por Aceñolaza \& Durand (1984), quienes atribuyeron a la forma típica de la especie rangos de 8 a 12 estipes y 5 a 7 disepimentos en $10 \mathrm{~mm}$, respectivamente, para colonias con relación longitud/anchura comprendida entre 1,1-1,8. El elevado número de estipes de alguno de los ejemplares, por encima del rango de 7-9 en $10 \mathrm{~mm}$ (Cooper et al., 1998; Wang et $a l ., 1998)$, indica que Aceñolaza \& Durand (1984) reunieron bajo la misma denominación más de un taxón, uno de los cuales se correspondería con $R$. f. socialis descrito en el presente trabajo.

De todo el material obtenido en la Sierra de Famatina, R. f. flabelliformis morfotipo "patula" es el graptolito más próximo morfológicamente a la descripción original de $R$. flabelliformis famatinensis (Turner, 1960). El holotipo de esta subespecie es muy similar en cuanto a la divergencia general del rabdosoma, carácter de la malla y cierta zonalidad de las dicotomías. Sin embargo, en la descripción acompañante deben mezclarse los caracteres de diversas especies distintas ya que, como indicamos en este estudio, la diversidad taxonómica de las asociaciones sucesivas con Rhabdinopora, en distintos niveles de la Formación Volcancito, es bastante superior a la sospechada por Turner (1960). De los caracteres considerados como más distintivos de R.f. famatinensis por este autor, utilizados para distinguirlo de otras formas del género, destacamos el gran número de disepimentos en $10 \mathrm{~mm}$ (dispuestos algo irregularmente y con evidencias de recrecimiento cortical), así como el amplio espaciamiento de las estipes en la región proximal de la colonia. La primera característica concuerda muy bien con el morfotipo " $p a$ tula" de R.f. flabelliformis, pero otra serie de caracteres, como la sícula con nema delicado, número de tecas reducido (12-13 en $10 \mathrm{~mm}$ ) y la presencia de 11 a 12 estipes en $10 \mathrm{~mm}$ en la porción proximal, impiden descartar que parte de estos caracteres se refieran a ejemplares distintos del holotipo. En consecuencia, en la descripción original de $R$.f. famatinensis podrían haberse mezclado caracteres diagnósticos de varias especies del género Rhabdinopora, lo que haría al taxón irreconocible. La consideración posterior (Aceñolaza \& Durand, 1984) de R. f. famatinensis, como sinónimo de R.f. anglica, se comenta en otro apartado de este trabajo.

La morfología de Rhabdinopora flabelliformis "tarijensis" (Steinmann \& Hoek), descrito en la parte superior de la Formación Iscayachi de la Cordillera Oriental boliviana, resulta a grandes rasgos muy similar a la del morfotipo "patula" de R. f. flabelliformis, tal como se deduce del material ilustrado por Bulman (1931) y Turner (1960). Ejemplares comparables fueron descritos posteriormente 
por Ortega \& Suárez-Soruco (1994) como Rhabdinopora sp. A, procedentes de afloramientos próximos al área tipo de la subespecie. R. f. "tarijensis" ha sido citado también en Argentina (parte media de la Formación Cardonal, Cordillera Oriental) en niveles correlacionables o ligeramente más antiguos que los bolivianos (Alonso et al., 1982; Moya et al., 1994). Todo el material publicado hasta ahora de "Rhabdinopora tarijensis" (apelación dada al taxón por Erdtmann et al., 1995) presenta signos evidentes de deformación tectónica, por lo que la relación longitud/anchura de los rabdosomas varía entre 0,4-1,39, si consideramos el material de Tacsará, Tarija y Culpina ilustrado en los trabajos precedentes. Sin embargo, aún teniendo en cuenta las colonias deformadas más transversalmente, puede observarse que $R$. $f$. "tarijensis" difiere del morfotipo "patula" de $R$. f. flabelliformis por la mayor regularidad en la disposición y morfología de los disepimentos, el mayor grosor de tales estructuras $(0,15-0,25 \mathrm{~mm})$ y un número de estipes (11-13 según diferentes autores) más elevado en 10 mm. El número de autotecas anotado por Turner (1960) para R.f. "tarijensis" también resulta más bajo (12 en 10 $\mathrm{mm}$ frente a 14-16 en $R$. f. flabelliformis).

Distribución: Rhabdinopora flabelliformis flabelliformis es una forma cosmopolita, cuyo registro se extiende entre las biozonas de Anisograptus matanensis (parte media del Tremadociense inferior) y de Adelograptus (parte baja del Tremadociense superior). En la Formación Volcancito, la subespecie nominal está representada en un amplio intervalo $(221 \mathrm{~m})$ del Miembro Peña Negra de la unidad, dentro de las biozonas de A. matanensis y de R. f. anglica. Fuera del Famatina, R. f. flabelliformis ha sido citado en otras localidades de Argentina, Chile (cf.), Bolivia, Colombia (cf.) y Méjico, según identificaciones que deberán ser reevaluadas a la luz de la moderna taxonomía del género (Cooper et al., 1998).

\section{Rhabdinopora flabelliformis acenolazai subsp. nov. Figs. 5, 14g, 15a-c}

1950 Dictyonema rusticum (Lapworth MS); Bulman, 77-78, lám. 5 fig. 4; non fig. 2, lám. 5 figs. 1-4 y lám. 8 figs. 11-13 (= Rhabdinopora rustica según Erdtmann, 1986, morfotipo geróntico).

? 1957 Dictyonema sp.; Turner en Harrington \& Leanza, 15, 24 y 26.

- 1960 Dictyonema sp. $b$; Turner, 44, lám. 3 fig. 11.

?p (1975) Dictyonema flabelliforme (Eichwald) var. famatinense nov. Turner; Toselli, 150-151, lám. 4 fig. 2.

vp 1984 Dictyonema flabelliforme (Eichwald) var. anglica Bulman; Aceñolaza \& Durand, 271-272, lám. 1 figs. 2 y 6.

v 1997 Rhabdinopora n. sp. 1; Esteban \& Gutiérrez-Marco, 60.

? 1998 Rhabdinopora parabola; Moya et al., 230, fig. 2.2.

v 1999 Rhabdinopora n. sp. 1; Esteban et al., 219.

? 2000 Rhabdinopora parabola (Bulman); Moya \& Albanesi, 115 .
? 2002 Rhabdinopora f. parabola; Albanesi \& Ortega, 152.

2003d Rhabdinopora flabelliformis; Moya et al., fig. 25.

v 2003 Rhabdinopora flabelliformis acenolazai n.n.; Gutiérrez-Marco \& Esteban, 40, figs. 2 y 3E.

p 2003 Rhabdinopora flabelliformis parabola (Bulman); Toro \& Brussa, 445 (tan sólo los ejemplares de la Fm. Saladillo; non lám. 1 figs. 2-3).

?p 2004 Rhabdinopora f. parabola (Bulman); Zhang et al. fig. 7.

Holotipo: Rabdosoma PIL 14482, depositado en la colección de paleoinvertebrados Lillo, Universidad Nacional de Tucumán (Argentina), e ilustrado aquí en la Fig. 5 y 14g.

Localidad tipo: Peña Negra, en la margen derecha del río Achavil, $72 \mathrm{~km}$ al oeste de la población de Famatina (La Rioja, Argentina).

Estrato tipo: Miembro Peña Negra de la Formación Volcancito, horizonte situado $246 \mathrm{~m}$ por encima de la base en el perfil de Peña Negra. Tremadociense superior (?), Biozona de Adelograptus?.

Derivación del nombre: La nueva subespecie está dedicada al Acad. Prof. Dr. Florencio Gilberto Aceñolaza, director del Instituto Superior de Correlación Geológica del CONICET y la Universidad Nacional de Tucumán (INSUGEO), quien estudió graptolitos ordovícicos en diversas localidades del Sistema de Famatina, e impulsó la prosecución de las investigaciones en el área, de las que da cuenta el presente trabajo.

Paratipos: Numerosos rabdosomas, esencialmente completos y en buen estado de preservación. Los ejemplares PIL 13794 a 13799 b, 14479 a 14481 y 14679-14680, proceden de las biozonas de Anisograptus matanensis, Rhabdinopora $f$. anglica y Adelograptus? de Peña Negra; los numerados como PIL 14483 a 14488, de la Biozona de Adelograptus? del río Volcancito.

Diagnosis: Rabdosoma muy ancho con región apical redondeada, generalmente de longitud inferior a $50 \mathrm{~mm}$. Estipes delgadas (anchura lateral 0,25-0,4 mm), separadas por interespacios más grandes $(0,5-0,9 \mathrm{~mm})$, en número de 8-11 en $10 \mathrm{~mm}$ (promedio 9-10). Disepimentos muy delgados, distribuidos irregularmente.

Broadly parabolic rhabdosome, usually less than 50 $\mathrm{mm}$ in length. Stipes are relatively thin (lateral width of 0.25-0.4 mm), generally straigth to moderate in sinuosity, with interstipe distance of 0.5-0.9 mm. Mean stipe spacing ranges from 8 to 11, averaging 9-10, in $10 \mathrm{~mm}$. Dissepiments very thin and irregularly arranged.

Descripción: Rabdosoma ampliamente cónico, con longitud máxima observada de $50 \mathrm{~mm}$ (normalmente 15 a $20 \mathrm{~mm}$ ) y relación longitud / anchura comprendida entre 0,5-0,8 (este valor típicamente se sitúa entre 0,6 y 0,7 , siendo igual o superior a la categoría 4c de Cooper et al., 1998: fig. 11). El rabdosoma se expande rápidamente a partir de una región proximal redondeada, de la que resalta el extremo apical de la sícula, normalmente inclinado con respecto al eje del rabdosoma y prolongado en un nema delicado y flexuoso, el cual alcanza una longitud de $2,7 \mathrm{~mm}$ y rara vez se conserva. El rabdosoma mantiene un crecimiento constante en anchura a lo largo de su astogenia, de modo que su ángulo de divergencia en perfil lateral varía entre 


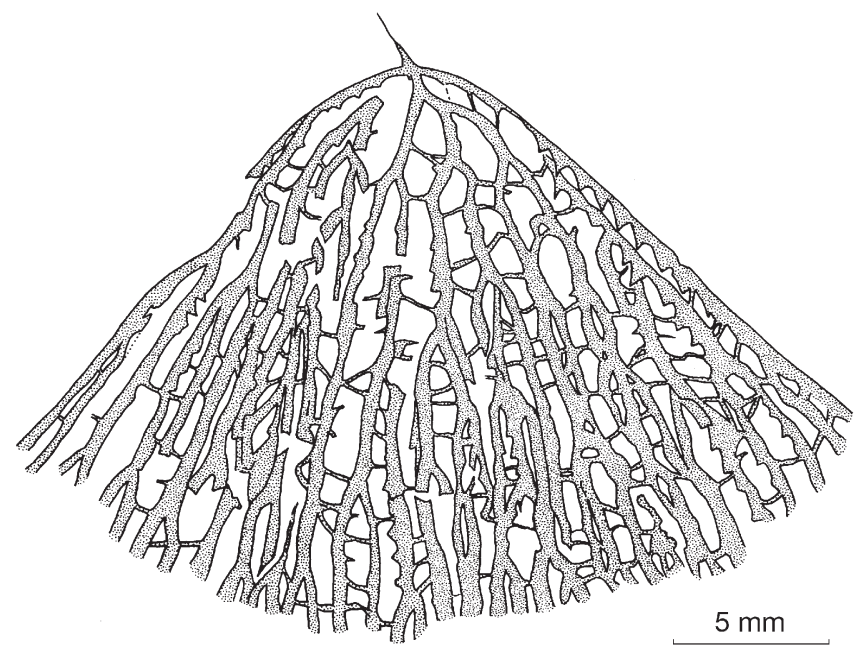

Figura 5. Rhabdinopora flabelliformis acenolazai subsp. nov. - Esquema de la región proximal del holotipo PIL 14482 (= Fig. 14g), procedente del horizonte de 221 m de la sección de Peña Negra (Miembro Peña Negra de la Formación Volcancito).

Rhabdinopora flabelliformis acenolazai subsp. nov. - Outline of the proximal region of the holotype, PIL 14482 (= Fig. $14 \mathrm{~g}$ ), from the horizon of $221 \mathrm{~m}$ above the base of the Peña Negra Member of the Volcancito Formation at Peña Negra. Scale bar in milimeters.

$68^{\circ}-95^{\circ}$ (promedio $75^{\circ}-80^{\circ}$ ). Esta variación se debe a que muchos rabdosomas se presentan algo contraídos distalmente, haciendo que sus perfiles laterales sean levemente convexos.

Las estipes son delgadas; su anchura lateral oscila entre 0,25-0,4 $\mathrm{mm}$ (promedio $0,35 \mathrm{~mm}$ ) y se encuentran separadas por interespacios claramente mayores $(0,5-0,9 \mathrm{~mm})$, dando a la malla un aspecto abierto. El número de estipes en sectores maduros de la colonia (a partir de $10-15 \mathrm{~mm}$ de la sícula) varía entre 8 y 11 (promedio 9-10) en $10 \mathrm{~mm}$. Las estipes en vista dorsal estricta son bastante rectilíneas y de bordes aproximadamente paralelos. La ramificación del rabdosoma se produce de una forma relativamente rápida, sin que existan zonas definidas de concentración radial de dicotomías, constantes de un rabdosoma a otro. El número de divisiones presente en los 20 primeros mm (sag.) oscila entre 4 y 6 . La separación entre dicotomías, en las porciones maduras del rabdosoma, varía entre 18 y más de $20 \mathrm{~mm}$.

Los disepimentos son muy delgados, la mayoría de 0,04-0,05 $\mathrm{mm}$ y se encuentran distribuidos irregularmente entre estipes contiguas o en regiones concretas del rabdosoma (unas veces hay distancias de 3 a $5 \mathrm{~mm}$ sin ningún disepimento entre estipes, y otras veces llegan a observarse concentraciones de 4 a 5 en 3 $\mathrm{mm})$. Por ello su número en $10 \mathrm{~mm}$ varía entre 6 y 8 en la parte proximal del rabdosoma y entre 8 y 10 en sus porciones maduras. La mayor parte de los disepimentos se disponen de forma alterna y perpendicular a las estipes, aunque rara vez se observa la inserción secundaria de disepimentos o la alineación horizontal de varios de ellos entre estipes adyacentes. En el primer caso, se constata la presencia de disepimentos oblicuos que se unen a otros disepimentos perpendiculares, o bien convergen en una de sus bases de inserción; en el segundo la alineación registrada ocurre normalmente entre 3 o 4 estipes y se produce de forma aislada, sin configurar áreas especiales del rabdosoma donde este fenómeno implique varios disepimentos sucesivos.

En la región distal de los rabdosomas adultos pueden observarse también algunos disepimentos excepcionalmente gruesos $(0,16-0,27 \mathrm{~mm})$ dispersos en el seno de la malla. Probablemente corresponden a fenómenos de recrecimiento cortical entre disepimentos contiguos, en fases avanzadas de la astogenia. La inserción de los disepimentos se inicia entre estipes de segundo y tercer orden, y en general estas estructuras son menos numerosas y más delicadas en la parte proximal del rabdosoma. Ello contribuye al colapso general de esta primera región, en colonias comprimidas lateralmente, de modo que la distorsión bioestratinómica impide reconocer normalmente la secuencia de producción de los primeros ordenes de dicotomías y su eventual zonalidad. Las autotecas se observan, generalmente, en las estipes más laterales de las colonias comprimidas, así como en sectores relativamente maduros del rabdosoma, donde el carácter abierto de la malla (que combina interespacios amplios con finos disepimentos) facilita la torsión parcial de muchas estipes durante la compactación. En la porción distal de la colonia, las autotecas están inclinadas $40^{\circ}-50^{\circ}$ con el eje dorsal de la estipe y poseen un margen apertural netamente cóncavo, lo que confiere a la apertura un carácter denticulado. Las autotecas se presentan solapadas en la mitad de su longitud, aproximadamente. El margen ventral libre mide 0,54 a $0,57 \mathrm{~mm}$ en las tecas de las estipes más distales. La mala conservación de las colonias impide apreciar las bitecas, que indirectamente parecen algo abultadas, dada la sinuosidad moderada que introducen en estipes comprimidas en forma oblicuo-dorsal.

Relaciones y diferencias: Rhabdinopora flabelliformis acenolazai subsp. nov. posee un rabdosoma dendroideo pendiente, con una sícula bien destacada en su extremo proximal, la cual tiene un nema delicado e indiviso. Su morfología comparte muchos caracteres con las poblaciones estratigráficas y ecológicas diferenciadas para $R h a b$ dinopora flabelliformis, razón por la cual el nuevo taxón se propone como una subespecie del mismo. El aspecto general de la colonia, ampliamente cónica con una región apical redondeada, resulta en cierto modo homeomórfico de algunas subespecies primitivas del género, como $R$. flabelliformis rustica (Bulman) o regiones proximales de $R$. flabelliformis parabola (Bulman) [= R. flabelliformis belgica (Bulman)]. Rhabdinopora parabola fue considerado por Erdtmann (1986, 1988a) como el morfotipo adulto avanzado a geróntico de $R$. f. belgica, sobre el que acreditaba además la prioridad nomenclatural. Ambas formas pertenecen a la Asociación 1 del Tremadociense basal (Cooper, 1979, 1999; Erdtmann, 1988a, 1988b; Cooper et al., 1998), correspondiendo al "bioevento 2 " en la biodiversificación de los graptoloideos planctónicos (Wang, 2000). Cooper et al. (1998) sinonimizaron recientemente con $R$. $f$. canadensis (Bulman) el material de Terranova atribuido previamente a $R$. f. rustica por Fortey et al. (1982) y Erdtmann (1988b), en tanto que el material tipo de $R$. f. rustica resultó sinonimizado provisionalmente con R. f. flabelliformis. 
De acuerdo con su descripción original, $R$. $f$. rustica posee estipes más robustas y sinuosas que $R$. $f$. acenola$z a i$, así como disepimentos más esporádicos e irregulares. Sin embargo, uno de los ejemplares ilustrados por Bulman (1950: lám. 5 fig. 4) difiere del resto del material tipo por sus estipes más delgadas y disepimentos menos angulares, por lo que fue adscrito con reservas a $R$. f. rustica. Esta colonia procede de una localidad diferente de Matane (Canadá) y se encuentra acompañada por Anisograptus, siendo por tanto, muy semejante al holotipo de R. f. acenolazai, no sólo morfológicamente, sino también por sus circunstancias estratigráficas. En nuestra opinión, creemos justificado asignar provisionalmente dicho ejemplar a la nueva subespecie del Famatina, en lugar de a R. f. rustica (sensu lato).

Entre las poblaciones de $R . f$. parabola, existen raros morfotipos extremos que recuerdan mucho a $R$. $f$. acenolazai. Tal es el caso del ejemplar ilustrado por Cooper et al. (1998: fig. 15k), virtualmente idéntico al holotipo de la especie argentina. Sin embargo, $R$. $f$. parabola es una subespecie más antigua, restringida a la biozona homónima del Tremadociense basal con anterioridad a la aparición de Anisograptus, un género que acompaña comúnmente a $R$. f. acenolazai en la Formación Volcancito. El citado morfotipo representa, además, una fracción mínima de las categorías morfológicas diferenciadas por Cooper et $a l$. (1998) y Wang et al. (1998), para la subespecie $R$. $f$. parabola. En este sentido, el ejemplar noruego antes citado (Cooper et al., 1998: fig. 15k) es un rabdosoma muy ancho, con un número de estipes relativamente bajo, que representa el $1 \%$ de la población de Digermul y que no se repite en otras poblaciones de esta subespecie (Wang et al., 1998). Por el contrario, el morfotipo equivalente en $R$. f. acenolazai puede ser considerado como una forma modal y característica de dicha subespecie. De acuerdo con Cooper et al. (1998), la comparación taxonómica en el seno de Rhabdinopora debe hacerse en función del análisis cuantitativo de poblaciones o entre sus morfotipos centrales, de modo que las semejanzas observadas entre este morfotipo extremo de R.f. parabola (categoría 4c) y el holotipo de $R$. f. acenolazai no resultan significativas, más aún cuando ambos taxones aparecen restringidos a horizontes estratigráficos y biocronológicos muy distintos (bioeventos 2 y 3 de Wang, 2000).

Rhabdinopora flabelliformis regillum Lin (ex Dictyonema flabelliforme regulare Lee \& Chen; non Dictyonema regulare Bouček) tiene un rabdosoma abierto parecido al de la subespecie del Famatina, pero se diferencia de ésta por la carencia de un contorno proximal parabólico, y discrepancias en cuanto a las dimensiones de algunos elementos de la colonia.

Rhabdinopora flabelliformis acenolazai subsp. nov. presenta también ciertas semejanzas con algunas especies de Rhabdinopora del Tremadoc inferior terminal, como $R$. f. anglica (Bulman) у R. f. flabelliformis morfotipo "patula". Ambos poseen un rabdosoma ancho, similar a $R$. $f$. acenolazai, pero los caracteres de sus mallas son muy diferentes.

Fuera del grupo de Rhabdinopora flabelliformis, la subespecie nueva tiene un aspecto bastante similar al $R$. novosemelicum Sobolevskaya, por la morfología general del rabdosoma y el carácter abierto de la malla, así como por una densidad comparable de estipes en $10 \mathrm{~mm}$ (8-11). Sin embargo, a diferencia del nuevo taxón aquí propuesto, la especie rusa procede de horizontes ligeramente más modernos (en su localidad tipo se encuentra asociada con $R$. $f$. flabelliformis, $R$. $f$. aff. bryograptoides, Anisograptus y Clonograptus: Sobolevskaya \& Koren, 1997: fig. 1), tiene estipes más gruesas (mínimo de 0,4-0,5 mm frente a un promedio de $0,3 \mathrm{~mm}$ en la forma argentina) y sus dicotomías presentan una clara zonalidad (con un mínimo de 9 zonas de concentración radial de dicotomías).

Observaciones: Si consideramos las descripciones previas de graptolitos en la Formación Volcancito, Rhabdinopora flabelliformis acenolazai concuerda perfectamente con Dictyonema sp. b de Turner (1960) en todos sus caracteres y dimensiones. Sin embargo, en nuestro material no existen indicaciones de un posible engrosamiento del nema como el indicado por Turner (1960) para Dictyonema sp. b.

Dictyonema flabelliforme famatinense, difiere claramente de la especie por la distinta morfología general del rabdosoma (la relación longitud / anchura se sitúa entre $1,5$ y 1,7$)$, por sus estipes más robustas y de trazado levemente ondulado, y por el mayor número de disepimentos (con promedio de 11 en $10 \mathrm{~mm}$ ). Aceñolaza \& Durand (1984) consideraron a la forma "famatinense" como un sinónimo posterior de R.f. anglica. El material ilustrado por Aceñolaza \& Durand $(1983,1984)$ no posee la malla amplia característica de la forma británico-escandinava (Bulman, 1927, 1954), ni tampoco concuerda enteramente con los parámetros morfológicos asignados por Turner (1960) a D.f. famatinense. Estos coinciden, en cambio, con los de R.f. acenolazai, salvo en el número de disepimentos (4-7 en $10 \mathrm{~mm}$ ). Sin embargo, esto podría haber sido estimado por defecto, dado que tales estructuras en el material estudiado son muy delicadas y difíciles de advertir y, en todo caso, la variación en el número de disepimentos no constituye un carácter diagnóstico importante para la distinción de especies o subespecies de Rhabdinopora (Cooper et al., 1998).

Por último, el ejemplar identificado como Dictyonema cf. D. scitulum por Aceñolaza \& Durand (1983, 1984: lám. 1 fig. 9) se trata de un rabdosoma comprimido discoidalmente. Éste evidencia una morfología cónica abierta, previa a la compactación, similar a la de $R$. f. acenolazai. El auténtico R. scitulum (Harris \& Keble) posee un rabdosoma infundibuliforme a ciatiforme de tamaño pequeño, con nema ramificado y malla compacta debido a un número elevado de disepimentos. Todo ello hace pensar 
que el ejemplar del Famatina se trataría de una variante bioestratinómica de R.f. acenolazai o, muy probablemente también, de un graptolito bentónico indeterminado, al que recordaría por el modo de ramificación y orientación de sus estipes.

Fuera del ámbito estudiado, asignamos a $R$. $f$. acenolazai el material ilustrado por Moya et al. (1998: fig. 2.2) como R. parabola y por Moya et al. (2003d: fig. 25) como Rhabdinopora flabelliformis, que procede en ambos casos de la Formación Saladillo en la sección del Angosto del Moreno, oeste de la Cordillera Oriental argentina. La asignación a $R$. f. parabola fue reiterada también por Moya \& Albanesi (2000) y Albanesi \& Ortega (2002). Además del aparente homeomorfismo con la nueva subespecie, estos ejemplares coexisten con Anisograptus matanensis (¿y con Rhabdinopora turneri?) en la Formación Saladillo de dicha localidad y proceden, por lo tanto, de niveles bastante más modernos que los propios de R. f. parabola (s. str.).

Distribución: Rhabdinopora flabelliformis acenolazai subsp. nov. ha sido registrado en un espesor de $245 \mathrm{~m}$ dentro del Miembro Peña Negra de la Formación Volcancito, en el perfil de Peña Negra. También en la parte más baja de este mismo miembro, en el perfil de puesto Volcancito. Dentro de la Cordillera Oriental, la nueva subespecie está representada muy probablemente en la sección de El Angosto del Moreno (cf. Moya et al., 1998: fig. 2.2). Desde el punto de vista bioestratigráfico, la distribución de $R$. f. acenolazai abarca las biozonas de Anisograptus matanensis y Rhabdinopora flabelliformis anglica (Cooper et al., 1998), representativas de la "Asociación 2" del Tremadociense inferior (Cooper, 1979, 1999; Erdtmann, 1988b; Cooper et al., 1998), y a su vez consecuente al "bioevento 3" en la biodiversificación de los graptolitos planctónicos (Wang, 2000). También parece extenderse a la Biozona de Adelograptus? del Tremadociense superior basal. Fuera de Argentina, $R$. $f$. acenolazai se encuentra muy probablemente representado en horizontes de la Biozona de Anisograptus matanensis del Grupo Matane en Québec (Canadá: véase Bulman, 1950: lám. 5 fig. 4) y también en la parte baja de esta misma biozona en el sur de China, donde los últimos registros de un presunto " $R$. $f$. parabola" (Zhang et al., 2004: fig. 7) claramente postdatan la aparición de Bryograptus y Kiaerograptus? en el Tremadociense superior.

\section{Rhabdinopora flabelliformis anglica (Bulman, 1927) \\ Figs. $14 \mathrm{~h}-\mathrm{j}$}

1927 Dictyonema flabelliforme var. anglica nov.; Bulman, 28, fig. 16, lám. 1 figs. 1, 3, 5-8; lám. 2 figs. 5-8.

1954 Dictyonema flabelliforme anglicum Bulman; Bulman, 17-18, fig. 5a, lám. 4 fig. 3-5.

v non 1984 Dictyonema flabelliforme (Eichwall) var. anglica Bulman; Aceñolaza \& Durand, 261-262, lám. 1 figs. 2 y 6 (= Rhabdinopora flabelliformis acenolazai subsp. nov.).

1997 Rhabdinopora n. sp. 3; Esteban \& Gutiérrez-Marco, 61 .

$\begin{array}{lll}\text { - } & 1998 & \text { Rhabdinopora flabelliformis anglica (Bulman); } \\ & & \text { Cooper et al., 16-18, figs. 6d, 19, } 20 \text { y 21e. } \\ \text { v } & 1999 & \text { Rhabdinopora sp. 3; Esteban et al., } 219 . \\ \text { v } & 2002 & \text { Rhabdinopora f. anglica; Esteban, 30. } \\ \text { v } & 2003 & \begin{array}{l}\text { Rhabdinopora f. anglica; Gutiérrez-Marco \& Es- } \\ \text { teban, fig. } 2 .\end{array}\end{array}$

Material: Diversas regiones proximales y fragmentos de rabdosomas de gran tamaño, PIL 14502-14505, procedentes del intervalo 45 a $167 \mathrm{~m}$ de la sección de Peña Negra. Biozona de Rhabdinopora $f$. anglica del Tremadociense inferior alto, y parte baja de la Biozona de Adelograptus? del Tremadociense superior basal.

Descripción: El rabdosoma presenta un perfil parabólico en las colonias juveniles, de relación longitud / anchura comprendida entre 1 y 1,5. Las dimensiones y morfología general del rabdosoma adulto se desconocen, pero los fragmentos más largos registrados alcanzan $40 \mathrm{~mm}$ de longitud por una anchura aparente de $45 \mathrm{~mm}$, lo que sugiere que la colonia sería muy alargada, con perfil variable entre vasiforme a manifiestamente divergente.

Las estipes tienen unos contornos rectilíneos y están distanciadas por interespacios que superan en 2-3,5 veces su anchura. Por esta razón, el número de estipes es inusualmente bajo, situándose entre 5 a 6 (raras veces 7 ) en $10 \mathrm{~mm}$. Las estipes miden $0,3-0,4 \mathrm{~mm}$ de achura lateral y $0,6-0,9 \mathrm{~mm}$ de achura dorso-ventral.

Los disepimentos son delgados $(0,07-0,09 \mathrm{~mm})$ y poco numerosos (2-4 a 3-5 en $10 \mathrm{~mm}$ en las regiones proximal y madura del rabdosoma, respectivamente). Su orientación general es perpendicular a ligeramente oblicua con respecto a las estipes.

Las colonias juveniles se ramifican rápidamente cerca del extremo proximal, sin generar zonas definidas de bifurcación, salvo a distancias de 6 y $14 \mathrm{~mm}$ de la sícula, observadas en algunos rabdosomas. En los sectores maduros de la colonia, los puntos de dicotomía aparecen distanciados a intervalos de 20 a $25 \mathrm{~mm}$.

Las autotecas maduras presentan un dentículo agudo. El margen ventral está inclinado $35^{\circ}-40^{\circ}$ con el eje dorsal de la estipe en la mayor parte de su recorrido, y se incurva en la proximidad de la apertura, cuyo borde resulta ligeramente oblicuo a la dirección de crecimiento de la autoteca. El número de autotecas en $10 \mathrm{~mm}$ oscila entre 12 y 14 .

Observaciones: El material del Famatina presenta la configuración típicamente abierta de la malla de $R$. $f$. anglica, una subespecie que ha sido revisada recientemente por Cooper et al. (1998). En particular, el bajo número de estipes y disepimentos por unidad de longitud, ha sido considerado como sus carácter más distintivos frente a las restantes subespecies de $R$. flabelliformis, situándose el límite en 7 estipes en $10 \mathrm{~mm}$. Los ejemplares estudiados muestran una gran variabilidad en cuanto a la morfología del rabdosoma y al espaciamiento tecal, que sin embargo entra dentro del rango establecido para $R$. $f$. anglica por Cooper et al. (1998). Nuestro material recuerda también a Rhabdinopora hunanensis Wang \& Wang pero esta especie, descrita recientemente en la Biozona de $R$. $f$. anglica de China, tiene un rabdosoma declinado-pendiente muy 
abierto y un desarrollo proximal aparentemente trirradiado, muy distintos a los del material examinado.

En Argentina, $R . f$. anglica podría estar representada también en los niveles con Adelograptus (base del Tremadociense superior) de la sección del Angosto de La Quesera, provincia de Salta (Moya et al., 2003e).

Distribución: Rhabdinopora flabelliformis anglica (Bulman) es una forma cosmopolita que ha sido registrada en todo tipo de sucesiones de plataforma y talud continental entre el Tremadociense inferior terminal y la base del Tremadociense superior (Cooper et al., 1998; Cooper, 1999), rango que concuerda también con el de los ejemplares del Famatina.

\section{Rhabdinopora flabelliformis socialis (Salter, 1858) \\ Fig. 14d-e}

* 1858 Graptopora (Fenestella) socialis n. sp.; Salter, 65.

1866 Dictyonema sociale (Salter); Salter, 331, lám. 4 figs. 1, 1a-c.

- 1927 Dictyonema flabelliforme (Eichwald) var. sociale (Salter); Bulman, 26-28, fig. 15, lám. 2 figs. 1, 2 (con sinonimia previa).

- 1954 Dictyonema flabelliforme sociale (Salter); Bulman, 27-29, fig. 10a, lám. 1 figs. 1-2.

1973 Dictyonema flabelliforme aff. sociale (Salter); Bulman \& Rushton, 20, fig. 2k.

vp 1984 Dictyonema flabelliforme flabelliforme; Aceñolaza \& Durand, 272 (p.p.= ejemplares con 9-12 estipes en 10 $\mathrm{mm})$.

v 1997 Rhabdinopora socialis (Salter); Esteban \& Gutiérrez-Marco, 60.

- 1998 Rhabdinopora flabelliformis socialis (Salter); Cooper et al., 18.

v 1999 Rhabdinopora flabelliformis socialis; Esteban et al., 219.

cf. 1999 Rhabdinopora flabelliformis cf. socialis (Salter); Tortello \& Esteban, 383-385, figs. 6A-6C, 6E.

v 2002 Rhabdinopora f. socialis; Esteban, 30.

v 2003 Rhabdinoporaf. socialis; Gutiérrez-Marco \& Esteban, 40, fig. 2.

Material: Ejemplares PIL 13775-13776, intervalo de 26 a 32 m de la sección de Peña Negra, Biozona de Anisograptus matanensis. Fragmentos de grandes rabdosomas encontrados en la parte inferior de la sección de río Volcancito (PIL 13777-13779) podrían pertenecer tanto a la subespecie como a morfotipos vasiformes de R. f. flabelliformis.

Descripción: El rabdosoma es alargado, con un predominio de los morfotipos 2a y 3a según las categorías de Cooper et al. (1998: fig. 11), y alcanza un longitud de más de $110 \mathrm{~mm}$ (reconstruida a partir de fragmentos). La relación longitud / anchura varía aproximadamente entre 1,2 y 1,7 , a $50 \mathrm{~mm}$ del extremo proximal.

En nuestra colección no hay ningún resto proximal del rabdosoma que pueda ser asignado con seguridad a la especie; los fragmentos más próximos a esta región muestran una concentración de dicotomías en la parte cónica inicial, con zonas incipientes de ramificación situadas aproximadamente a 3-4 mm, 10-13 mm y 14-19 mm, definidas por la existencia de 4-6 dicotomías observables al mismo nivel en el rabdosoma. En el resto de las porciones maduras y gerónticas de las colonias, las dicotomías son raras y se presentan de forma dispersa.

Las estipes en vista dorsal son delgadas y prácticamente rectilíneas: las principales irregularidades de su recorrido vienen inducidas por las bases espesadas de inserción de los disepimentos. La anchura lateral de las estipes varía entre $0,20-0,25 \mathrm{~mm}$, y los interespacios que las separan son levemente más anchos. Este carácter, unido a la existencia de disepimentos muy finos, confiere a la malla su aspecto denso y delicado característico. El número de estipes en $10 \mathrm{~mm}$ varía de 11 a 13, contabilizándose 12 en los casos más habituales.

Los disepimentos son delgados (0,07-0,09 mm) y numerosos (8 a 10, como máximo 15), y en su mayoría se orientan perpendiculares al eje de las estipes, presentándose espesados en sus puntos de unión con aquellas. A lo largo de un mismo rabdosoma se registran numerosas irregularidades en cuanto al espaciamiento y orientación de los disepimentos, que llegan a disponerse oblicuos, presentar anastomosis o espesamientos corticales, o incluso alineaciones horizontales entre 3-6 estipes adyacentes.

Las autotecas se reconocen raramente, debido al carácter "cerrado" de la malla, aunque algunos vestigios de autotecas conservados en una estipe lateral del ejemplar PIL 13775 permiten estimar su número en torno a 15 en $10 \mathrm{~mm}$ ( 5 en $3 \mathrm{~mm}$ ), en un sector situado a menos de $20 \mathrm{~mm}$ del extremo proximal. La anchura dorso-ventral de la estipe, medida en este mismo punto, es de $0,63 \mathrm{~mm}$. Las autotecas son denticuladas por la presencia de un margen apertural orientado oblicuamente; sus paredes ventrales se solapan aproximadamente en algo más de la mitad de su longitud, y la inclinación del sector ventral libre varía entre $30^{\circ}$ y $35^{\circ}$.

Observaciones: Rhabdinopora flabelliformis socialis es una de las formas más difundidas en la parte media del Tremadociense inferior, donde es considerada como una subespecie ecofenotípica que se dispersa rápidamente en las secuencias de plataforma y talud superior, para ser luego reemplazada por $R$.f. flabelliformis (Cooper et al., 1998; Cooper, 1999). En Sudamérica, R. f. socialis fue identificada con reservas por Turner (1960: 35) en la Cordillera Oriental, y mencionada más tarde por Moya et al. (1994) en la misma región (Formación Saladillo) en niveles correlacionables con los del Famatina (Asociación Graptolítica IV de estos últimos autores). El presente estudio confirma la presencia de este taxón en Sudamérica. Los caracteres más distintivos de nuestro material son el número elevado de estipes en $10 \mathrm{~mm}$ y la gran densidad de disepimentos, que concuerdan con los rasgos diagnósticos de la subespecie, revisados por Cooper et al. (1998). Sin embargo, los ejemplares estudiados son demasido fragmentarios como para poder compararlos con las variantes morfotípicas de la subespecie descritas por Legrand (1973) en el norte de Africa. No obstante, todas ellas parecen diferir del material 
famatinense por la presencia de un número considerablemente inferior de disepimentos.

Distribución: Rhabdinopora flabelliformis socialis es una forma cosmopolita, cuyo registro se extiende entre las biozonas de $R$. $f$. parabola y de A. matanensis. En la Formación Volcancito, la subespecie aparece en un corto intervalo estratigráfico del Miembro Peña Negra de la unidad, dentro de la Biozona de A. matanensis, pero su representación podría iniciarse ya a partir de la parte alta del Miembro Filo Azul (Tortello \& Esteban, 1999).

\section{Rhabdinopora flabelliformis bryograptoides} (Bulman, 1954)?

Fig. 7b

\section{?cf.1954 Dictyonema flabelliforme bryograptoides var. nov.; Bulman, 18-19, figs. 5b, 5c; lám. 4 figs. 6-7. \\ p? 1984 Bryograptus sp.; Aceñolaza \& Durand, 273-274, lám. 1 fig. 13. \\ v 2003 Rhabdinopora f. bryograptoides; Gutiérrez-Marco \& Esteban, fig. 2.}

Material: Una región proximal de rabdosoma PIL 14823, procedente del horizonte de $105 \mathrm{~m}$ en la sección de Peña Negra, Miembro medio de la Formación Volcancito. Biozona de Rhabdinopora flabelliformis anglica, parte alta del Tremadociense inferior.

Descripción: La única colonia estudiada se reduce a una parte proximal de aproximadamente $5 \mathrm{~mm}$ de longitud y $6,5 \mathrm{~mm}$ de anchura, con seis estipes terminales. La colonia tiene un aspecto birradiado y simétrico bilateralmente, con las primeras bifurcaciones de estipes situadas a 1,35 y $1,57 \mathrm{~mm}$ del extremo proximal, y una segunda división a 2,56 $\mathrm{mm}$ de las anteriores que afecta a las dos estipes más internas.

Las estipes tienen una anchura dorsal de 0,36-0,4 mm y una anchura dorsoventral de $0,63 \mathrm{~mm}$. Los interespacios que las separaran son considerablemente más anchos $(0,81-1,3 \mathrm{~mm}), \mathrm{y}$ existen indicios de la presencia de un disepimento localizado a $2 \mathrm{~mm}$ del extremo proximal de la colonia, entre las dos ramas surgidas de la primera bifurcación antes citada. Las tecas, visibles sobre ambas estipes marginales, tienen un aspecto normal denticulado y aparecen en número de 18,8 en $10 \mathrm{~mm}$.

Observaciones: El material estudiado es muy parecido al ejemplar de "Bryograptus sp." identificado en la Formación Volcancito por Aceñolaza \& Durand (1984: lám. 1 fig. 13), que sin embargo muestra 8 estipes terminales por la presencia de sendas dicotomías adicionales en las ramas marginales del rabdosoma. Tanto este ejemplar como el aquí descrito, presentan claras diferencias con las colonias juveniles de las restantes subespecies de Rhabdinopora flabelliformis caracterizadas en el Famatina, particularmente por la ausencia de disepimentos proximales y por la enorme separación entre las estipes. Ambos caracteres permiten relacionarlos con Rhabdinopora flabelliformis bryograptoides, que sin embargo presenta las primeras dicotomías más alejadas de la sícula, un ancho de estipes levemente inferior (menor de $0,5 \mathrm{~mm}$ ) y tecas menos numerosas (12?-13 en $10 \mathrm{~mm}$ ). Estos rasgos se refieren al material tipo de la subespecie (Bulman, 1954), si bien los ejemplares identificados posteriormente como Dictyonema flabelliforme cf. bryograptoides por Bulman \& Rushton (1973: figs. 3a-3b) tienen las dos primeras bifurcaciones más cerca del extremo proximal del rabdosoma, como es el caso del material estudiado, y recuerdan también a los ejemplares de Dictyonema flabelliforme cf. anglicum y D. flabelliforme aff. belgicum de estos mismos autores (Bulman \& Rushton, 1973: figs. 3c y 3f). Todos ellos fueron encontrados en un mismo tramo estratigráfico dentro del sondeo Deanshanger, y deben de corresponder a $R$. $f$. bryograptoides, a $R$. $f$. anglica, o bien a un trasiente entre ambas formas. La misma deducción puede aplicarse a los dos únicos ejemplares famatinenses identificados aquí como $R$. f. bryograptoides?, que en todo caso se adscriben a la transición evolutiva entre $R$. f. anglica y $R$. f. bryograptoides postulada por diversos autores (Cooper et al., 1998), que pudo concluir con la aparición de Bryograptus (véase Bulman, 1954).

\section{Rhabdinopora flabelliformis famatinensis (Turner, 1960)}

? $1960 \quad$ Dictyonema flabelliforme (Eichwald) var. famatinense nov.; Turner, 36-38, lám 1 fig. 2 [= Rhabdinopora flabelliformis flabelliformis (Eichwald)?].

?non (1975) Dictyonema flabelliforme (Eichwald) var. famatinense nov. Turner; Toselli, 150-151, lám. 4 fig. 2 (= Rhabdinopora flabelliformis acenolazai subsp. nov.).

1982 a Dictyonema famatinense; Erdtmann, 9.

$1982 b$ Rhabdinopora flabelliformis famatinensis (Turner); Erdtmann, 129.

p $1996 \quad$ Rhabdinopora flabelliforme (Eichwald); Tortello et al., 128-129, lám. 10.2 fig. 2 [= holotipo de $R$. f. famatinensis (Turner)].

Holotipo: Rabdosoma no 5403, figurado por Turner (1960: lám. 1 fig. 2) y depositado originalmente en el Departamento de Geología de la Universidad de Buenos Aires.

Observaciones y discusión: Al igual que en otra importante revisión previa de los graptolitos tremadocienses del Famatina (Aceñolaza \& Durand, 1983, 1984), en el presente trabajo tampoco se ha logrado identificar la subespecie propuesta por Turner (1960), aparentemente endémica de la Formación Volcancito.

Desde su descripción original, $R$. f. famatinensis ha sido citada en algunos listados taxonómicos (por ejemplo, Erdtmann, 1982a y b) sin añadir nuevos ejemplares que confirmasen la variabilidad y rango de la subespecie. Tan sólo Toselli (1975) relacionó con D.f. famatinense un ejemplar que, en nuestra opinión, no tiene nada que ver 
con la forma nominal, y que pertenece muy probablemente a $R$. f. acenolazai subsp. nov.

Aceñolaza \& Durand (1984) consideraron a la subespecie "famatinense" como un sinónimo posterior de $R$. $f$. anglica, pero su argumentación carece de significado a la luz de los modernos criterios taxonómicos aplicados al género Rhabdinopora (ver también apartado de Observaciones a $R$.f. acenolazai). Es posible que este mismo criterio sea mantenido por Albanesi \& Ortega (2002), quienes citan la sola presencia de R.f. anglica entre los ejemplares estudiados por Bodenbender (1916) y Turner (1960) en la sección del río Volcancito.

La revisión emprendida para el presente trabajo permite considerar que en la descripción original de R. f. famatinensis podrían haberse mezclado caracteres diagnósticos de varias especies del género Rhabdinopora. También que el holotipo de $R$. f. famatinensis recuerda mucho por su morfología a la de un rabdosoma de $R$. $f$. flabelliformis del antiguo morfotipo "patula", lo cual se discute en el apartado de Observaciones a esta subespecie.

Al ser R.f. famatinensis un taxón irreconocible en la práctica, pese a haber sido descrito en forma plenamente válida (con descripción y figura del material tipo), en este trabajo se sugiere restringir el taxón a su holotipo (Turner, 1960: lám. 1 fig. 2), al menos hasta que una revisión directa del mismo permita resolver si se trata de un sinónimo posterior de $R$. f. flabelliformis o bien corresponde a una subespecie independiente.

\section{Rhabdinopora turneri sp. nov.}

Figs. 6a-h, 15d-i

v 1997 Rhabdinopora n. sp. 2; Esteban \& Gutiérrez-Marco, 61.

? 1998 Rhabdinopora flabelliformis cf. R.f. socialis (Salter); Moya et al., 230, fig. 2.1.

v 1999 Rhabdinopora n. sp. 2; Esteban et al., 219.

? 2000 R. flabelliformis cf. R. f. socialis (Salter); Moya \& Albanesi, 115.

?p 2003d Rhabdinopora flabelliformis ssp.; Moya et al., fig. $22 \mathrm{~g}$.

v 2003 Rhabdinopora turneri n.n.; Gutiérrez-Marco \& Esteban, 40 , figs. 2 y $3 \mathrm{a}-\mathrm{b}$.

Holotipo: Rabdosoma juvenil, PIL 14491a, depositado en la colección de paleoinvertebrados Lillo, Universidad Nacional de Tucumán (Argentina), e ilustrado en la Fig. 6a y 15h (borde inferior derecho).

Localidad tipo: Peña Negra, en la margen derecha del río Achavil, 72 km al oeste de la población de Famatina (La Rioja, Argentina).

Estrato tipo: Miembro Peña Negra de la Formación Volcancito, horizonte situado $9 \mathrm{~m}$ por encima de la base del perfil Peña Negra. Tremadociense inferior, Biozona de Anisograptus matanensis.

Derivación del nombre: En memoria del Acad. Prof. Dr. Juan
Carlos Manuel Turner (1918-1979), eminente geólogo y paleontólogo argentino, quien describió por vez primera los graptolitos de la Formación Volcancito.

Paratipos: Abundantes rabdosomas comprimidos, pero en buen estado de preservación, procedentes de la Biozona de Anisograptus matanensis de la sección de Peña Negra (ejemplares PIL 14489-14494), y de la Biozona de Rhabdinopora flabelliformis anglica a la de Adelograptus? en este mismo perfil (ejemplares PIL 14495-14501).

Diagnosis: Rabdosoma pequeño, compacto y marcadamente pendiente, de longitud generalmente inferior a 20 $\mathrm{mm}$. Disepimentos muy escasos y extremadamente finos $(0,045-0,090 \mathrm{~mm})$. Estipes de 0,5 a 0,6 $\mathrm{mm}$ de anchura lateral, ligeramente flexuosas, en número de 10 en $10 \mathrm{~mm}$. Nema de gran longitud, con extremo rara vez subdividido y tendencia a unirse en sinrabdosomas.

Small, compact and strongly pendent rhabdosome, usually less than $20 \mathrm{~mm}$ in length. Dissepiments very sparse and very thin $(0.045-0.090 \mathrm{~mm})$. About 10 stipes in 10 $\mathrm{mm}$, slightly flexuous, $0.5-0.6 \mathrm{~mm}$ in lateral width. Long nema, commonly undivided and with tendency to form synrhabdosomes.

Descripción: Rabdosoma pequeño, con una longitud máxima en torno a $20 \mathrm{~mm}$, y morfología variable cuando se conserva comprimido lateralmente (categorías 2a a 3a de Cooper et al., 1998). El contorno original debe ser parabólico amplio, con una relación longitud / anchura de aproximadamente 0,8 y estipes laterales ligeramente convexas. Sin embargo, el caso más frecuente de conservación, en rabdosomas que superen los 10 $\mathrm{mm}$ de longitud axial, implica relaciones longitud / anchura de alrededor de 2-2,2 y morfologías cónicas relativamente agudas, con perfil lateral convexo. La anchura máxima del rabdosoma se logra, por tanto, antes de alcanzar el extremo distal de la colonia. Previamente a éste, el rabdosoma se expande con un ángulo que oscila entre $25^{\circ}-40^{\circ}$, y con posterioridad las estipes laterales se curvan ventralmente llegando a tomar una orientación convergente. Sólo en raras ocasiones, la distorsión del rabdosoma conduce a formas de perfiles cóncavos distalmente.

La colonia se inicia a partir de una sícula delgada, muy notoria y de aproximadamente $1 \mathrm{~mm}$ de longitud, provista de un rutelo (rutellum) muy marcado. La sícula se prolonga en un nema delicado (anchura: 0,05-0,07 $\mathrm{mm}$ ) que alcanza gran longitud $(6,5$ $\mathrm{mm}$ ). En ocasiones se han conservado lo que podrían ser varios nemas unidos de diferentes colonias, tal vez vestigio de un sinrabdosoma (Fig. 6h). El ápice de la sícula de otro rabdosoma aislado se prolonga en una estructura nemática de 2,29 $\mathrm{mm}$ de longitud y $0,36 \mathrm{~mm}$ de anchura que parece aglutinar varias fibras (Fig. 6d), aunque posiblemente se trate de un caso patológico.

Los rabdosomas comprimidos muestran, en la región proximal, dicotomías espaciadas por dos o tres autotecas unicalicales, seguidas por una concentración irregular de ramificaciones a cierta distancia de la sícula. Las partes maduras de la colonia contrastan, por su mayor densidad de estipes, frente a la porción proximal.

Los disepimentos son muy delgados $(0,045-0,090 \mathrm{~mm})$ y se distribuyen muy irregularmente en el rabdosoma, comenzando su inserción a partir de las dicotomías de segundo a cuarto or- 
den. Por lo general se orientan perpendiculares a las estipes y con un trazado rectilíneo. Raras veces se observan disepimentos aislados, oblicuos o anastomosados (dos consecutivos) en un mismo punto de inserción. El número de disepimentos en 10 $\mathrm{mm}$ es poco significativo, dado su carácter esporádico, pero a veces se observan 3 o 4 disepimentos sucesivos en una porción determinada de la colonia.

Las estipes miden 0,25-0,36 mm de anchura en vista dorsal y 0,5-0,6 mm en vista lateral. En la región madura del rabdosoma, el número de estipes es de alrededor de 10 en $10 \mathrm{~mm}$.

Las autotecas son denticuladas en perfil lateral; están inclinadas $30^{\circ}$ a $40^{\circ}$ con respecto al eje de la estipe, y su número varía entre 13 y 15 en $10 \mathrm{~mm}$.

Relaciones y diferencias: Rhabdinopora turneri sp. nov. tiene un aspecto muy próximo a la forma del Ordovícico basal $R$. praeparabola Erdtmann, a la que recuerda por el pequeño tamaño de un rabdosoma fuertemente pendiente, con estipes flexuosas y de "aspecto denso", debido a la ausencia generalizada de disepimentos (Erdtmann, 1982b, 1988b; Landing, 1993; Cooper et al., 1998). Sin embargo, la especie argentina tiene un número más elevado y regular de disepimentos, y estipes ligeramente más robustas (0,5-0,6 mm, frente a 0,3-0,4 mm de anchura lateral en $R$. praeparabola), aparte de provenir de niveles estratigráficos muy diferentes. Rhabdinopora? taojiangensis (Jin \& Wang) se diferencia de $R$. turneri sp. nov. por los mismos caracteres citados para $R$. praeparabola, de la que constituye un más que probable sinónimo prioritario y a cuya biozona reemplaza en las secciones chinas (véase Jin \& Wang, 1977, Wang \& Wang, 2001). No obstante, Zhang
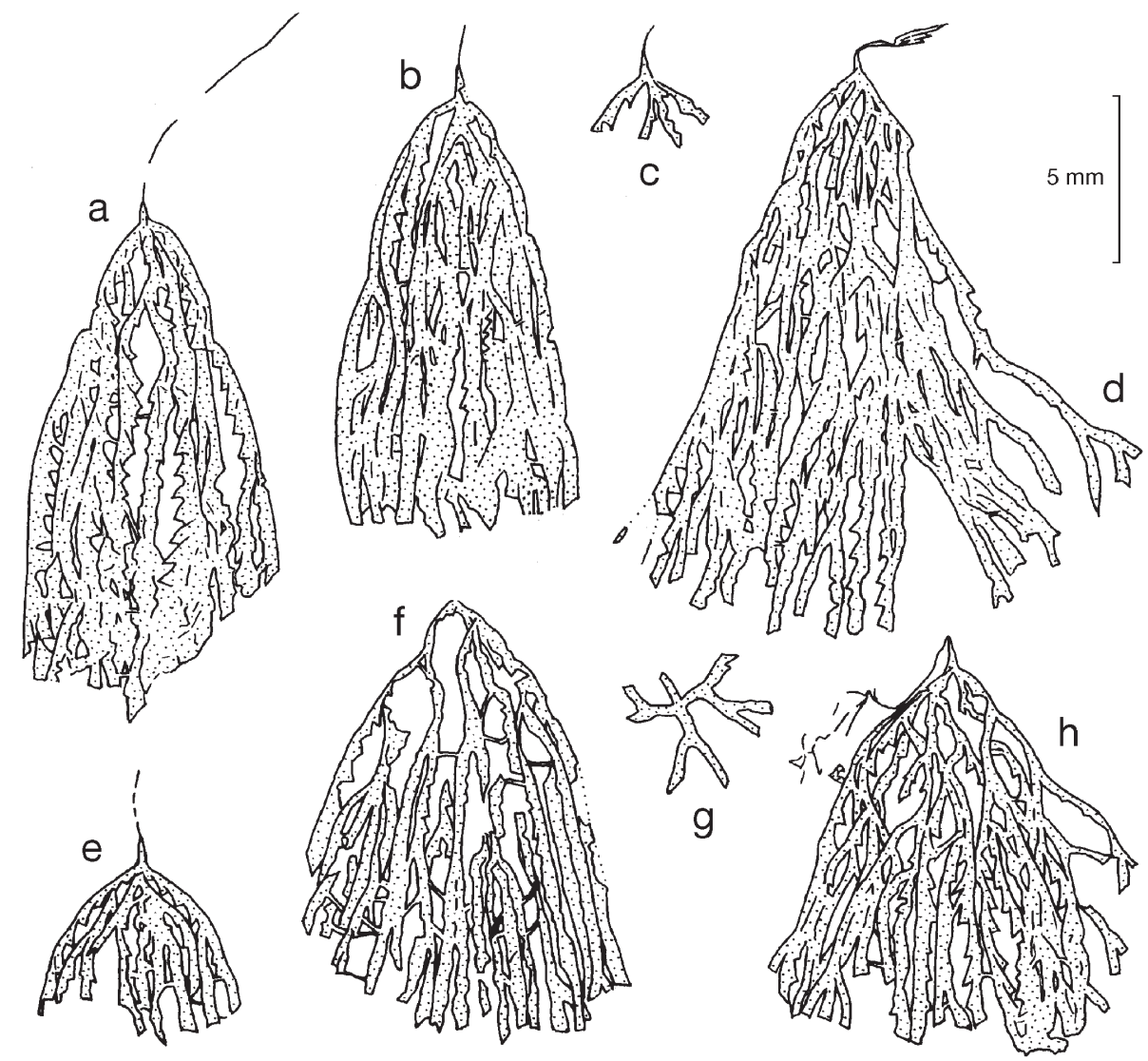

Figura 6. Rhabdinopora turneri sp. nov. a, Holotipo, PIL 14491a. b, Paratipo PIL 14491b asociado al anterior (= Fig. 15h). c, colonia en estado inicial, PIL 14501a. d, rabdosoma con nema aparentemente dividido y estipes distorsionadas durante la compactación, PIL 14489a. e, rabdosoma joven de perfil parabólico, PIL 14491c. f, PIL 14491d. g, vista discoide de un estado de desarrollo inicial, mostrando cuatro estipes primarias, PIL 14501b. h, rabdosoma con estipes flexuosas por distorsión tafonómica, y nema entrelazado con los de otras colonias. Todos de la sección de Peña Negra, horizontes de 4 y 9 m por encima de la base del Miembro Peña Negra de la Formación Volcancito).

Rhabdinopora turneri sp. nov. a, Holotype, PIL 14491a. b, Paratype PIL 14491 from the same slab (= Fig. 15h). c, developmental stage PIL 14501a. d, rhabdosome with an apparently divided nema and distorted stipes, PIL 14489a.e, young rhabdosome with parabolic outline, PIL 14491c.f, PIL 14491d. g, developmental stage in discoidal view, PIL 14501b. h, distorted specimen, showing loose flexuous stipes and tangled nema, probably from a synrhabdosome of the species. All from the horizons of 4 and $9 m$ above the base of the Peña Negra Member of the Volcancito Formation at Peña Negra. 
\& Erdtmann (2004: 157-158) expresan dudas sobre la sinonimia entre $R$.? taojiangensis y $R$. parabola, aludiendo a que su material tipo pueda proceder de niveles enclavados en la parte superior de la Biozona de R. f. parabola o en la parte baja de la de A. matanensis, si bien optan tentativa y contradictoriamente por caracterizar una Biozona de $R$.? taojiangensis como previa al primer registro de $R$. praeparabola y $R$. $f$. parabola en China (véase Zhang \& Erdtmann, 2004: figs. 5, 7 y 9).

Rhabdinopora enigma, del Lancefieldiense 1 de Australia y Terranova (Cooper \& Stewart, 1979; Erdtmann \& Botsford, 1986), se caracteriza por colonias compactas con nema delgado y dividido, cuyo aspecto recuerda a las formas juveniles de $R$. turneri sp. nov. No obstante, la constitución del rabdosoma es muy diferente a la de la especie argentina, por la ausencia de disepimentos, las autotecas espinosas y el rabdosoma diminuto (longitud inferior a 11 $\mathrm{mm}$ ), distintos a los de la forma argentina.

Observaciones: La presencia de un nema tan elongado en $R$. turneri sp. nov. parece vinculada con su tendencia a agruparse en sinrabdosomas. En las muestras PIL 14490 y 14491 (parte inferior de la Biozona de Anisograptus matanensis de Peña Negra) se observan tres de estas posibles estructuras, formadas por 5 a 7 colonias que tienden a orientarse radialmente, con sus extremos proximales convergentes hacia una región central, donde existe una compleja superposición de nemas entrelazados. También el ejemplar PIL 14489b podría conservar retazos de cuatro nemas, unidos entre sí por sus extremos distales, pertenecientes a otras tantas colonias (Fig. 6h). La formación de sinrabdosomas en Rhabdinopora ha sido acreditada en escasos representantes del género (Gutiérrez-Marco \& Lenz, 1998, con referencias), y por ello reviste cierto interés.

Los rabdosomas de mayor tamaño de Rhabdinopora turneri sp. nov. se presentan frecuentemente colapsados, debido a la escasez de disepimentos, que no oponen obstáculo a la torsión de las estipes durante la compactación. En estas circunstancias, las estipes adquieren un aspecto flexuoso, y el perfil del rabdosoma llega incluso a volverse cóncavo distalmente. En ese sentido, un ejemplar identificado como R. flabelliformis $\mathrm{cf}$. socialis por Moya et al. (1998: fig. 2.1), de la Biozona de A. matanensis del oeste de la Cordillera Oriental argentina, tiene un aspecto muy semejante al de $R$. turneri sp. nov., con el que podría estar relacionado, además de un segundo ejemplar de la misma procedencia e identificado como Rhabdinopora flabelliformis ssp. (Moya et al., 2003d: fig. 22g). Otro factor de semejanza para el primer caso es su concurrencia en niveles comunes a los de $R$. f. acenolazai subsp. nov., que a su vez resultarían inusualmente elevados para el auténtico R. f. socialis.

Por último, Rhabdinopora turneri sp. nov. recuerda a algunos rabdosomas identificados como Rhabdinopora flabelliformis subsp. cf. R. f. anglica en un olistolito aislado en el este de Pennsylvania (EE.UU.: Ganis et al., 2001: figs. 6E-F, 6J-M). Éstos se caracterizan por sus escasos a imperceptibles disepimentos, excepcionalmente delgados, y un bajo ángulo de inclinación de las autotecas. También por la presencia de un nema largo, que en una de las colonias termina en un nematulario contorsionado. Pese a que las circunstancias estratigráficas del hallazgo norteamericano no están totalmente claras, su asociación con Anisograptus matanensis apoya su contemporaneidad con la forma del Famatina, si bien la sinonimización completa entre ambos taxones requiere el hallazgo de mejores ejemplares en la localidad estadounidense.

Distribución: El registro de Rhabdinopora turneri sp. nov. se restringe, por el momento, a las biozonas de Anisograptus matanensis, Rhabdinopora flabelliformis anglica y Adelograptus? en el Miembro Peña Negra de la Formación Volcancito (Sistema de Famatina, Argentina). La nueva especie podría estar igualmente representada en la Biozona de A. matanensis de la sección del Angosto del Moreno [Cordillera Oriental jujeña: véase Moya et al., (1998: fig. 2.1), Moya \& Albanesi (2000) y Moya et al. (2003d: fig. 22g)], donde se registran colonias de Rhabdinopora con largos nemas y escasos disepimentos.

\section{Rhabdinopora cf. enigma (Cooper \& Stewart, 1979)}

Fig. $7 \mathrm{a}$

cf. 1979 Dictyonema? enigma sp. nov.; Cooper \& Stewart, 778-779, figs. 3d, h-j; lám. 103 figs. 8, 12-13.

v 2003 Rhabdinopora cf. enigma; Gutiérrez-Marco \& Esteban, fig. 2.

Material: un único rabdosoma PIL 14825 procedente del horizonte de 26,5 m en el Miembro Peña Negra de la Formación Volcancito en la sección de Peña Negra. Biozona de Anisograptus matanensis del Tremadociense inferior.

Descripción: Rabdosoma compacto, de $7 \mathrm{~mm}$ de longitud por 7,7 mm de anchura y perfil parabólico. Ramificaciones concentradas en torno al extremo proximal, y espaciadas distalmente (a $5 \mathrm{~mm}$ de la sícula), con un mínimo de 13 estipes terminales de unos $0,4 \mathrm{~mm}$ de anchura lateral.

La sícula mide 1,1 $\mathrm{mm}$ de longitud y es cuneiforme. No se observaron autotecas y falta cualquier evidencia de disepimentos.

Observaciones: El rabdosoma estudiado, pequeño, compacto y sin disepimentos, tiene un aspecto enteramente comparable a la especie Rhabdinopora enigma descrita en el Lancefieldiense 1 (1a) del sur de Australia y en niveles comparables del oeste de Terranova, Canadá (Cooper \& Stewart, 1979; Erdtmann \& Botsford, 1986). Ambos registros concordarían con la Biozona de Anisograptus matanensis, donde la especie podría estar representada también en Famatina (Fig. 2). No obstante, el hecho de disponer de un sólo ejemplar en el que no pueden adver- 
tirse otros caracteres diagnósticos como el espaciamiento y la espinosidad tecal, así como la subdivisión del nema, aconseja identificar el material en nomenclatura abierta hasta el hallazgo de nuevos ejemplares.

$R$. enigma ha sido relacionado con una posible forma de transición (pedomórfica) entre Rhabdinopora y Bryograptus, así como con estadios de desarrollo juveniles de R. scitulum (Harris \& Keble), con mayor probabilidad hacia la primera hipótesis (Erdtmann \& Botsford, 1986). La presencia de "Dictyonema" cf. scitulum en la Formación Volcancito fue sugerida por Aceñolaza \& Durand (1984: lám. 1 fig. 9), pero el ejemplar ilustrado por estos autores podría corresponder a una forma preservada discoidalmente tanto de $R$. flabelliformis acenolazai, como de un dendroideo bentónico. Por ello, descartamos que exista cualquier relación entre el registro de $R$. cf. enigma y la presencia de $R$. scitulum en la sucesión del Famatina, dado que esta última tampoco ha sido acreditada.
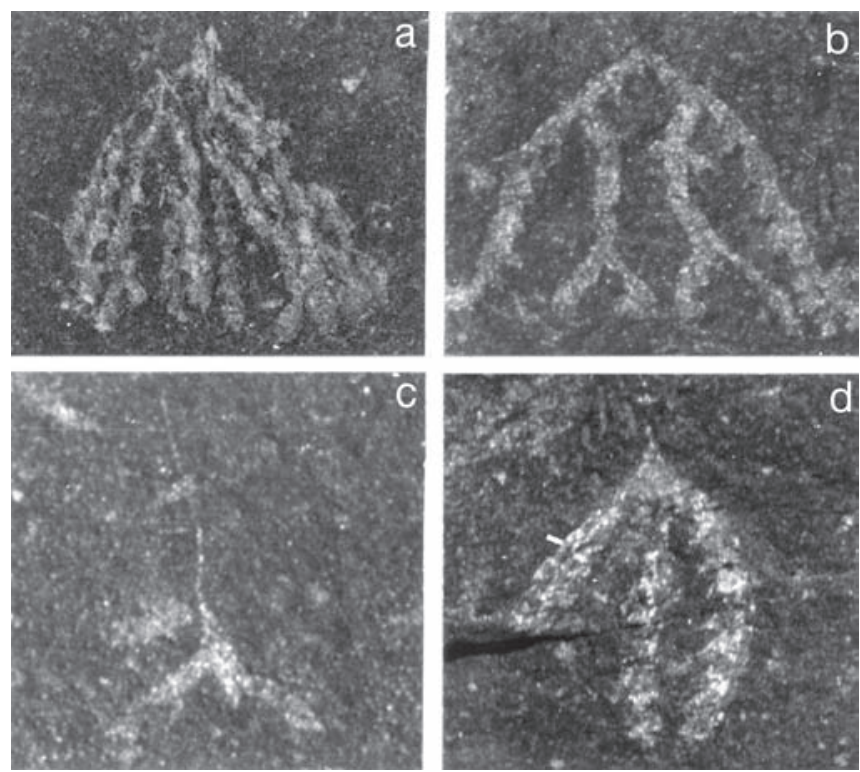

Figura 7. a, Rhabdinopora cf. enigma (Cooper \& Stewart, 1979). Peña Negra, horizonte de 26,5 m, PIL 14825 (x 4,5). b, Rhabdinopora flabelliformis ?bryograptoides (Bulman, 1954). Peña Negra, horizonte de $105 \mathrm{~m}$, PIL 14823 (x 5,5). c, “Adelograptus" sp. Peña Negra, base de la sección, PIL 14826 (x 10). d, Bryograptus? sp. Río Volcancito, ejemplar encontrado suelto hacia la parte baja del Miembro Peña Negra, PIL 14824 (x $6,5)$.

a, Rhabdinopora $c f$. enigma (Cooper \& Stewart, 1979). Peña Negra, horizon of 26.5 m, PIL 14825 ( $x$ 4.5). $\boldsymbol{b}$, Rhabdinopora flabelliformis ?bryograptoides (Bulman, 1954). Peña Negra, horizon of 105 m, PIL 14823 (x 5.5). c, “Adelograptus” sp. Peña Negra, base of section, PIL 14826 (x 10). d, ?Bryograptus sp. Rio Volcancito, float specimen from lower part of the Peña Negra Member of the Volcancito Formation, PIL 14824 (x 6.5).
Género Anisograptus Ruedemann, 1937

Especie tipo: Anisograptus matanensis Ruedemann, 1937, por designación original.

\section{Anisograptus matanensis Ruedemann, 1937}

Figs. 8a-f, 16a-e

1916 Staurograptus dichotomous Emmons; Bodenbender, 142

* 1937 Anisograptus matanensis n. sp.; Ruedemann, 62, figs. 6-9.

1957 Anisograptus sp. cf. A. flexuosus Bulman; Turner en Harrington \& Leanza, 15, 24 y 26.

- 1957 Anisograptus sp. cf. A. richardsoni Bulman; Turner en Harrington \& Leanza, 15, 24 y 26.

- 1960 Anisograptus cf. richardsoni Bulman; Turner, 48-49, lám. 3 fig. 2.

1960 Anisograptus cf. flexuosus Bulman; Turner, 49-50, lám. 3 fig. 1.

.v p (1975) Anisograptus cf. richardsoni Bulman; Toselli, 154-155, lám. 4 fig. 3 (non lám. 4 fig. 11= Rhabdinopora? sp.).

.v (1975) Clonograptus sp.; Toselli, 155-156, lám. 4 fig. 6.

.v 1984 Clonograptus sp.; Aceñolaza \& Durand, 271, lám 1 fig. 12.

.v 1984 Anisograptus cf. A. flexuosus; Aceñolaza \& Durand, 273, lám 1, fig. 11.

1996 Anisograptus cf. richardsoni Bulman; Tortello et al., 128, lám. 10.2 fig. 6.

1996 Anisograptus cf. flexuosus Bulman; Tortello et al., 128, lám. 10.2 fig. 1.

.v 1997 Anisograptus richardsoni Bulman; Esteban \& Gutiérrez-Marco, 61.

.v 1997 Anisograptus flexuosus Bulman; Esteban \& Gutiérrez-Marco, 61

1998 Anisograptus sp.; Moya et al., 230, fig. 2.3.

1998 Anisograptus richardsoni Bulman; Moya et al., 230, fig. 2.4 .

1998 Anisograptus matanensis Ruedemann; Cooper et al., 28-30, fig. 21b-d, 24, 25k-m. (con sinonimia esencial de la especie).

.v 1999 Anisograptus richardsoni Bulman; Esteban et al., 219.

.v 1999 Anisograptus flexuosus Bulman; Esteban et al., 219.

? 2002 Anisograptus; Rubiolo et al., 359.

- $2003 a$ Anisograptus matanensis Ruedemann; Moya et al., 109.

2003 Anisograptus matanensis; Buatois et al., 400.

2003 b Anisograptus matanensis; Moya et al., 443.

.v 2003 Anisograptus matanensis Ruedemann; GutiérrezMarco \& Esteban, 40, figs. 2, 3c y $3 \mathrm{~h}$.

2003d Anisograptus matanensis Ruedemann; Moya et al., 32, figs. 22 b, d, e-f, h y fig. 26 (ejemplares de la Fm. Saladillo).

Material: Restos de tres rabdosomas adultos y numerosas colonias jóvenes, PIL 11425, 13174, 14511-14513 y 14802-14811, procedentes del intervalo de 4 a 110 m en la sección de Peña 
Negra. Biozonas de Anisograptus matanensis y Rhabdinopora f. anglica del Tremadociense inferior alto.

Descripción: El rabdosoma es horizontal y suele presentarse aplastado dorsoventralmente; su diámetro máximo es de $35 \mathrm{~mm}$ en el material estudiado, donde predominan las colonias jóvenes, de diámetro comprendido entre 12 y $16 \mathrm{~mm}$.

El desarrollo proximal es trirradiado, con tres estipes primarias divergentes entre sí a $120^{\circ}$ (vista apical) en los ejemplares mejor conservados. El número de autotecas presentes en las estipes primarias 2 y 3 varía entre una y dos, dependiendo del ejemplar considerado. La estipe 1 es aún más corta. Por causa de su orientación bioestratinómica, la posición de la sícula suele indicarse como mucho por un abultamiento o muesca en la porción central del rabdosoma, pero en un ejemplar donde ésta se conserva parcialmente aplastada de modo lateral, la sícula mide al menos $1 \mathrm{~mm}$ de longitud y se prolonga en un nema de aproximadamente $1,2 \mathrm{~mm}$.

Dentro de una misma colonia, las estipes se ramifican de un modo dicotómico a intervalos progresivamente más amplios (son más largas conforme avanza su orden de división), pero existe una gran variabilidad intraespecífica entre el número y posición concreta de las dicotomías, por lo cual la longitud de una estipe de un orden determinado suele ser diferente para rabdosomas distintos. Las colonias más grandes registradas en la Formación Volcancito alcanzan al menos cinco órdenes de división dicotómica, pero el último de ellos se genera de un modo irregular, por lo que el número total de estipes terminales (de cuarto o quinto orden) oscila entre 27 y 30 como máximo. En vista dorsal, las estipes son bastante rígidas y de trazado rectilíneo, pero en ejemplares concretos muchas de las estipes generadas a partir del tercer orden de división pueden incurvase convergentemente en la primera mitad de su recorrido, con tendencia a volverse paralelas antes de generar una nueva dicotomía. Ello armoniza la divergencia entre las estipes terminales y equilibra el rabdosoma mediante un distanciamiento proporcional entre las mismas.

Las estipes miden $0,3-0,4 \mathrm{~mm}$ de anchura lateral y $0,6-0,7$ $\mathrm{mm}$ de anchura dorsoventral. Las autotecas suelen presentarse inclinadas entre 20 y 30 grados en estipes comprimidas lateralmente, y su número oscila entre 9,5-12 autotecas en $10 \mathrm{~mm}$.

Observaciones: Los representantes de Anisograptus en la Formación Volcancito exhiben caracteres intermedios entre las "especies" A. richardsoni Bulman (de la que difieren estrictamente por un menor número de ramificaciones y de estipes terminales), A. flexuosus Bulman (aunque con rabdosomas más simétricos y bifurcaciones menos irregulares que en ésta), A. matanensis Ruedemann sensu Bulman (pero con mayor proximidad entre las dicotomías de segundo a cuarto orden en los ejemplares de Famatina) y A. norvegicus Bulman (con estipes terminales menos numerosas que en material argentino). En cierto sentido, el material estudiado podría compararse preferiblemente con las "formas anormales" de A. matanensis descritas por Bulman (1950: fig. 4b y lám. 7 fig.1), que según este autor se caracterizarían por unas estipes de primer orden de longitud comparable, con las restantes bifurcaciones bastante próximas y distribuidas con cierta regularidad. La misma incertidumbre en cuanto a la asignación específica de ejemplares de Anisograptus obtenidos en la Formación Volcancito fue expresada por Turner (1960), Toselli (1975) y autores posteriores, con referencia a A. flexuosus y A. richardsoni.

El trabajo de revisión llevado a cabo por Cooper et al. (1998) ha permitido despejar todas estas incógnitas, al establecer la variabilidad intraespecífica de Anisograptus matanensis (sensu stricto), y resolver que formas tales como A. richardsoni, A. flexuosus, A. matanensis tetragraptoides, A. norvegicus y, posiblemente también A. grandis, A. ruedemanni y Didymograptus primigenius, definidas en distintos trabajos de Bulman (1941, 1950, 1954), no son más que morfotipos variados de A. matanensis Ruedemann, que retendría la prioridad nomenclatural. Además de éstos, Erdtmann \& Comeau (1980) citan a Anisograptus communis Tzaj, "?Clonograptus" heres Westergård y a "?Bryograptus" retroflexus Brögger, como posibles sinónimos de A. richardsoni o de A. flexuosus (= A. matanensis fide Cooper et al., 1998). En el mismo trabajo, Erdtmann \& Comeau (1980) sinonimizan el material de Famatina descrito por Turner (1960) como A. cf. richardsoni enteramente con dicha "especie" (= A. matanensis auct.), si bien su propio material del taxón mencionado, procedente de Nevada central, es atribuido en un trabajo posterior con dudas a A. compactus Cooper \& Stewart (ver Erdtmann \& Bostford, 1986: 771).

El registro en la Formación Volcancito de formas trasientes entre algunas de las "especies" o variedades morfotípicas o bioestratinómicas más difundidas del mismo y único taxón $A$. matanensis, documenta una vez más la variabilidad de dicha especie, de acuerdo con la revisión llevada a cabo por Cooper et al. (1998). En el presente trabajo se sinonimizan también, con A. matanensis, los rabdosomas horizontales de "ramificación regular" que habían sido identificados como Clonograptus sp. por Toselli (1975) y Aceñolaza \& Durand (1983, 1984). El más notorio de estos ejemplares (reproducido aquí en la Fig. 8a) es una forma claramente trirradiada de A. matanensis.

Finalmente, Aceñolaza \& Durand (1984: lám. 1 fig. 8, redibujado de Toselli, 1975: lám. 4 fig. 11) ilustran una porción proximal atribuida a Anisograptus sp. que es enteramente cuadrirradiada, y en consecuencia debe de corresponder a un estado inicial de desarrollo de Rhabdinopora sp., preservado discoidalmente.

Distribución: Anisograptus matanensis es una especie cosmopolita cuyo rango se extiende entre la base de la biozona homónima y el techo de Biozona de Rhabdinopora flabelliformis anglica (Tremadociense inferior), preludiando la aparición de los graptolitos birradiados en el Tremadociense superior. Dentro de la Formación Volcancito, la especie se distribuye en las biozonas ya citadas, si bien su extensión vertical no abarcaría la totalidad del rango indicado (Fig. 3). 
Por otro lado resulta interesante señalar que Anisograptus es un género relativamente raro en Sudamérica, donde por el momento aún no ha sido registrado en la sucesión graptolítica del sur de Bolivia, que pasa por ser la más completa propuesta para el Tremadociense de América meridional (Ortega \& Suárez-Soruco, 1994 y referencias previas; Erdtmann et al., 1995; Maletz \& Egenhoff, 2001, 2003; Egenhoff et al., 2004). En Argentina, Moya et al. (1994) tampoco hicieron referencia a ningún hallazgo de Anisograptus entre las asociaciones de rhabdinoporínidos del Tremadociense inferior de la Cordillera Oriental, pero poco después Moya et al. (1998) señalan A. richardsoni y Anisograptus sp. en niveles del Tremadociense inferior situados entre 10 y 32 $\mathrm{m}$ bajo la Discordancia Tumbaya al noroeste de la ciudad de Jujuy (área de El Moreno). Esta cita y la de Albanesi et al. (2000a) se corresponde con el hallazgo de Anisograptus matanensis en la Formación Saladillo del Angosto del Moreno, acompañado por Rhabdinopora spp. (pp=R.f. acenolazai?), que fuera inicialmente identificado como R.f. parabola (Albanesi \& Ortega, 2002; Toro \& Brussa, 2003). Ortega (in Moya et al., 2003d) aporta magníficas ilustraciones de A. matanensis procedente de dicha localidad.
Otra especie argentina del género Anisograptus (A. andinus $n$. $n$.) ha sido reconocida recientemente en la parte inferior de la Formación Floresta de la Sierra de Mojotoro (Monteros, 1999; Monteros \& Moya, en preparación), en lo que constituye el segundo hallazgo de un Anisograptus de rabdosoma delgado en el ámbito iberoamericano, tras las primeras citas de Anisograptus delicatulus Cooper \& Stewart en la Formación Tiñú (Tremadociense) del área de Oaxaca, México (Sour \& Buitrón, 1987).

\section{Género Bryograptus Lapworth, 1880}

Especie tipo: Bryograptus kjerulfi Lapworth 1880, por designación posterior de Gurley (1896).

\section{Bryograptus? sp.}

Fig. 7d

Material: un rabdosoma juvenil, PIL 14824, recogido suelto en la sección de río Volcancito, hacia la parte baja del Miembro Peña Negra de la Formación Volcancito.

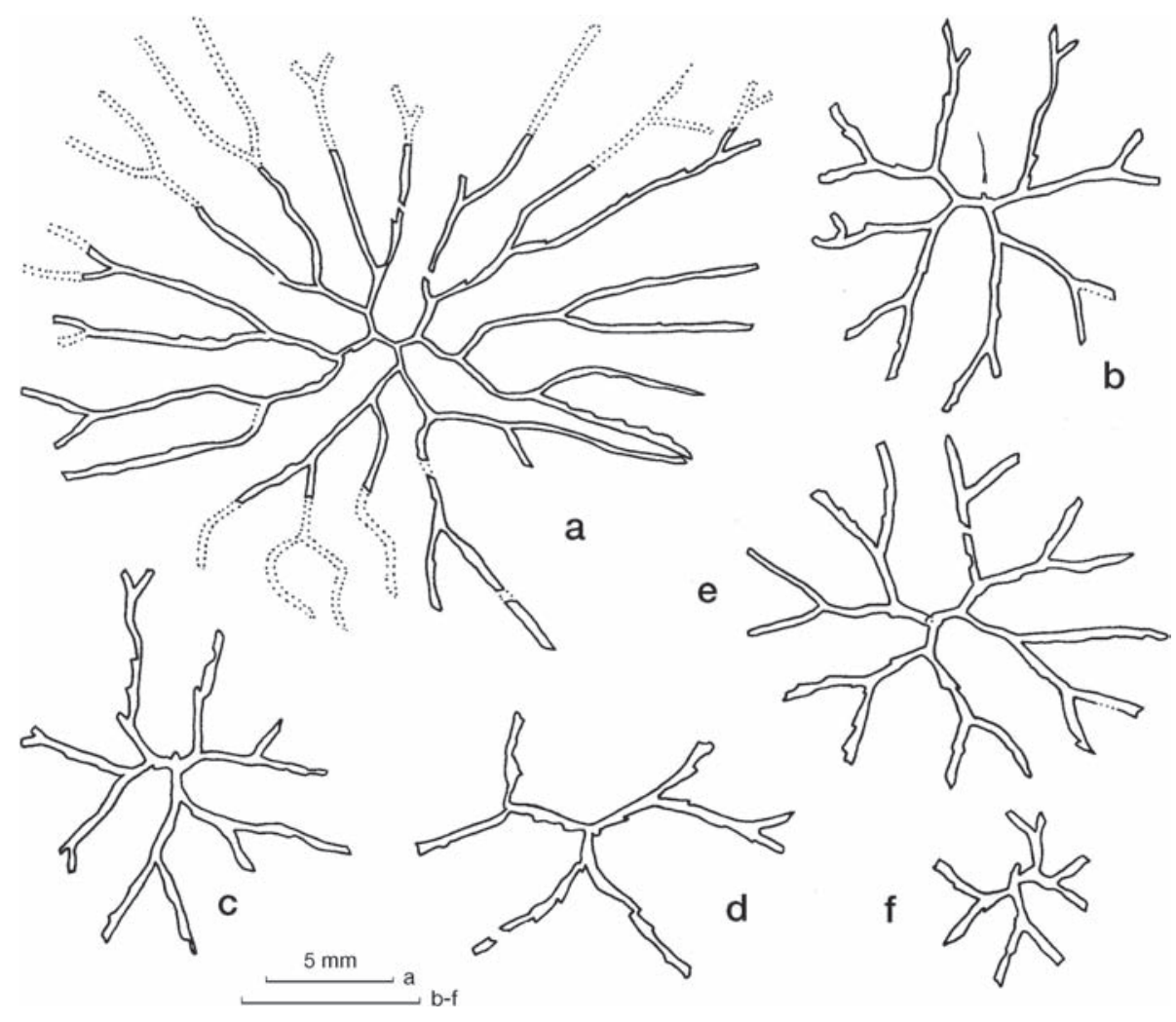

Figura 8. Anisograptus matanensis Ruedemann, 1937. Rabdosomas comprimidos dorsalmente, procedentes de la localidad de Peña Negra (Formación Volcancito). a, colonia geróntica PIL 11425, identificada como "Clonograptus sp." por Toselli (1975: lám. 4 fig. 6), en la cual se han redibujado algunas partes que faltan actualmente, a partir de la fotografía original de aquel autor (en punteado). b, PIL 14513 (= Fig. 16c), horizonte de 25 m. c, PIL 14805, idem. 110 m. d, PIL 14809 (= Fig. 16e), idem. 10 m. e, PIL 14512 (= Fig. 16b), idem. 110 m. f, PIL 14804, idem. 110 m.

Anisograptus matanensis Ruedemann, 1937. Dorsally flattened specimens, all from Peña Negra section, Peña Negra Member of the Volcancito Formation. a, gerontic rhabdosome PIL 11425 from the Toselli collection, identified by him as "Clonograptus sp." and partly redrawn according to the original picture (Toselli, 1975: pl. 4 fig. 6). The broken-off and lost distal parts are indicated by dotted lines. $\boldsymbol{b}$, PIL 14513 (=Fig. 16c), from the horizon of $25 \mathrm{~m}$ above the base. $\mathrm{c}$, PIL 14805, horizon of $110 \mathrm{~m} . \boldsymbol{d}$, PIL 14809 (= Fig. 16e), horizon of $9 \mathrm{~m} . \boldsymbol{e}$, PIL 14512 (= Fig. 16b), horizon of $110 \mathrm{~m} . \mathrm{f}$, PIL 14804 , horizon of $110 \mathrm{~m}$. 
Descripción: Se trata de un único rabdosoma pendiente, de 6 mm de longitud y 4,6 de anchura, formado por tres estipes recurvadas hacia el interior de la colonia. La sícula mide $1,1 \mathrm{~mm}$ de longitud y se prolonga en un nema delgado $(0,5 \mathrm{~mm}$ de longitud por $0,07 \mathrm{~mm}$ de anchura). En el punto de intersección con las estipes, existen recubrimientos corticales que impiden reconocer el tipo de estructura proximal.

Las estipes son gruesas, de 0,85-0,9 mm de anchura dorsoventral, y en ellas se reconocen autotecas con dentículos agudos, en número de 9 en $10 \mathrm{~mm}$.

Discusión: El reconocimiento de Bryograptus en la Formación Volcancito es una cuestión polémica, por sus implicaciones bioestratigráficas en el reconocimiento de materiales del Tremadociense superior en el Miembro medio de la unidad, donde como mucho se han reconocido graptolitos del Tremadociense inferior terminal. De los Bryograptus ilustrados por Aceñolaza \& Durand (1984: lám. 1 figs. 4 y 13), el primero es un ejemplar irreconocible y el segundo nos parece asimilable a Rhabdinopora flabelliformis bryograptoides? Ninguno de ellos ha podido ser reencontrado en la colección del trabajo antes mencionado, depositada en la Universidad de Tucumán.

Entre los varios miles de ejemplares recolectados para el presente trabajo, tan sólo la muestra PIL 14824 podría aproximarse al género Bryograptus, siendo muy diferente de las restantes partes proximales cuadrirradiadas de Rhabdinopora sp. con las que se presenta asociada en la misma muestra. Hasta ahora, la forma de Bryograptus que coexiste con los últimos representantes del género Rhabdinopora es B. kjerulfi Lapworth, que difiere del ejemplar famatinense tan sólo por su mayor número de autotecas (12-15 en $10 \mathrm{~mm}$ frente a 9 en $10 \mathrm{~mm}$ ) y por una sícula más acuminada y prominente $(1,5 \mathrm{~mm}$ de longitud frente a 1,1 mm en el ejemplar estudiado). En este sentido, la colonia juvenil de B. kjerulfi ilustrada por Bulman (1971: fig. 1c) parece ser muy semejante a la muestra del Famatina, debido al trazado recurvado de sus estipes laterales. Pese a todo, disponiendo de un solo ejemplar no resulta posible precisar la identificación taxonómica ni siquiera a nivel genérico, y por ello optamos por determinarlo como Bryograptus? sp.

En el norte argentino, la primera cita incuestionable de Bryograptus corresponde al hallazgo de $B$. aff. kjerulfi en una localidad de la Cordillera Oriental ubicada al sur de la ciudad de Salta (González Barry \& Alonso, 1984). Los niveles con este graptolito se sitúan entre 175 y 200 $\mathrm{m}$ por encima de la primera aparición del trilobites Jujuyaspis keideli, muy próxima a su vez al contacto con el Grupo Mesón. De acuerdo con González Barry \& Alonso (1984), B. aff. kjerulfi se presentaría asociado a raros ejemplares de Staurograptus sp., pero las ilustraciones originales de este último taxón parecen corresponder más bien a colonias juveniles de Rhabdinopora sp., tetrarradiadas y en conservación oblicua a discoidal (González Barry \& Alonso, 1984: figs. 4 y 5). Ello concordaría también con los registros mundiales de los tres géneros implicados, dado que Staurograptus se extingue mucho antes de la aparición de Bryograptus, y la asociación de este último con Rhabdinopora sólo sería posible en horizontes del Tremadociense superior temprano (Cooper et al., 1998; Cooper, 1999). Moya et al. (2003a) amplían la mención de Bryograptus aff. kjerulfi, acompañado por Anisograptus sp., a las localidades de La Quesera, Sierra de Mojotoro, Pascha y Angosto del Moreno. Bryograptus kjerulfi ( $s$. str.) es citado y brevemente descrito e ilustrado por Toro \& Brussa (2003) en las secciones de Parcha, La Pedrera, La Quesera, El Angosto, Sococha y Miraflores. El material de los niveles con Adelograptus y Rhabdinopora del Angosto de La Quesera se adscribe, de acuerdo con Aceñolaza et al. (2003) a Bryograptus kjerulfi, y según Moya et al. (2003e) a Bryograptus? sp.

Otra mención argentina a Bryograptus sp. ocurre en el sector oeste de la Cordillera Oriental (Angosto de Lampazar, $60 \mathrm{~km}$ al noroeste de Salta), donde Ortega et al. (1998), Albanesi et al. (2001) y Ortega \& Albanesi (2002: lám. 2 fig. 21) definen la biozona homónima de este graptolito situándola entre 13 y $51 \mathrm{~m}$ por encima de la base de la Formación Saladillo, y equiparan su rango con la parte alta de la Biozona de Cordylodus angulatus de conodontos (incluyendo también la extensión vertical de Rossodus spp.). En adición a los registros ya conocidos de $B$. aff. kjerulfi en la Formación Floresta de la finca Miraflores, Moya et al. (2003c: fig. 11d) ilustran y sitúan algunos representantes modernos de Bryograptus? nov. sp. en la Formación San Bernardo de la Sierra de Mojotoro.

\section{Género Adelograptus Bulman, 1941}

Especie tipo: Bryograptus? hunnebergensis Moberg, 1892, por designación original.

\section{"Adelograptus" sp.}

Fig. $7 \mathrm{c}$

Material: Un estadio inicial del crecimiento del rabdosoma, PIL 14826, procedente de la base del Miembro Peña Negra de la Formación Volcancito, en la sección de Peña Negra. Biozona de Anisograptus matanensis del Tremadociense inferior.

Discusión: El ejemplar estudiado representa el único rabdosoma de aspecto birradiado encontrado en el conjunto del material examinado, procedente de las dos secciones del Miembro Peña Negra de la Formación Volcancito. El extremo proximal es marcadamente asimétrico y tiene un aspecto muy similar al de los primeros representantes del género Adelograptus, por lo cual nos ha parecido interesante darlo a conocer. Sin embargo, este ejemplar único ha sido registrado en un horizonte bien datado dentro de la Biozona de Anisograptus matanensis, que precede largamente a la aparición del desarrollo birradiado entre los 
graptolitos planctónicos a nivel mundial. El mismo se sitúa en la base del Tremadociense superior (Cooper et al., 1988; Cooper, 1999), y por lo tanto lo más probable es que el ejemplar de Famatina corresponda a una colonia patológica de Anisograptus. Otra posible alternativa es que se trate de un tafón de este mismo género, en el cual la tercera estipe se halle orientada hacia el interior del sedimento u obliterada por la primera estipe, como parece denotar el perfil ventral de la sícula en su intersección con la línea dorsal de la estipe 1.

Hasta el momento el registro más antiguo comprobado de Adelograptus en Argentina, corresponde al hallazgo de A. tenellus (Linnarsson) en el Tremadociense superior basal de la Sierra de Cajas, Cordillera Oriental (Ortega \& Rao, 1995; Ortega et al., 1998), el cual concuerda perfectamente con la aparición de Adelograptus en otras áreas mundiales. En referencia a la "Asociación Graptolítica IV" de una sección diferente de la Cordillera Oriental (El Angosto), Moya et al. (1994: 96, lám. 1 fig. 9) citan un ejemplar de Adelograptus? sp. en una asociación equivalente en su opinión a la de los graptolitos del Miembro Peña Negra de la Formación Volcancito, incluso con formas bentónicas asociadas. Sin embargo, la ilustración publicada no resulta en modo alguno concluyente, y el ejemplar en cuestión podría corresponder también a una forma trirradiada de Anisograptus.

Orden DENDROIDEA Nicholson, 1872

Familia Dendrograptidae Roemer in Frech, 1897

\section{Género Dendrograptus Hall, 1858}

Especie tipo: Graptolithus hallianus Prout, 1851, por designación posterior de Hall (1862).

\section{Dendrograptus sp.}

Figs. 9a-b, 16m

\section{Dendrograptus sp.; Gutiérrez-Marco \& Esteban, 43.}

Material: Dos rabdosomas de la sección de Peña Negra, PIL 11423b (colección original de Toselli, 1975) y PIL 14818 (horizonte de $246 \mathrm{~m}$ ). Tremadociense superior (?).

Descripción: La colonia de mayor tamaño (Fig. 9b) consiste en un rabdosoma dendroideo alargado, de $17 \mathrm{~mm}$ de altura y alrededor de $5 \mathrm{~mm}$ de anchura. Éste se origina a partir de un tallo principal delgado, de 1,7 $\mathrm{mm}$ de longitud, sin disco basal conservado. Del tallo divergen dos estipes cortas $(2 \mathrm{~mm})$ que forman entre sí un ángulo de $32^{\circ}$. Las estipes restantes se ramifican dicotómicamente a intervalos irregulares (1-3,5 mm), con ángulos de $40-60^{\circ}$. Su divergencia inicial decrece rápidamente tras cada bifurcación, de modo que existe una tendencia a volverse subparalelas, un hecho notorio en las ramas más distales. Por lo general, las estipes laterales interrumpen su crecimiento al separarse del eje principal del rabdosoma, generado a expensas de una de las dos primeras estipes. En cualquier sección transversal al mismo se observa que el número de estipes es siempre inferior a seis, pudiendo variar entre 1 y 5 . En sectores con escasa distorsión tafonómica aparente, el número de estipes es 3 en $3 \mathrm{~mm}$. Las estipes tienen una anchura casi uniforme (alrededor de $0,3 \mathrm{~mm}$ ), sin distinguirse en ellas aperturas o procesos tecales. El trazado de las ramas individuales suele ser ligeramente arqueado a débilmente flexuoso, alternando con otras estipes casi rectilíneas.

El segundo rabdosoma estudiado (Fig. 9a) difiere del precedente por su menor tamaño, con ramificaciones más numerosas y un desarrollo más equilibrado a partir de las dos primeras estipes.

Observaciones: El escaso material disponible se adscribe sin duda al género Dendrograptus por el aspecto del rabdosoma y su modo de ramificación, en ausencia de disepimentos y sin evidencia de un carácter compuesto de las estipes.

El hábito general de la colonia recuerda considerablemente al de algunas formas del Tremadociense de China, como D. yangtzensis $\mathrm{Mu} ; D$. hsui $\mathrm{Mu} ; D$. yini $\mathrm{Mu} ; D$. mui Yu, Liu \& Fang o D. delicatus Lin (Mu, 1955; Wang et al., 1977; Chen et al., 1980; Yu et al., 1985; Mu et al.,

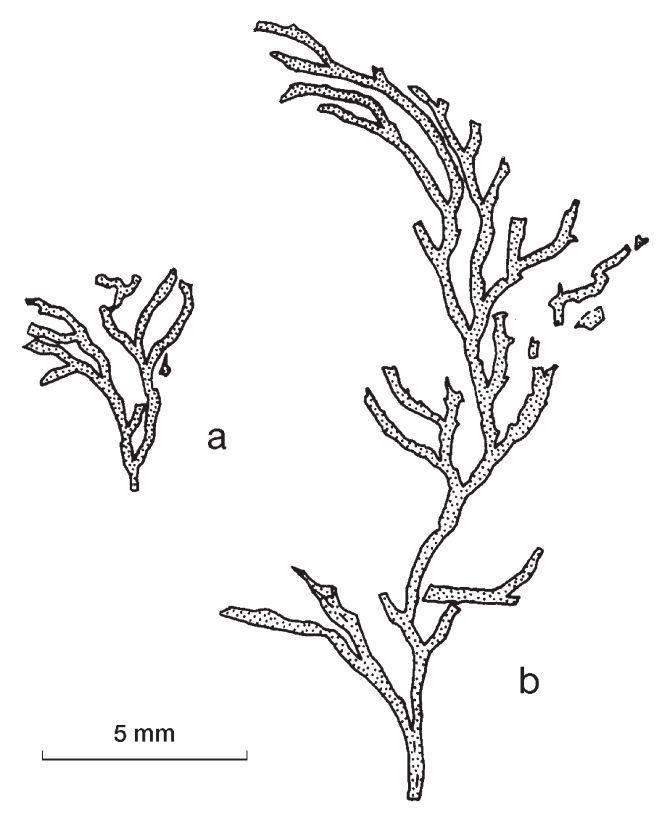

Figura 9. Dendrograptus sp. a, fragmento basal de la colonia PIL 14818 (= Fig. 16m); horizonte de $246 \mathrm{~m}$ en la sección de Peña Negra. b, rabdosoma PIL 11423b (original de Toselli,1975), procedente de un nivel indeterminado de la misma sección.

Dendrograptus sp. a, proximal fragment of rhabdosome, PIL 14818 (= Fig. 16m); from the horizon of $246 m$ above the base in the Peña Negra section. $\boldsymbol{b}$, rabdosome PIL 11423b (original from Toselli,1975), coming from an unknown horizon in the same section. 
1979, 2002), así como a diversas especies del Silúrico de Europa y Norteamérica. Sin embargo, el reducido número del material estudiado y su estado de conservación, impide establecer comparaciones taxonómicas precisas hasta no disponer de nuevos ejemplares significativos, que incluyan por lo menos alguna forma geróntica con el rabdosoma plenamente desarrollado.

\section{Género Dictyonema Hall, 1851}

Especie tipo: Gorgonia retiformis Hall, 1843, por designación posterior de Miller (1889).

\section{Dictyonema sp. nov. 1}

Figs. 10a-b, 16i-k

? 1960 Aspidograptus cf. implicatus (Hopkinson); Turner, 31-32, lám. 1 fig. 4.

- 1975 Aspidograptus cf. implicatus Hopkinson; Toselli, 151152, lám. 4 fig. 4.

? 1984 Dictyonema cf. D. scitulum Harris \& Keble; Aceñolaza \& Durand, 272, lám. 1 fig. 9.

? 1996 Aspidograptus cf. implicatus (Hopkinson); Tortello et al., 128.

- 1997 Callograptus? sp.; Esteban \& Gutiérrez-Marco, 60.

v 2003 Dictyonema sp.1; Gutiérrez-Marco \& Esteban, 43.

Material: Restos de cuatro rabdosomas, PIL 14816, 14817 , 14821 y 11423a. Los dos primeros son fragmentos proximales que proceden del horizonte de $27 \mathrm{~m}$ del Miembro Peña Negra de la Formación Volcancito en la sección de Peña Negra; el tercero del nivel de $247 \mathrm{~m}$ del mismo perfil; y el cuarto es un original de Toselli (1975, lám. 4, fig. 4), recogido en un nivel desconocido de la sección de río Volcancito. Tremadociense inferior a superior (?).

Descripción: Rabdosoma erguido, con una parte estrecha basal y abierto distalmente en forma de abanico, algo arqueado en sección transversal. Las dimensiones máximas observadas son $18 \mathrm{~mm}$ de altura en una colonia estrecha, y 18,7 mm de anchura en el rabdosoma mejor conservado, que es ligeramente más ancho que alto (relación $\mathrm{L} / \mathrm{A}=0,9$ ).

Las estipes presentan una ramificación irregular, sin una zonalidad reconocible. Las dicotomías están separadas por intervalos de 2-4 mm en la parte proximal, cada 1-3 $\mathrm{mm}$ en el sector de expansión de la colonia, y finalmente 2,5-7 mm entre las dicotomías del tercio distal del rabdosoma. Las estipes son delgadas $(0,3 \mathrm{~mm}$ de anchura lateral), ligeramente sinuosas a escala de detalle, y su número varía entre $15-16$ en $10 \mathrm{~mm}$. El trazado general de cada estipe es arqueado y subparalelo al de sus estipes adyacentes en la mitad inferior del rabdosoma, donde los disepimentos son muy esporádicos y adquiere un aspecto general de Callograptus. Sin embargo, en porciones más maduras de la colonia el número de disepimentos aumenta ostensiblemente (2-4 en $5 \mathrm{~mm}$ ), aunque por su extrema delgadez estas estructuras no suelen ser muy notorias. Su presencia se marca más bien por la aproximación que fijan entre estipes adyacentes, las cuales parecen seguir engrosándose durante la astogenia sin que los disepimentos crezcan en longitud y aumenten la separación. En estas condiciones, se suelen formar fenéstrulas ojivales alargadas entre disepimentos sucesivos o entre un punto de dicotomía y el primer disepimento que relaciona las dos estipes de ella surgidas. La convergencia y divergencia sucesiva de las estipes, causada por la inserción de los disepimentos, no está asociada a procesos de anastomosis con auténtica coalescencia tecal; a lo sumo pueden apreciarse recrecimientos corticales que podrían llegar a evocar aquél aspecto por simple deformación tafonómica.

Observaciones: Los ejemplares designados como Dictyonema sp. nov. 1 tienen una morfología común con muchas especies silúricas y devónicas del género Dictyonema, que en cierto modo debe de estar relacionada con los aspectos ecofenotípicos que condicionan el rabdosoma flabelado. La mayoría de las colonias comparables del Ordovícico Inferior, con una forma de abanico erguido de reducidas dimensiones, o bien carecen de una neta distinción específica [caso de Dictyonema dumosus de Berry (1960: lám. 7 fig. 10)], o bien han sido simplemente ilustradas en nomenclatura abierta [caso de Dictyonema sp. de Ross \& Berry (1963: lám. 1 fig. 3)], por reseñar tan sólo dos de estos ejemplos.

De cualquier modo, el problema del material del Famatina es la escasez de ejemplares suficientemente significativos y determinativos, por lo que de momento optamos por describir el taxón en nomenclatura abierta. De las colonias de graptolitos bentónicos ilustradas por Toselli

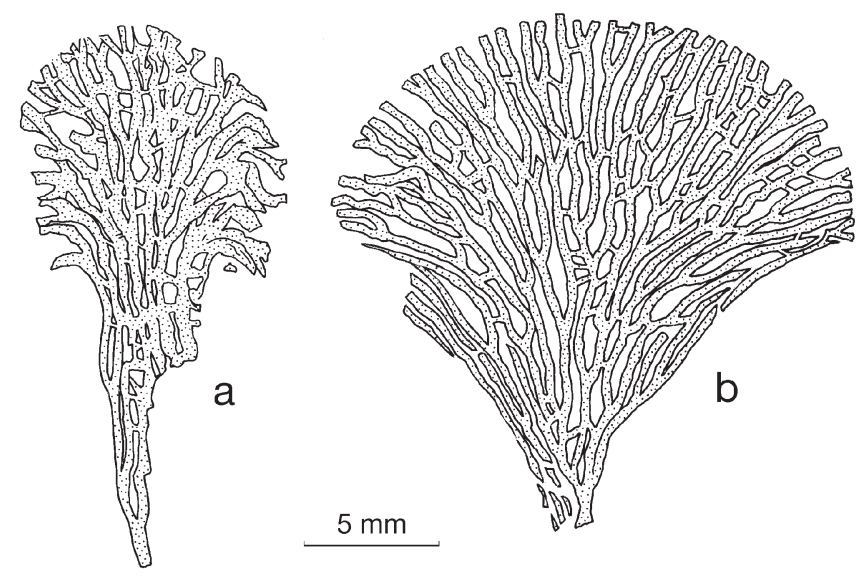

Figura 10.Dictyonema sp. nov. 1. Rabdosomas procedentes del Miembro Peña Negra de la Formación Volcancito en la sección de Peña Negra. a, Ejemplar inédito de la colección Toselli, PIL 11423a. b, rabdosoma adulto carente de la región proximal, PIL 14821 (contraparte en Fig. 16j), recogido $247 \mathrm{~m}$ por encima de la base del miembro.

Dictyonema sp. nov. 1. Two rabdosomes from the Peña Negra Member of the Volcancito Formation, Peña Negra section. a, Unfigured specimen from the Toselli collection, PIL 11423a. b, Adult rhabdosome PIL 14821, counterpart of specimen illustrated in Fig. 16j, from the horizon of $247 \mathrm{~m}$ above the base of the member. 
(1975), su Aspidograptus cf. implicatus es claramente comparable al material que acabamos de describir, e implica la presencia de Dictyonema sp. nov. 1 en la sección del río Volcancito. Otro ejemplar ilustrado por el mismo autor como Callograptus sp. (Toselli, 1975: lám. 4 fig. 10) presenta estipes onduladas y un aspecto bastante semejante al de las partes proximales estudiadas aquí (Fig. 16k). Sin embargo, en su ilustración original no se advierten disepimentos, y el ejemplar en sí no hemos podido revisarlo. Más dudosa aún es la afiliación de Aspidograptus cf. implicatus descrito por Turner (1960: lám. 1 fig. 4) el cual, pese a tener un rabdosoma en abanico bastante similar en aspecto al de Dictyonema sp. nov. 1, tiene unas estipes rotundamente más gruesas $(0,5 \mathrm{~mm})$ conforme se indica en su descripción.

\section{Dictyonema? sp. cf. D. cordillerensis Braithwaite, 1976}

Fig. 11

\author{
?cf.1976 Dictyonema cordillerensis n. sp.; Braithwaite, 10-11, \\ lám. 2 figs. 1-4. \\ v 2003 ?Dictyonema sp. cf. D. cordillerensis; Gutiérrez-Mar- \\ co \& Esteban, 43.
}

Material: Un fragmento de rabdosoma (PIL 15150), procedente del horizonte de $137 \mathrm{~m}$ de la Formación Bordo Atravesado en la sección del Portezuelo de La Alumbrera, ubicada $2 \mathrm{Km}$ al noreste del paraje de Bordo Atravesado (Fig. 1.2J), en la vertiente meridional del Nevado de Famatina (La Rioja). Tremadociense superior, biozona indeterminada, probablemente Biocronozona de Kiaerograptus o posterior.

Observaciones: Ilustramos aquí un raro resto de graptolito tremadociense encontrado en la unidad suprayacente a la Formación Volcancito, donde hasta la fecha sólo se habían citado formas planctónicas (Paradelograptus y Kiaerograptus), por encima del rango indicado por la Sub-biozona de Paltodus deltifer pristinus de conodontos (Albanesi et al., 2000b, 2001, 2005). El ejemplar presenta una marcada ondulación de las estipes, con una disposición regular en zig-zag, incluso inmediatamente después de los puntos de ramificación. Aunque la convexidad de las ondulaciones hacen que dos estipes contiguas puedan entrar en contacto reiteradas veces, no existen evidencias de que en estas uniones temporales se desarrollen procesos de anastomosis. Como mucho, se aprecia algún disepimento esporádico delgado a grueso por recrecimiento cortical, relacionando estipes contiguas en sus puntos de convexidad coincidente (Fig. 11).

La presencia de estipes en zig-zag y de disepimentos delgados, constituyen los elementos diagnósticos de Dictyonema cordillerensis, el cual fue descrito en la Zona de Adelograptus de Utah, EE.UU. Esta especie se distribuye en la parte baja de la Biozona de Protopliomerella compacta de trilobites (G-2) en el área tipo del Ibexiense, correspondiéndole una edad Tuleaniense superior, la cual suele correlacionarse con el Moriduniense británico (Arenigiense inferior). Sin embargo, el pequeño fragmento del Famatina resulta insuficiente para asegurar la identificación plena con la citada especie, y ni siquiera posibilita su asignación genérica, dada la conservación esporádica de los disepimentos. Las ondulaciones de las estipes, tanto en la forma estadounidense como en el ejemplar estudiado por nosotros, resultan ser más pronunciadas aún que en Dictyonema yichangense Wang (= D. eudodum $\mathrm{Ni}$ ), única especie comparable con el material tipo de la forma norteamericana, y que aparece restringida

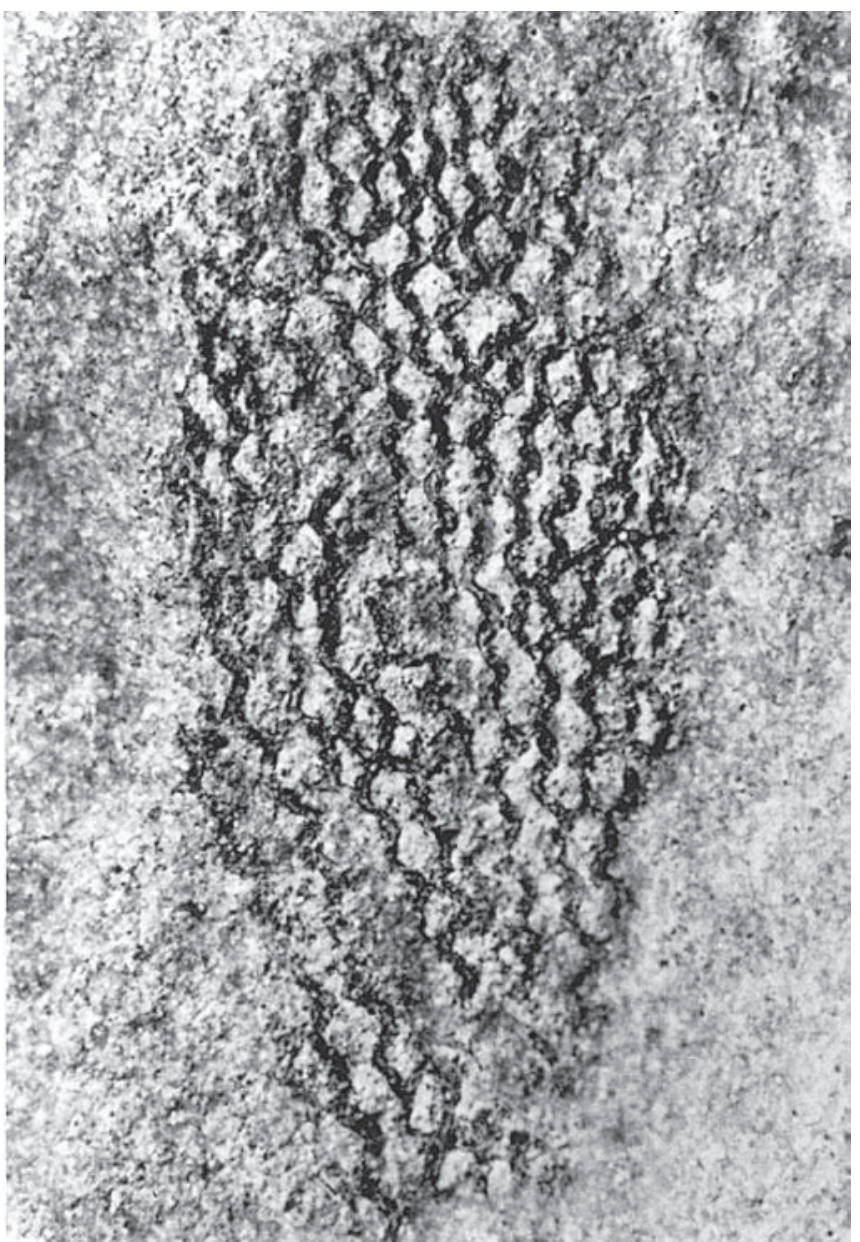

Figura 11.Dictyonema? cf. D. cordillerensis Braithwaite, 1976. Fragmento de rabdosoma procedente de la Formación Bordo Atravesado en la sección del Portezuelo de La Alumbrera. Tremadociense superior, posición desconocida dentro del rango de las biozonas de Araneograptus murrayi y Hunnegraptus copiosus. PIL 15150 (x 7).

Dictyonema $c f$. D. cordillerensis Braithwaite, 1976. Fragment of rhabdosome from the Bordo Atravesado Formation, recorded at the Portezuelo de la Alumbrera section. Upper Tremadocian, uncertain position within the range of the Araneograptus murrayi and Hunnegraptus copiosus biozones. PIL 15150 (x 7). 
a la Biozona de Rhabdinopora flabelliformis de China (ver referencias en Mu et al., 2002: 96, lám. 27 fig. 2).

La presencia de estipes paralelas y de trazado sinuoso no es exclusiva de Dictyonema cordillerensis o de D. yichangensis (nomen correctum), sino que también se conoce, en forma más atenuada, en algunas colonias de Rhabdinopora (por ejemplo Erdtmann, 1982b: lám. 2 fig. 6a; Yin et al., 1984: lám. 1 fig. 13). Sin embargo, en dicho género lo normal es que el aspecto ondulado de las estipes, en conservación dorsal, venga condicionado por la inserción alterna de disepimentos con espesamientos corticales en la base. Entre los dendroideos bentónicos, presentan también estipes onduladas por ejemplo Dictyonema sp. (Ross \& Berry, 1963: lám. 1 fig. 2), D. bulmani Ruedemann, D. fillmorensis Braithwaite, D. flexiliramosum $\mathrm{Mu}$, D. intermedium Prantl \& Přibyl, D. poctai Prantl \& Přibyl, D. simile Ruedemann, D.? scopulatum (Lin) (=? R. flabelliformis liaotungensis $\mathrm{Mu}$ fide $\mathrm{Mu}$ et al., 2002), Callograptus undosus Kraft, etc. No obstante, en ninguno de estos taxones las estipes alcanzan el trazado tan regular en zig-zag observado tanto en $D$. cordillerensis, como en D. yichangensis y en el ejemplar del Famatina; si bien, en cualquier caso, necesitaríamos disponer de un material más abundante para establecer la identidad taxonómica.

Distribución: El ejemplar estudiado procede de un nivel fosilífero de limolitas arcillosas grises, ubicado estratigráficamente a unos $137 \mathrm{~m}$ por encima de la base de la Formación Bordo Atravesado, y a unos $30 \mathrm{~m}$ sobre el horizonte fosilífero que contiene notables restos de filocáridos y graptolitos, además de una asociación muy variada de trilobites pelágicos y bentónicos. Entre los trilobites se identificaron Degamella famatinensis, Prospectatrix sp., Sagavia durandi, Illaenopsis sp. nov., cf. Homalopteon, Hapalopleura longirachis, $H$. aff. longicornis, Proteuloma sp. nov., Shumardia sp., Bienvillia sp., Leptobenthos roartei y Corrugatagnostus sp. (Esteban, 1992, 1996b, 1999b; Tortello \& Esteban, 1995, 2003b). Los graptolitos se citan provisionalmente como Kiaerograptus spp. y Paradelograptus spp. (Albanesi et al., 2005).

El descubrimiento de conodontos de la parte inferior de la Biozona de Paltodus deltifer, $25 \mathrm{~m}$ por encima de la base de la Formación Bordo Atravesado, y de la asociación formada por los trilobites y graptolitos de la Biocronozona de Kiaerograptus (horizonte de $105 \mathrm{~m}$ ), hace posible que el graptolito bentónico aquí estudiado, obtenido en un nivel más moderno (horizonte de $137 \mathrm{~m}$ ), pueda tener una edad posterior incluso a la Biocronozona de Kiaerograptus. En este sentido, optamos por adjudicarle, tentativamente, una edad grosso modo equivalente a la de las biozonas de Araneograptus murrayi o de Hunnegraptus copiosus del Tremadociense superior tardío, teniendo en cuenta también el desarrollo notable que alcanzan ambas biozonas en numerosas secciones sudamericanas (Maletz et al., 1999, con referencias previas; Albanesi et al., 2001; Ortega \& Albanesi, 2002; Benedetto et al., 2002; Albanesi \& Ortega, 2002).

Independientemente de la incertidumbre taxonómica, el ejemplar del Famatina contribuye a llenar el hueco en el registro de dendroideos bentónicos, con estipes en zig-zag, existente entre el Tremadociense inferior (Dictyonema yichangensis) y el Arenigiense basal (D. cordillerensis).

Género Aspidograptus Bulman, 1934 emend. Rickards et al., 1990

Especie tipo: Clematograptus implicatus Hopkinson in Hopkinson \& Lapworth 1875, por designación original.

\section{Aspidograptus cuerdai sp. nov.}

Figs. 12a-c, 161

? 1960 Aspidograptus? cf. minor Bulman; Turner, 32-33, lám. 3 fig. 3.

v 1975 Callograptus sp.; Toselli, 153-154, lám. 4 figs. 7 y 10? (=? Dictyonema sp. nov. 1).

v 1984 Callograptus sp.; Aceñolaza \& Durand, 273, lám. 1 fig. 5 ? y 7.

v 1996 Aspidograptus? cf. minor Bulman; Tortello et al., 128, lám. 2,fig. 5.

v 1996 Callograptus cf. salteri Hall; Tortello et al., 128, lám. 2, fig. 8.

v 1997 Aspidograptus sp.; Esteban \& Gutiérrez-Marco, 60.

v 2003 Aspidograptus sp.; Gutiérrez-Marco \& Esteban, 43.

Holotipo: Rabdosoma adulto PIL 14815, depositado en la colección de paleoinvertebrados Lillo, Universidad Nacional de Tucumán (Argentina), e ilustrado aquí en la Figs. 12c y 16l).

Localidad tipo: Peña Negra, en la margen derecha del río Achavil, $72 \mathrm{~km}$ al oeste de la población de Famatina (La Rioja, Argentina).

Estrato tipo: Miembro Peña Negra de la Formación Volcancito, horizonte situado a $26 \mathrm{~m}$ por encima de la base del perfil de Peña Negra. Tremadociense inferior, Biozona de Anisograptus matanensis.

Derivación del nombre: La especie está dedicada al Prof. Dr. Alfredo J. Cuerda (Museo de La Plata) en homenaje a su importante contribución al estudio de los graptolitos argentinos, dendroideos bentónicos inclusive.

Paratipos: PIL 11426a-11426b (localidad Peña Negra, original de Toselli (1975: lám. 4 figs. 7 y 10); PIL 14818 (Peña Negra, nivel de 247 m); 14819-14820 (río Volcancito).

Diagnosis: Frondes formados a partir de 4-5 zonas de ramificación; estipes estrechas (0,25-0,30 mm de anchura) y espaciadas regularmente (12-15 en $10 \mathrm{~mm})$, sin aparente anastomosis. Disepimentos muy finos y distribuidos irregularmente.

Large fronds formed by 4-5 branching zones, with narrow and regularlly spaced stipes, 0,25-0,30 $\mathrm{mm}$ wide, numbering 12-15 in $10 \mathrm{~mm}$. Dissepiments very thin and irregularlly arranged; anastomosis not seen.

Descripción: El rabdosoma está formado por al menos tres frondes infundibuliformes que convergen en la parte basal de la colonia, donde se observa un corto tallo $(1,5 \mathrm{~mm}$ de longitud por $0,5 \mathrm{~mm}$ de anchura) del cual surge un número equivalente 
de estipes primarias. Cada estipe principal se halla fuertemente recurvada en vista lateral, y de su cara convexa surgen estipes "laterales" que se bifurcan repetidamente a distancias de 1-1,35 mm, 3-4 mm, 8,5-10 mm, 12-15 mm y 20-25 mm medidas desde la estipe principal, dando lugar a cuatro o cinco zonas de ramificación en los rabdosomas adultos.

Debido a su particular constitución y a la preservación frecuente de los frondes en compresión oblicuo-lateral, las dimensiones generales del rabdosoma no pueden ser establecidas con exactitud. El tamaño máximo de los frondes más completos (en vista lateral plena) es de $36 \mathrm{~mm}$ de altura por $30 \mathrm{~mm}$ de anchura (esta última magnitud medida transversalmente al eje de la colonia). Los rabdosomas aplastados lateralmente en el plano de estratificación alcanzan 50-60 mm de anchura, dependiendo de que involucren restos de dos o más frondes.

Las estipes se observan casi siempre en vista dorsal $u$ oblicuo-dorsal; su anchura lateral es de alrededor de 0,25-0,3 mm y están separadas por interespacios dos veces más anchos $(0,5-$ $0,7 \mathrm{~mm}$ ). La anchura dorsoventral de las estipes, medida en un solo caso a una distancia de $25 \mathrm{~mm}$ del extremo proximal del rabdosoma, es de $0,5 \mathrm{~mm}$ a nivel de los dentículos de 3 autotecas conservadas en una longitud de $1,5 \mathrm{~mm}$. Las autotecas no presentan evidencias de aislamiento apertural y su número en 10 mm, deducido del ejemplo anterior, oscilaría entre 19 y 20.

Las estipes en vista dorsal aparentan ser levemente sinuosas a escala de detalle, pero a nivel general su trazado es bastante rectilíneo, manteniendo un gran paralelismo entre sí después de cada bifurcación y entre estipes adyacentes surgidas de bifur-

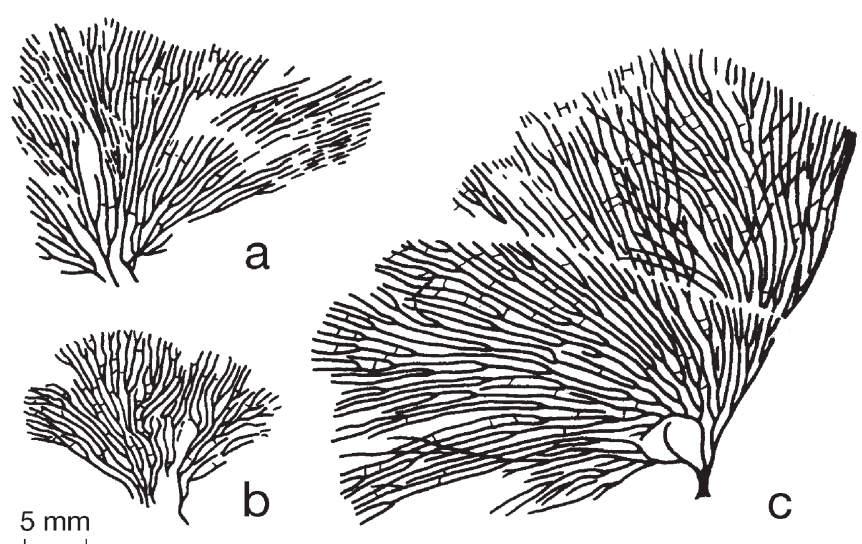

Figura 12.Aspidograptus cuerdai sp. nov. a, rabdosoma original de Aceñolaza \& Durand (1983, 1984: lám. 1 fig. 7, identificado como Callograptus sp.), PIL 13136, en el cual se perciben tres de sus cuatro "frondes". b, ejemplar ilustrado por Toselli (1975: lám. 4 fig. 7), citado originalmente como Callograptus sp., PIL 11426a. c, rabdosoma adulto, Holotipo PIL 14815 (= Fig. 16 1), procedente del horizonte de $27 \mathrm{~m}$ por encima de la base en la sección de Peña Negra. Aspidograptus cuerdai $s p$. nov. $\boldsymbol{a}$, original specimen of Callograptus sp. from Aceñolaza \& Durand (1983, 1984: pl. 1 fig. 7), PIL 13136, showing three of its four fronds. $\boldsymbol{b}$, rhabdosome originally identified as "Callograptus sp.” by Toselli (1975: pl. 4 fig. 7), PIL 11426a. c, holotype, adult rhabdosome PIL 14815 (= Fig. 16 l), Peña Negra section, horizon of $27 m$ above the base. caciones distintas. El número de estipes varía entre 12 y 15 en $10 \mathrm{~mm}$, medidas en las porciones maduras de aquellos frondes mejor conservados en vista lateral. Las estipes pueden presentarse unidas por disepimentos a intervalos irregulares, pero casi siempre inferiores a los 2 disepimentos en $10 \mathrm{~mm}$. No obstante, en sectores distales de algunos frondes se aprecian concentraciones irregulares de disepimentos que pueden variar entre 3 y 5 en $10 \mathrm{~mm}$. Los disepimentos son siempre muy finos $(0,10-0,15$ $\mathrm{mm}$ ) y carecen de espesamientos corticales localizados, pero con una inserción perpendicular a ligeramente oblicua.

Relaciones y diferencias: Aspidograptus cuerdai sp. nov. tiene un rabdosoma de dimensiones y aspecto comparables a la especie tipo del género, A. implicatus (Hopkinson), de la que se diferencia por sus estipes principales menos recurvadas, estipes claramente más estrechas $(0,25-0,3 \mathrm{~mm}$ de anchura lateral, frente a 0,5-0,6 mm en A. implicatus), y dicotomías emplazadas de una forma más regular y espaciada que en la especie del Arenigiense británico (Bulman, 1934). Aspidograptus? minor Bulman tiene unas estipes de anchura comparable a las de A. cuerdai pero carece de disepimentos: ambos caracteres llevaron a Turner (1960) a identificar con dudas a esta segunda forma del Arenigiense británico y Tremadociense superior de China en la Formación Volcancito, si bien a través de tres rabdosomas juveniles de difícil adscripción. Lo más probable es que estos últimos pertenezcan también a $A$. cuerdai, que se diferencia de A.? minor por el mayor tamaño del rabdosoma, la presencia de al menos tres estipes principales, la ramificación más regular y espaciada, estipes de trazado más uniforme y subparalelo unidas por disepimentos esporádicos, y un distinto contenido tecal (19-20 en 10 $\mathrm{mm}$ en $A$. cuerdai, frente a 24 autotecas en $10 \mathrm{~mm}$ en $A$.? minor). Adicionalmente, uno de los dos sintipos de A.? minor (Bulman, 1934: lám. 10 fig. 5) pertenece tal vez al género Dendrograptus, donde modernamente ha quedado acreditada la presencia de ramificación lateral a partir de las estipes basales de algunas formas primitivas (Chapman et al., 1996: fig. 4a).

Entre los representantes de Aspidograptus conocidos en depósitos temporal y ecológicamente correlacionables con los de la Formación Volcancito en el resto del mundo, cabe citar en primer lugar a A. uniflexilis Yu, Liu \& Fang, y a "Dictyonema” xiushuicum Yu, Liu \& Fang, representados ambos en la parte inferior de la Biozona de Aorograptus asiaticus del sur de China (= Cronozona de Rhabdinopora flabelliformis anglica), junto a un amplio cortejo de dendroideos bentónicos de otros géneros (Yu et al., 1985; Feng \& Erdtmann, 1999). Los ejemplares de Aspidograptus? sp. citados junto a $R$. flabelliformis en afloramientos del este de Nueva York (Landing, 1993: figs. 5.4-5.5) están demasiado mal conservados como para permitir su comparación con A. cuerdai, e incluso podrían corresponder a fragmentos de Dictyonema (Landing, 1993: 10). Por otra parte, el ejemplar único de Aspidograptus cf. implicatus descrito por Mu et al. (1979: 21, lám. 2 figs. 
3a-b) en el Tremadociense inferior del suroeste de China, difiere del material argentino por la mayor anchura de las estipes y la práctica ausencia de disepimentos, que dota a la malla de un aspecto mucho más irregular (véase también la redescripción de Mu et al., 2002). Finalmente, A. lotolatzensis $(\mathrm{Mu})$ [= A. firmus Lin], posee un rabdosoma diminuto con una ramificación mucho más abierta que la de A. cuerdai sp. nov., y también un contenido tecal sensiblemente inferior (4-4,5 autotecas en $5 \mathrm{~mm}$, de acuerdo con la redescripción de Mu et al. (2002: lám. 15 fig. 7) y Zhang \& Erdtmann (2004a). Los mismos caracteres diferencian también el material argentino con respecto a Aspidograptus sp. (Mu, 1955: lám. 3 fig. 8), otra forma del Ordovícico Inferior de China que permanece en nomenclatura abierta.

La especie Aspidograptus rarus Sobolevskaya, del Ordovícico Superior de Rusia, tiene estipes más anchas $(0,5 \mathrm{~mm})$ y menos numerosas $(6-7$ en $10 \mathrm{~mm})$, con escaso paralelismo, pero con una zonación radial de dicotomías claramente definida (Sobolevskaya, 1971: lám. 1 fig. 1).

Entre las formas del Cámbrico superior, Aspidograptus cuerdai sp. nov. recuerda bastante a A.? parallelus Ruedemann, en especial por la anchura lateral de las estipes $(0,4$ $\mathrm{mm}$ ) y un número elevado de autotecas (20 en $10 \mathrm{~mm}$ ). Sin embargo, la especie norteamericana presenta una malla más densa (las estipes están separadas por interespacios de anchura equivalente), y las ramas laterales (aquéllas que surgen de cada estipe principal) no se ramifican tan repetidamente como en la forma argentina. Aspidograptus smithsonensis Rickards, Baillie \& Jago, del Cámbrico superior de Australia, es una especie notoriamente distinta por sus frecuentes procesos de anastomosis (a veces incompleta) entre estipes adyacentes (Rickards et al., 1990: figs. 6A y 7A).

Por último, Aspidograptus obuti Bouček, la especie más moderna del género, es una forma radicalmente distinta de A. cuerdai sp. nov. Entre las diferencias observadas citamos las dimensiones reducidas de su rabdosoma, la distinta zonalidad de las ramificaciones y las estipes de mayor anchura, en parte anastomosadas, que caracterizan en su conjunto a la especie del Silúrico superior de Bohemia (República Checa: Bouček, 1957).

Observaciones: La presencia de estipes principales recurvadas, de cuya cara convexa surgen lateralmente el resto de las ramas, permite diferenciar el material estudiado del género Callograptus, el cual posee una malla de constitución idéntica e indiferenciable de la de Aspidograptus en ausencia de fragmentos proximales. Ello explica la frecuente confusión de ambos géneros entre el material previo de la Formación Volcancito (Toselli, 1975; Aceñolaza \& Durand, 1983, 1984), que sólo ahora podemos aclarar gracias a los nuevos hallazgos aquí descritos. Sorprende, en cambio, que los estudios aportados por autores precedentes ignorasen reiteradamente la presencia de disepi- mentos, tal vez por su escasa notoriedad frente al ancho de las estipes, o por la manifiesta irregularidad en cuanto a la ubicación de tales estructuras. La identificación de Aspidograptus sp. hecha por Toselli (1975: lám. 4 figs. 5, 8 y 9) no corresponde a ningún graptolito bentónico, ya que bajo esta denominación se ilustran tres rabdosomas juveniles de Rhabdinopora sp.

\section{Género Pseudocallograptus Skevington, 1963}

Especie tipo: Callograptus salteri Hall, 1865, por designación original.

\section{Pseudocallograptus? sp.}

1960 Callograptus cf. salteri Hall; Turner, 33-34, lám. 2 fig. 8.

non 1975 Callograptus sp.; Toselli, 153-154, lám. 4 figs. 7 y 10 ? (= Aspidogratus cuerdai sp. nov.).

v.non 1984 Callograptus sp.; Aceñolaza \& Durand, 273, lám. 1 figs. 5 ? y 7 (= Aspidograptus cuerdai sp. nov.).

v.non 1996 Callograptus cf. salteri Hall; Tortello et al., 128, lám. 2 fig. 8 (= Aspidograptus cuerdai sp. nov.).

v.non 1997 Callograptus? sp.; Esteban \& Gutiérrez-Marco, 60 (= Dictyonema sp. nov. 1).

v $2003 \quad$ ?Pseudocallograptus sp.; Gutiérrez-Marco \& Esteban, 43.

Discusión: La confirmación de la presencia de Callograptus o Pseudocallograptus en la Formación Volcancito, una vez descartados la mayor parte de los ejemplares referidos por autores previos tanto al primer género, como a la especie tipo del segundo, queda por el momento supeditada a la revisión del único rabdosoma de Callograptus cf. salteri identificado por Turner (1960: lám. 2 fig. 8). Se trata de una colonia cónica de tamaño medio $(50 \mathrm{~mm}$ de longitud por $35 \mathrm{~mm}$ de anchura), cuya fotografía recuerda mucho a un rabdosoma de Rhabdinopora típicamente mal conservado, al estilo de muchos horizontes graptolíticos de la sección del río Volcancito. La ausencia de disepimentos puede estar relacionada también con un problema de conservación en este ejemplar único. Sin embargo, Turner (1960) describió lo que aparentaría ser un "tallo algo grueso" en la región proximal, semejante al de muchos dendroideos bentónicos, por lo que no puede descartarse la interpretación de dicho material como Callograptus o como Pseudocallograptus, habida cuenta de los restantes elementos morfológicos. La vinculación con Pseudocallograptus salteri va mucho más allá y no puede ser mantenida en función de las evidencias disponibles, cuando se carece especialmente de los detalles de la estructura compuesta de las estipes, típica de esta especie definida en el Arenigiense (Skevington, 1963; Fortey \& Owens, 1978) y que surge probablemente en elTremadociense superior 
(Zhang \& Erdtmann, 2004). La identificación restante de $C$. cf. salteri en la Formación Volcancito es la de Tortello et al. (1996) [= Callograptus sp. pro parte en Aceñolaza \& Durand, 1984] y corresponde a un ejemplar revisado aquí como Aspidograptus cuerdai sp. nov.

Otras menciones de Callograptus cf. salteri en Argentina son, en primer lugar, la de Cuerda et al. (1983: 246247, lám. 1 figs. 4-5), con referencia al hallazgo de cuatro fragmentos de rabdosoma en el Tremadociense inferior de la Precordillera de San Juan. Moya et al. (1994, 2003a, 2003b) y Malanca (2002) citan igualmente Callograptus (Pseudocallograptus) salteri en su "Asociación Graptolítica IV" (techo del Tremadociense inferior) de la Cordillera Oriental, concretamente en la Formación Saladillo en su sección del Angosto del Moreno. En el Angosto de La Quesera, Moya et al. (2003e) identifican Callograptus (Pseudocallograptus) sp. en los niveles con Adelograptus y Rhabdinopora. Finalmente, Malanca et al. (1998) citan en la Formación Las Vicuñas (Tremadociense de la Puna) el hallazgo de restos de dendrográptidos de estipes lineales y sin disepimentos, que deben de tener un aspecto muy similar al de las formas en cuestión.

La presencia de Pseudocallograptus salteri en el Tremadociense ha sido mencionada también en China (Wang et al., 1977; Yu et al., 1985; Feng \& Erdtmann, 1999; Mu et al., 2002; Zhang \& Erdtmann, 2004a) pero, tal y como sucede con los registros argentinos, no podrá considerarse plenamente probada hasta no conocer en detalle la estructura de las estipes. Según Chapman et al. (1996: fig. 2), los únicos géneros del Cámbrico Superior y Tremadociense con estipes claramente compuestas (como las de Pseudocallograptus) serían, por el momento, Thallograptus y Palaeodictyota.

Dentro del ámbito iberoamericano, Sour \& Buitrón (1987: fig. 1-2) indican el hallazgo de Callograptus cf. elegans en el Tremadociense inferior (Formación Tiñú) de Oaxaca, México. Sin embargo, el material ilustrado corresponde sin duda a fragmentos de rabdosomas de formas planctónicas (Rhabdinopora sp.) semejantes a las que abundan en los mismos niveles.

\section{Género Airograptus Ruedemann, 1916}

Especie tipo: Dictyonema furciferum Ruedemann, 1904, por designación original.

Discusión: De acuerdo con su definición original, el género Airograptus comprende graptolitos dendroideos bentónicos cuyas autotecas tienen procesos peltados prominentes, a menudo bifurcados, que conectan estipes adyacentes sustituyendo a los disepimentos auténticos. Estos últimos, en caso de existir, serían muy esporádicos. Además de la forma tipo Airograptus furciferus, del Arenigiense inferior y medio de Pennsylvania y Nueva York (EE.UU.), Ruedeman $(1916,1947)$ incluyó en Airograptus a otras especies ordo- vícicas y silúricas del norte de Europa, tales como Dictyonema cervicorne Holm, D. tuberosum Wiman, D. peltatum Wiman y $D$. cavernosum Wiman, más tarde revisadas por Bulman (1933) o Bulman \& Rickards (1966). Ninguna de ellas pertenece al género Airograptus a pesar de mostrar procesos autotecales peltados y espinosos muy notorios.

Airograptus fue considerado por Bulman (1938, 1970b) y Obut (1964) como un sinónimo posterior de Dictyonema, una opinión mantenida por casi todos los investigadores posteriores, con la limitada excepción de los autores de hallazgos cambro-ordovícicos en Asia. Además de las especies europeas de Dictyonema antes citadas, en el Ludlow de Australia y en el Wenlock superior de Canadá existen otras formas con procesos autotecales bifurcados, que de registrarse en el Ordovícico Inferior serían consideradas como Airograptus, y cuya morfología es ciertamente parecida a la de la forma argentina Airograptus? guillermoi sp. nov. que describimos más adelante (véase por ejemplo Dictyonema sp. de Rickards et al., 1995, fig. 14G). Otra subespecie del Ludlow australiano y canadiense, Dictyonema delicatulum barnbyensis Rickards \& Wrigth, tiene también procesos ventrales autotecales bifurcados, formados por láminas planares de tejido fuselar (Rickards \& Wright, 1997: figs. 4A y 6C; Sherwin \& Rickards, 2002: fig. 4a; Lenz \& Kozlowska-Davidziuk, 2002: figs. 8.2 y 8.13), lo cual revela que tales elementos no son exclusivos de Airograptus, sino que se constatan esporádicamente en el género Dictyonema.

Tras los trabajos de Ruedemann, tanto Airograptus furciferus como nuevas formas relacionadas con dicho taxón en nomenclatura abierta, han sido citadas en el Arenigiense de EE.UU. (Berry, 1962) y, sobre todo, en el Tremadociense de China (Mu, 1953, 1955; Chen et al., 1980a; Yu et al., 1985; Wang \& Erdtmann, 1987; Mu et al., 2002; Zhang \& Erdtmann, 2004a, 2004b) y Asia central (Obut \& Sennikov, 1984; Sennikov, 1994). De China proceden también los representantes más antiguos de Airograptus, caracterizados en las formaciones Fengshan y Changshan del Cámbrico Superior (Lin, 1983, 1992; Lin en Zhou et al., 1984; Mu et al., 2002), así como los últimos hallazgos del género en el Ordovícico Medio (Xiao \& Zhong, 1988).

Zhang \& Erdtmann (2004a, 2004b) propusieron recientemente una nueva diagnosis para Airograptus basada en 17 fragmentos de colonias relativamente bien conservadas de A. furciferus y A. aff. furciferus, procedentes de la Biozona de Aorograptus victoriae (Tremadociense superior) del NE de China. Entre los caracteres genéricos más distintivos, los autores citan el origen alterno de las autotecas a partir de las caras latero-ventrales de estolotecas consecutivas, el desarrollo de procesos peltados prominentes en la apertura de las autotecas y la ausencia de disepimentos auténticos, con posibles relaciones entre estipes contiguas por contacto o anastomosis. Sin embargo, para la revisión diagnóstica del género no se tuvo en 
cuenta ningún ejemplar original de la serie tipo de A. furciferus, o al menos topotipos de las localidades de Ruedemann $(1904,1947)$, disponiéndose tan sólo del material del Tremadociense chino atribuido, sin evidencias claras, a la especie tipo de Airograptus procedente del Arenigiense norteamericano. En este sentido, el auténtico A. furciferus continúa siendo un taxón muy mal conocido, restringido en la práctica a los tres ejemplares incompletos ilustrados por su autor (Ruedemann, 1904, 1916, 1947). Pese a su buena conservación, los dos fragmentos chinos de A. furciferus figurados por Zhang \& Erdtmann (2004a, 2004b) tienen poco en común con el primero de los ejemplares de Ruedemann (1904: fig. 28 y lám. 3 fig. 11), único ilustrado junto con la descripción original y virtual holotipo de la especie, particularmente en lo que respecta al menor espaciamiento de las estipes y a la estructura tecal piritizada en relieve. En cuanto a los restantes ejemplares de Ruedemann $(1916,1947)$, uno de ellos es una porción de estipe con largos procesos autotecales bifurcados, y el otro una región proximal del rabdosoma con el disco basal de fijación, caracteres ambos no observables en las ilustraciones de Zhang \& Erdtmann (2004a, 2004b). No obstante, concordamos con estos autores en que el carácter furcado del proceso apertural de las autotecas de muchos ejemplares de Airograptus puede ser una variante tafonómica a partir de procesos peltados originales, que sufren torsión y conservación diferencial de sus extremos distales durante la fosildiagénesis.

El mayor interés de la nueva diagnosis de Airograptus, fundada en unos ejemplares chinos atribuidos subjetivamente a la especie tipo del género, es el notable parecido que presenta la estructura de tríadas tecales de uno de ellos (Zhang \& Erdtmann, 2004b, fig. 2A-B, 3 y 4) con relación a la de los graptolitos planctónicos primitivos. Es por ello que estos autores proponen como un posible ancestro de Rhabdinopora a formas bentónicas del tipo Airograptus, una vez descartada su derivación a partir de Staurograptus (ex Radiograptus rosieranus flexibilis) o a la vista de los problemas que rodean al dendroideo cámbrico Dictyonema wutingshanense $(\mathrm{Mu})$ : véase Zhang \& Erdtmann (2004b).

La objeción principal a esta hipótesis tan atractiva de Zhang \& Erdtmann (2004b), es que tampoco debemos excluir la posibilidad de que los fragmentos chinos atribuidos a $A$. furciferus correspondan en realidad a restos de un graptolito planctónico, y no a una forma bentónica del género Airograptus. En este sentido, los autores afirman que Rhabdinopora difiere de Airograptus porque sus aperturas tecales son mucho más simples, pudiendo desarrollar como mucho los rutelos (rutelli) autotecales ilustrados por Cooper et al. (1998: figs. 9m-n, o, u) en $R$. praeparabola. Sin embargo, con esta simplificación Zhang \& Erdtmann (2004b) parecen ignorar el registro de procesos autotecales peltados en ejemplares de Rhabdinopora flabelliformis socialis de Green Point (Terranova, Canadá), descritos por Ruedemann (1947: lám. 2 fig. 15); y también las estipes con tecas espinosas bífidas, asociadas al material tipo de R. f. canadensis (Lapworth), en la localidad clásica de Matane (Québec, Canadá). Incluso Bulman (1950) considera como carácter diagnóstico de este último taxón la presencia de "espinas aperturales de 1,4-1,6 $\mathrm{mm}$ de longitud, con terminaciones bifurcadas". Pero las ilustraciones de las mismas (Bulman, 1950: lám. 4 figs. 1-3, 9-11 y lám. 8 fig. 3) corresponden principalmente a fragmentos de estipes aisladas, a los que se suman otras ramas desplazadas o bien dispuestas como estipes marginales de algunos rabdosomas, en orientación inversa a la que normalmente tendrían las aperturas en las estipes marginales de un rabdosoma cónico pendiente. La revisión moderna de $R$. $f$. canadensis no ha logrado confirmar la presencia de procesos autotecales espinosos en material bien conservado de la sección de Green Point, por lo que Cooper et al. (1998: 16) concluyeron que la característica en cuestión "debería de confirmarse en material aislado y bien conservado, antes de que pueda ser tomada como diagnóstica de la subespecie" $R$. f. canadensis. Lo mismo alegamos aquí para el caso inverso, y es que en tanto ello no se aclare, la propia entidad genérica de Airograptus con su presunta estructuración tecal en tríadas anisográptidas, dista también de quedar confirmada. La diagnosis genérica revisada que aportan Zhang \& Erdtmann (2004a) tampoco es utilizable, ya que la morfología general del rabdosoma y la presencia de procesos autotecales prominentes no es exclusiva de las especies cámbrico-ordovícicas atribuidas a Airograptus, sino que son compartidas por una decena de especies ordovícico-silúricas del género Dictyonema, de típica arquitectura tecal dendroidea.

\section{Airograptus? guillermoi sp. nov.}

(Figs. 13a-c, 16f-h)

v 2003 ?Dictyonema sp. 2 (ex “Airograptus”); GutiérrezMarco \& Esteban, 43.

Holotipo: Rabdosoma PIL 13799a, depositado en la colección de paleoinvertebrados Lillo, Universidad Nacional de Tucumán (Argentina); ilustrado aquí en la Fig. 13c.

Localidad tipo: Peña Negra, en la margen derecha del río Achavil, $72 \mathrm{~km}$ al oeste de la población de Famatina (La Rioja, Argentina).

Estrato tipo: Miembro Peña Negra de la Formación Volcancito, horizonte situado a $246 \mathrm{~m}$ por encima de la base del perfil de Peña Negra. Tremadociense superior basal, Biozona de Adelograptus?.

Derivación del nombre: La especie está dedicada al investigador del Ordovícico argentino Dr. Guillermo F. Aceñolaza (INSUGEO, Tucumán), compañero y amigo de los autores.

Paratipos: Un rabdosoma juvenil PIL 14812 (localidad Peña Negra, nivel de 105 m) y tres estipes maduras aisladas, PIL 
14827 (idem., nivel de 110 m), 14813 (idem., nivel de 167 m) y 14814 (idem., nivel de 246 m).

Diagnosis: Rabdosoma cónico estrecho, con alta densidad de estipes (26-30 en $10 \mathrm{~mm}$ ) y posibles disepimentos esporádicos. Autotecas con largos procesos bifurcados, cuya longitud representa más de la mitad de la anchura dorsoventral de la estipe. 20-22 autotecas en $10 \mathrm{~mm}$.

Narrow conical rhabdosome with stipes closely arranged, about 26-30 in $10 \mathrm{~mm}$ and sparse? dissepiments. Mature stipes with long bifurcate autothecal processes, representing more than a half of the dorso-ventral width, and numbering 20-22 in $10 \mathrm{~mm}$.

Descripción: Rhabdosoma cónico alargado y de aspecto masivo; la relación longitud / anchura varía entre 1,4 y 3,5. La longitud
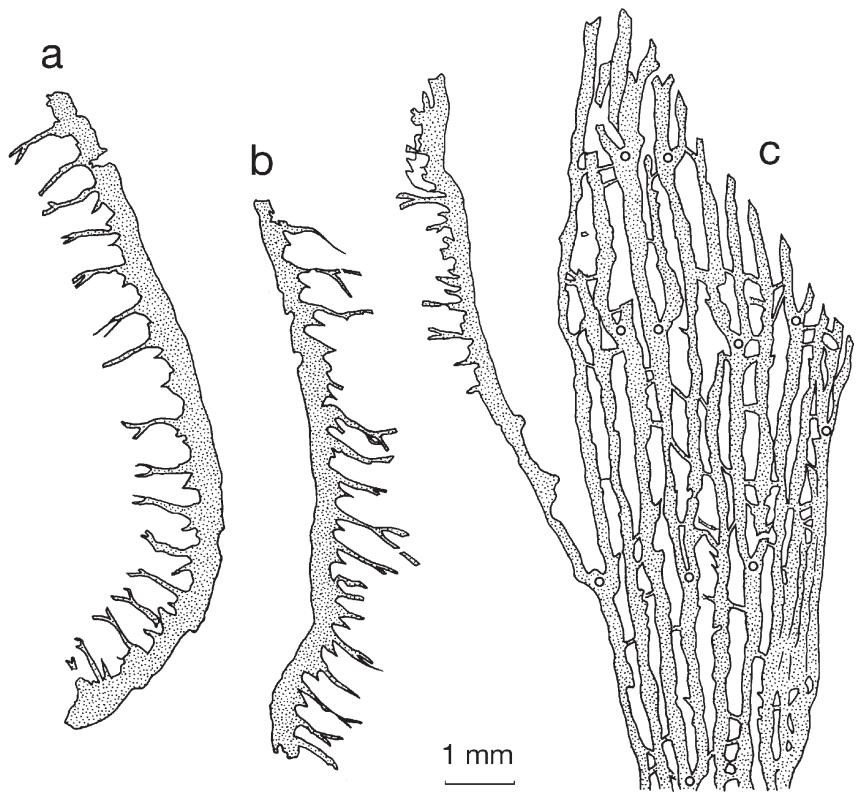

Figura 13.Airograptus? guillermoi sp. nov., ejemplares procedentes de la sección de Peña Negra (Formación Volcancito). a-b, estipes maduras con largos procesos autotecales bifurcados, ilustradas también en las Figs. $16 \mathrm{f}-\mathrm{g}$, respectivamente. c, rabdosoma inmaduro con una estipe torsionada hacia fuera e indicios de posibles disepimentos; los círculos indican la posición de las dicotomías. a, Paratipo PIL 14813 (horizonte de 167 m); b, Paratipo PIL 14814 (idem. 246 m); c, Holotipo PIL 13799a (nivel 246 m).

?Airograptus guillermoi sp. nov., Peña Negra Member of the Volcancito Formation at Peña Negra section. $\boldsymbol{a}-\boldsymbol{b}$, mature stipes with long bifurcate autothecal processes, also illustrated in Figs. $16 f$ and $g$, respectively. c, Inmature rhabdosome with a twisted stipe showing autothecal processes, ?dissepiments and dichotomies, the last indicated by small circles. a, Paratype PIL 14813 (fossiliferous horizon of 167 $m$ above the base); $\boldsymbol{b}$, Paratype PIL 14814 (idem. 246 m); c, Holotype PIL 13799a (level of $246 \mathrm{~m}$ ). máxima es de alrededor de 10-14 mm para los restos proximales de rabdosomas y de $10 \mathrm{~mm}$ para las estipes maduras sueltas.

Las estipes miden 0,18-0,2 mm de anchura lateral y se disponen con notable paralelismo y muy juntas entre sí (26-30 en 10 $\mathrm{mm}$ ), por lo que a veces los interespacios quedan prácticamente obliterados durante la compactación diagenética (Fig. 16h). Por la misma razón, las posibles trazas de disepimentos se reconocen también en forma bastante esporádica (Fig. 13c), disponiéndose en una forma perpendicular u oblicua a las estipes, pero sin aparentar ser espinosos.

En vista lateral, las autotecas se presentan en número de 2022 en $10 \mathrm{~mm}$. Su rasgo más distintivo es la presencia de largas espinas bífidas en posición apertural a supra-apertural (?). La longitud de cada espina es de alrededor de 0,8-1 mm, superior a la anchura dorsoventral del resto de la estipe $(0,5 \mathrm{~mm})$.

Observaciones: La atribución de la nueva especie a $A i$ rograptus refleja los problemas que subsisten en la propia definición del género, considerado generalmente como un sinónimo posterior de Dictyonema (Bulman, 1938, 1970b; Obut, 1964), pero a cuya especie tipo se le han atribuido recientemente caracteres que tal vez sean los de un taxón diferente, incluso un graptolito planctónico primitivo (véase Zhang \& Erdtmann, 2004b y nuestra discusión al género).

En cualquier caso, los ejemplares estudiados pertenecen a una forma bentónica con indicios de disepimentos como los de Dictyonema, conjugados con unos caracteres aperturales de las autotecas más propios de las especies cámbricas y ordovícicas de Airograptus, que constan expresamente en la revisión diagnóstica de Zhang \& Erdtmann (2004a). Estos autores atribuyen una morfología peltada a los procesos autotecales observados entre su material, que adquirirían secundariamente un aspecto bifurcado en los casos en que no se conserven sus extremos distales (ventrales). Y todo ello mediando una torsión tafonómica de los procesos que no es extrapolable a las decenas de autotecas conservadas en nuestro material, el cual se halla representado por estipes literalmente contorsionadas con distintas curvaturas dorsales y ventrales (Fig. 13a-b). Es por ello que pensamos que los procesos autotecales de $A$.? guillermoi sp. nov. habrían sido originalmente espinosos, todo lo más con una expansión ventral peltada muy fina, de la que pudieran conservarse diferencialmente sus bordes laterales espesos a modo de espinas divergentes.

Relaciones y diferencias: El material tipo de Airograptus furciferus (véase Ruedemann, 1904: fig. 28 y lám. 3 fig. 11) recuerda bastante a $A$ ? guillermoi sp. nov. por la morfología alargada del rabdosoma (Fig. 16h) y la gran densidad de estipes. Sin embargo, el número de ramas es notablemente inferior en la especie norteamericana (14 en $10 \mathrm{~mm}$ frente a $26-30 \mathrm{en} 10 \mathrm{~mm}$ en la forma argentina), y lo mismo sucede con el contenido tecal ( 16 en $10 \mathrm{~mm}$ en el material tipo de A. furciferus, frente a 20-22 autotecas en $10 \mathrm{~mm}$ en los ejemplares estudiados), por citar tan sólo las diferencias más significativas. 
Los registros asiáticos de A. furciferus proceden de horizontes más antiguos que los del material tipo norteamericano, concretamente de los niveles más elevados con Rhabdinopora en torno al límite Tremadociense inferior - superior. Este es el caso también del material argentino, encuadrado en una posición estratigráfica similar, pero aparentemente diferenciable por una mayor espinosidad y densidad tecal. Los ejemplares asiáticos publicados hasta el momento (véanse, entre otros, Obut \& Sennikov, 1984; Yu et al., 1985; Wang \& Erdtmann, 1987; Mu et al., 2002; Zhang \& Erdtmann, 2004a, 2004b) son muy fragmentarios y tampoco pueden asimilarse con seguridad a la especie arenigiense A. furciferus. De las formas chinas restantes, A. digitatus Lin y A. sinensis Weng (redescritas e ilustradas por Mu et al., 2002) difieren del material estudiado por la ramificación más abierta y los procesos digitados en el primer caso, y por una densidad de estipes y tecas bastante menor en el segundo (19-20 estipes en $10 \mathrm{~mm}$ frente a 2630 en la forma argentina, 15-16 autotecas en $10 \mathrm{~mm}$ frente a 20-22 en el material examinado). Con todo, A. sinensis es una especie que recuerda a grandes rasgos a nuestros ejemplares, debido a su rabdosoma estrecho y compacto, que sin embargo mantiene importantes diferencias biométricas y unos detalles tecales mal conocidos.

Las especies cámbricas Airograptus anfractus Lin y A. longispicus Lin se distinguen bien de A.? guillermoi sp. nov. por la morfología arbustiva del rabdosoma en el primer caso (= Dendrograptus?), y por las tecas peltadas prominentes, en el segundo, sin indicios de disepimentos. La ramificación arbustiva de $A$. anfractus resulta en cierto modo comparable a la del material tipo de Callograptus grabaui Hahn, sinonimizado por Ruedemann (1947, lám. 14, fig. 1-2) con A. furciferus. Los ejemplares de Montana descritos por este autor como A. cf. furciferus (Ruedemann, 1947: lám. 14 figs. 3-7) tienen un rabdosoma flabelliforme muy semejante al de las especies silúricas de Dictyonema atribuidas a Airograptus por Ruedemann (1947). Una de ellas, Dictyonema cervicorne Holm, tiene una estructura tecal característica, con las bitecas más grandes que las autotecas, lo que se traduce en una relación particular entre las autotecas espinosas y las aperturas notorias de las bitecas en el perfil lateral de la estipe, que posibilitaría interpretar de un modo parecido a las irregularidades observadas en las estipes espinosas aplastadas registradas en la Formación Volcancito. A diferencia de D. cervicorne, caracterizado en el Silúrico de Gotland (Suecia: Bulman, 1933, con referencias previas), A.? guillermoi sp. nov. tiene una malla mucho más compacta y carece de procesos espinosos en los disepimentos y en la cara dorsal de las estipes (véase Bulman, 1933: lám. 3 figs. 110). En cierto modo, algunas estipes de la forma nueva argentina recuerdan vagamente a Dictyonema bitubulata Rickards, Hamedi \& Wright, una especie del Arenigiense tardío de Irán cuyas largas bitecas se presentan aisladas y se proyectan hasta $0,5 \mathrm{~mm}$ (Rickards et al., 2001: figs. $5 \mathrm{c}$ y $5 \mathrm{f}$ ). El estado de conservación de nuestro material no permite saber si parte de las proyecciones observadas corresponden a bitecas aisladas, pero lo que es seguro es que A.? guillermoi sp. nov. tiene numerosos procesos espinosos (simples o bifurcados) que no son homologables con proyecciones tecales.

En cuanto a la similitud morfológica de la especie argentina con determinadas formas planctónicas hay que citar, en primer lugar, a algunos ejemplares bien conservados de Rhabdinopora? enigma Cooper \& Stewart, que presentan también espinas simples o divididas, asociadas posiblemente con aperturas autotecales. Sin embargo, el aspecto de tales espinas es muy diferente a las de A.? guillermoi sp. nov., al ser más delgadas y poder coalescer entre sí desde la misma estipe o entre estipes adyacentes (ver Cooper \& Stewart, 1979: figs. 3h y 3j). Por lo que respecta al material canadiense de Rhabdinopora flabelliformis con tecas espinosas bífidas, citado por Ruedemann (1947: lám. 2 fig. 15) y Bulman (1950: lám. 4 figs. 1-3, 911 y lám. 8 fig. 3) en un contexto ecoestratigráfico y temporal estrechamente comparable con el de A.? guillermoi sp. nov., apuntamos la posibilidad de que el mismo pueda corresponder a fragmentos de estipes de un graptolito bentónico semejante al aquí descrito, que concurriría en superposición palimpséstica con rabdosomas planctónicos de Rhabdinopora.

Distribución: Miembro Peña Negra de la Formación Volcancito, horizontes de 105, 110, 167 y $246 \mathrm{~m}$. Parte alta del Tremadociense inferior (Biozona de R. f. anglica) a parte baja del Tremadociense superior (Biozona de Adelograptus?).

Además de los hallazgos de Famatina, A.? guillermoi sp. nov., o una forma muy próxima al mismo, podría estar representada en la parte inferior de la Biozona de Anisograptus matanensis en Canadá (Terranova y Québec), a través de ciertos ejemplares previamente atribuídos a Rhabdinopora por Ruedemann (1947) y Bulman (1950).

\section{CONCLUSIONES}

Se identifican y describen diversos graptolitos planctónicos obtenidos en las secciones clásicas del Miembro Peña Negra de la Formación Volcancito, tras un muestreo capa a capa a lo largo de unos 400 m de sucesión de pizarras negras graptolíticas. Además de confirmarse la presencia de formas ya citadas como Rhabdinopora flabelliformis flabelliformis, $R$. f. anglica, $R$. f. socialis y Anisograptus matanensis, $R$. f. bryograptoides?, R. cf. enigma y Bryograptus? sp. se describen por vez primera en la unidad. La forma Rhabdinopora flabelliformis famatinensis se opta por restringirla al holotipo por causa de su mala caracterización taxonómica y la imposibilidad de adscribir nuevo material a la especie. Se definen dos nuevos taxones, 

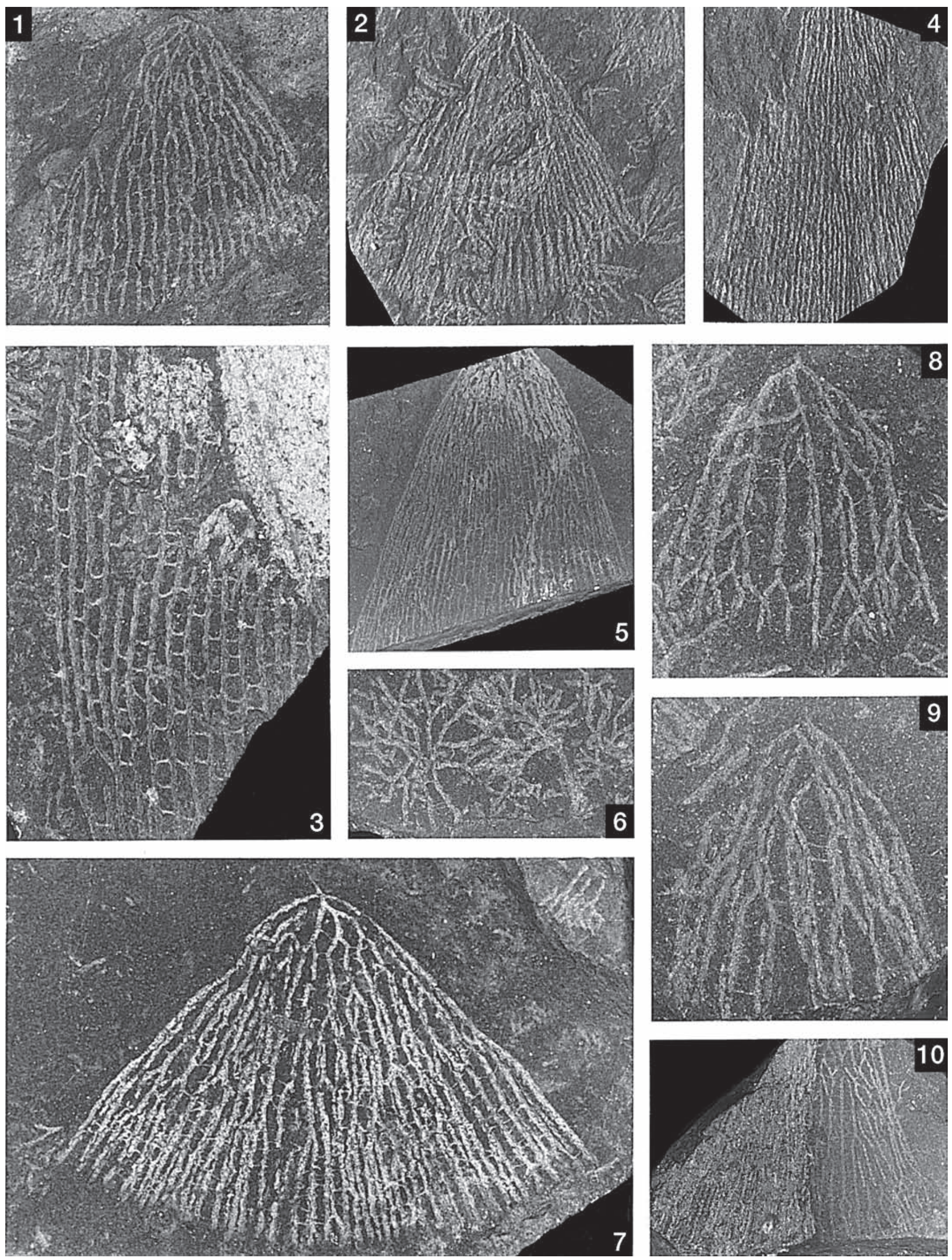
Rhabdinopora turneri sp. nov. y R. flabelliformis acenolazai subsp. nov., que se parecen mucho a sendas formas primitivas del Tremadociense basal, pero que en realidad tienen dimensiones distintas y proceden de horizontes mucho más modernos (posteriores a la aparición del desarrollo proximal trirradiado).

En algunos tramos de la sección de Peña Negra se registraron restos transportados de graptolitos bentónicos, identificados y descritos aquí como Dendrograptus sp. (primera cita del género en Sudamérica) y Dictyonema sp. nov. 1, además de las nuevas especies Aspidograptus cuerdai sp. nov. y Aspidograptus? guillermoi sp. nov. La presencia de Pseudocallograptus? sp. se discute con referencia a los datos proporcionados por autores previos. El estudio adicional del primer graptolito bentónico encontrado en la Formación Bordo Atravesado, Dictyonema? sp. cf. D. cordillerensis, completa el conocimiento de los graptolitos dendroideos del Tremadociense del Sistema de Famatina. Si exceptuamos los hallazgos en ambas formaciones, los graptolitos bentónicos son tremendamente escasos en el Ordovícico sudamericano, y se limitan a escasas citas en Precordillera (Peralta, 1986; Ortega, 1987; Cuerda et al., 1983, 1998, 2004; Brussa, 1997; Toro \& Brussa, 2003), Cordillera Oriental (Moya et al., 1994, 2003a, 2003b, 2003e; Malanca, 2002) y Puna (Malanca et al., 1998), además de en Perú (Steinmann, 1929; Bulman, 1931; Lemon \& Cranswick, 1956) y Venezuela (Hughes, 1980), en gran parte sin descripciones o ilustraciones del material paleontológico.

La revisión taxonómica de los diferentes graptolitos identificados en la Formación Volcancito se complementa con el establecimiento de sinonimias pormenorizadas para los hallazgos realizados con anterioridad en las secciones estudiadas, ampliándolas además a todo el continente americano para el caso de las nuevas formas descritas.

Desde el punto de vista bioestratigráfico y biocronoló- gico, los resultados obtenidos fundamentan la correlación de la Formación Volcancito en virtud de las asociaciones evolutivas y cronozonas globales de graptolitos del Tremadociense, que a su vez permiten reevaluar todas las dataciones e identificaciones previas realizadas en la unidad. Las asociaciones graptolíticas de la parte baja del Miembro Peña Negra pertenecen a las cronozonas de A. matanensis and $R$. $f$. anglica, indicativas del Tremadociense superior tardío (A2). Los dos tercios restantes del Miembro Peña Negra se correlacionan probablemente con el Tremadociense superior temprano (cronozona de Adelograptus?, A3), en ausencia de asociaciones batipelágicas típicas con adelográptidos de estipes finas, o de formas epipelágicas de aguas cálidas como Psigraptus. Tal atribución tentativa a la cronozona de Adelograptus se apoya también en los fósiles del Tremadociense superior identificados en la Formación Bordo Atravesado suprayacente, donde se registran conodontos de la Biozona de Paltodus deltifer y graptolitos de la Biocronozona de Kiaerograptus (A4): Albanesi et al. (2000b, 2001, 2005).

El presente estudio completa el conocimiento de las biozonas de graptolitos del Tremadociense argentino y sudamericano (Aceñolaza \& Durand, 1983, 1984; Moya et al., 1994, 1998; Ortega \& Suárez-Soruco, 1994; Erdtmann et al., 1995; Maletz \& Ortega, 1995; Maletz et al., 1999; Ortega \& Albanesi, 2002; Benedetto et al., 2002; Albanesi \& Ortega, 2002; Maletz \& Egenhoff, 2001, 2003; Egenhoff et al., 2004), y la sucesión del Sistema de Famatina se propone aquí como patrón para la correlación internacional del Tremadociense inferior en Argentina.

Otra aplicación del estudio bioestratigráfico se refiere a la correlación del Miembro Peña Negra de la Formación Volcancito en ambas secciones estudiadas, que se han revelado representativas de intervalos cronológicos distintos. En este sentido, las pizarras negras graptolíticas de la sucesión de Peña Negra (260 m: Tremadociense inferior a

Figura 14. Graptolitos planctónicos del Miembro Peña Negra de la Formación Volcancito, secciones de Río Volcancito (ejemplares a y d) y Peña Negra (ejemplares b-c y e-j), Tremadociense. Rabdosomas comprimidos en vista lateral excepto f (vista dorsal discoide). - a-c, Rhabdinopora flabelliformis flabelliformis (Eichwald, 1840): a, PIL 13971, base de la sección (x 2,1); b, PIL 13790, horizonte de 246 m (x 2,1); c, PIL 13786, horizonte de 27 m, detalle de la malla (x 3,3). - d-e, Rhabdinopora flabelliformis socialis (Salter, 1858): d, PIL 13778, horizonte de 3.30 m (x 1,6); e, PIL 13775, horizonte de $27 \mathrm{~m}$ (x 1,45). - f, Rhabdinopora flabelliformis (Eichwald, 1840) subsp. indet.: estadios juveniles de desarrollo en preservación discoidal, PIL 14822, horizonte $167 \mathrm{~m}$ (x 2,5). - g, Rhabdinopora flabelliformis acenolazai subsp. nov.: rhabdosoma juvenil designado como holotipo, PIL 14482, horizonte de 246 m (x 3). - h-j, Rhabdinopora flabelliformis anglica (Bulman, 1927): h, PIL 14504, horizonte de 167 m (x 3,3); i, PIL 14505, horizonte de 167 m (x 3,85); j, PIL 14502, horizonte de 45 m (x 1,2). Tremadocian graptolites from the Peña Negra Member of the Volcancito Formation, sections of Río Volcancito (a and d) and Peña Negra (b-c and e-j). All rhabdosomes in lateral view, except of fig. 6 in discoidal (= dorsally compressed) view. - $\boldsymbol{a}-\boldsymbol{c}$, Rhabdinopora flabelliformis flabelliformis (Eichwald, 1840): $\boldsymbol{a}$, PIL 13971, from the base of the section (x 2.1); $\boldsymbol{b}$, PIL 13790, horizon of 246 m (x 2.1); c, PIL 13786, detail of the mesh, horizon of $27 m$ (x 3.3). - d-e, Rhabdinopora flabelliformis socialis (Salter, 1858): d, PIL 13778, horizon of $3.30 \mathrm{~m}$ (x 1.6); $\boldsymbol{e}$, PIL 13775, horizon of $27 \mathrm{~m}(x 1.45)$. $-\boldsymbol{f}$, Rhabdinopora flabelliformis (Eichwald, 1840) subsp. indet.: Developmental juvenile stages preserved in dorsal (discoidal) view, PIL 14822, horizont of $167 m$ (x 2.5). - g, Rhabdinopora flabelliformis acenolazai subsp. nov.: Holotype, young rhabdosome PIL 14482 -see also Text-fig. 5, horizon of $246 m$ (x 3). - h-j, Rhabdinopora flabelliformis anglica (Bulman, 1927): $\boldsymbol{h}$, PIL 14504, horizon of $167 \mathrm{~m}$ (x 3.3); $\boldsymbol{i}$, PIL 14505, horizon of $167 \mathrm{~m}$ (x 3.85); $\boldsymbol{j}$, PIL 14502, horizon of $45 \mathrm{~m}$ (x 1.2). 

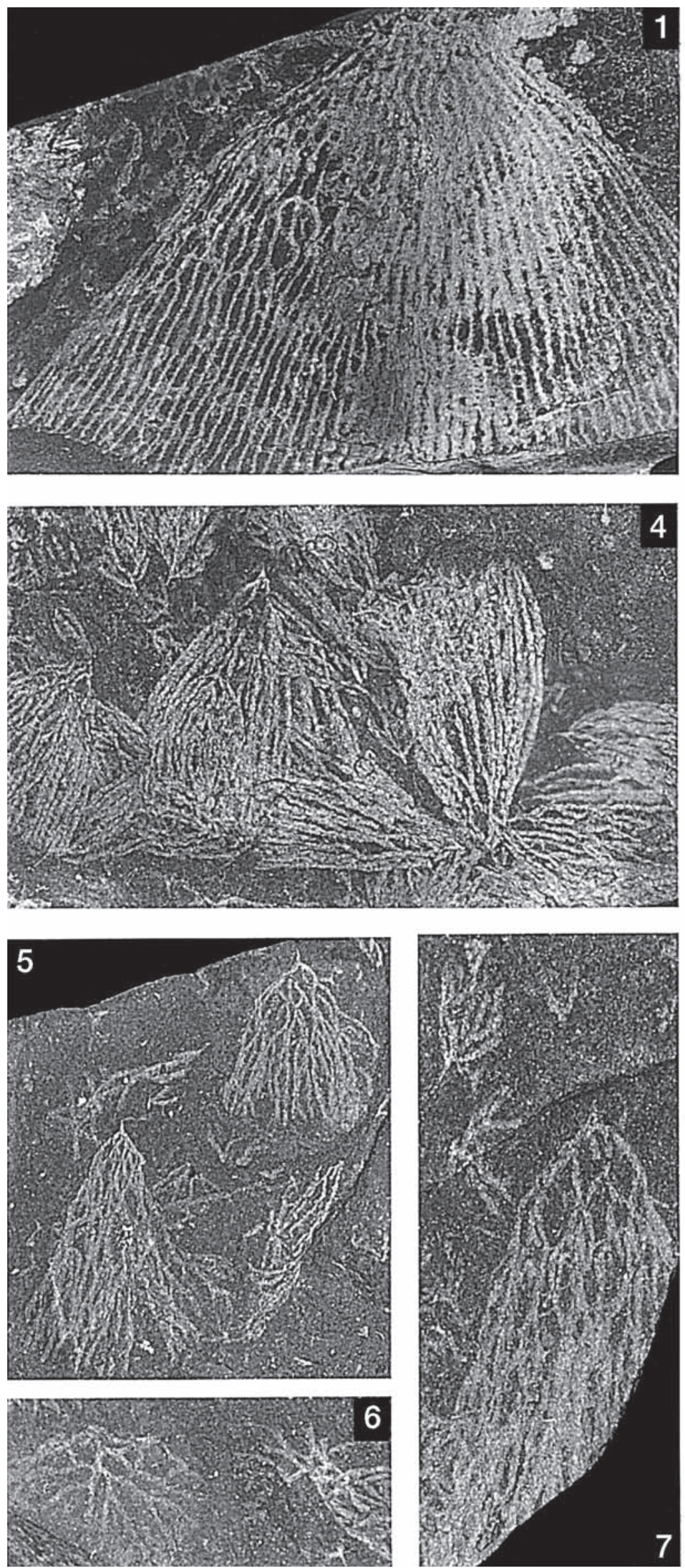
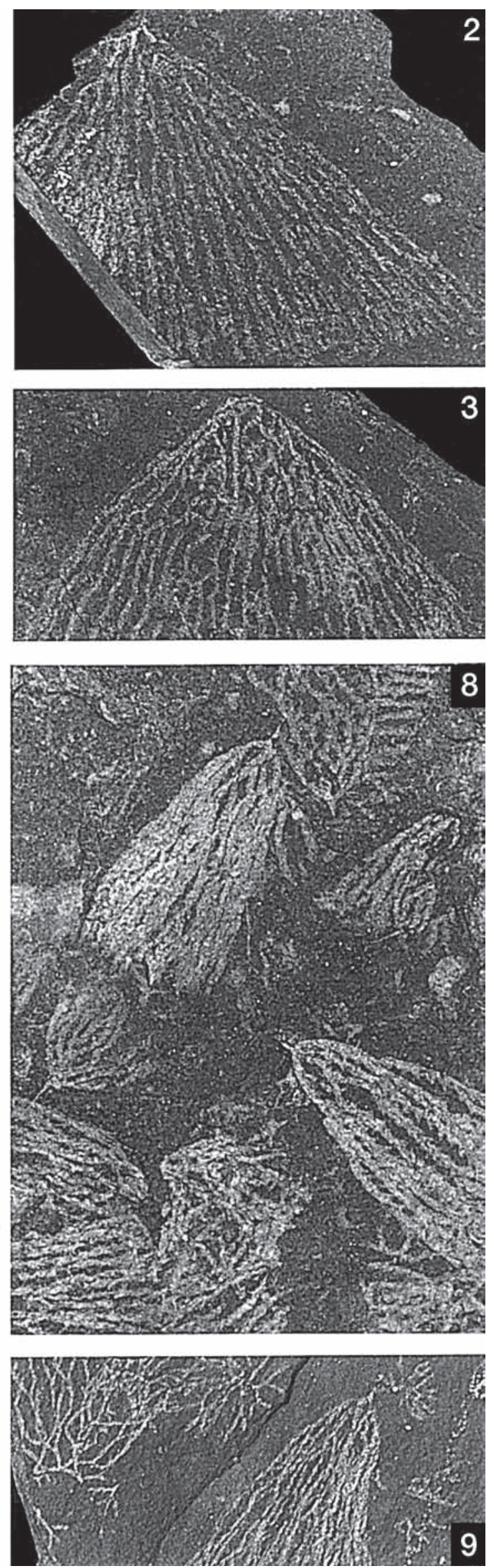
superior basal?) serían más antiguas que las de la misma unidad en el río Volcancito (180 m: Tremadociense superior). La ausencia de un obvio solapamiento permite incrementar por vez primera el espesor mínimo, asignado al Miembro Peña Negra de la Formación Volcancito, en torno a los 400-440 m. La extensión del Tremadociense basal al Miembro Filo Azul de la Formación Volcancito, y del Tremadociense superior a la Formación Bordo Atravesado, implica por lo tanto un espesor mínimo de $500 \mathrm{~m}$ para los materiales de dicha edad en el Sistema de Famatina. Ello posibilita deducir una tasa media de sedimentación desmesurada, superior incluso a los $0,1 \mathrm{~mm}$ compactados por año calculados por Astini (2003) para el Miembro Peña Negra de la Formación Volcancito, y sobre todo si tenemos en cuenta que las condiciones normales de sedimentación para pizarras negras graptolíticas implican una acumulación media de 1-10 mm cada 10.000 años. Aún así, la gran potencia local de los materiales tremadocienses es comparable a la de ciertos contextos perigondwánicos coetáneos, como por ejemplo los de la Cordillera Oriental argentino-boliviana, norte de África y Europa central.

Las lutitas negras graptolíticas de la Formación Volcancito se depositaron en fondos anóxicos profundos (de plataforma externa a planicie cuencal) en el margen de Gondwana occidental, previamente al nacimiento y emersión del Arco Volcánico Famatinense. El desarrollo de condiciones anóxicas tuvo que ver con la aparición de un área de afloramiento oceánica con elevada productividad orgánica, la cual constituyó un hábitat favorable para los rhabdinoporínidos holo- y mesopelágicos, además de favorecer el desarrollo de algunas formas endémicas. La presencia de graptolitos bentónicos, transportados por corrientes desde la plataforma, no es un hecho infrecuente en Asia y Norteamérica, en ambientes profundos comparables con los estudiados.

\section{AGRADECIMIENTOS}

Los autores agradecen la colaboración prestada por el Prof. F.G. Aceñolaza (CONICET-Universidad Nacional de Tucumán), por poner a nuestra disposición todos los medios y facilidades del Instituto Superior de Correlación Geológica, y a los Prof. A. Cuerda (La Plata) y B.-D. Erdtmann (Berlín), quienes se encargaron de la revisión crítica del manuscrito, manteniendo este último ciertas reservas sobre los nuevos taxones planctónicos. $\mathrm{Al}$ arquitecto Daniel Ruiz Holgado (Tucumán) por las ilustraciones del mapa y la columna; al Dr. R. Gozalo (Valencia) por la cuidada y prolija revisión editorial; a Uly Martín y Carlos Alonso (Madrid) por las fotografías. Este trabajo es una contribución surgida del proyecto "Dinámica faunística perigondwánica", del Programa de Cooperación Científica con Iberoamérica del antiguo Ministerio de Educación, Cultura y Deporte de España, y constituye también una contribución al proyecto IGCP 503 (Ordovician palaeogeography and palaeoclimate) del Programa Internacional de Geociencias (IUGS-UNESCO).

\section{BIBLIOGRAFÍA}

Aceñolaza, F.G. 1992. El Sistema Ordovícico de Latinoamérica. In: Paleozoico Inferior de Iberoamérica (Eds. J.C. Gutiérrez-Marco, J. Saavedra \& I. Rábano). Universidad de Extremadura, 85-118.

Aceñolaza, F.G. \& Aceñolaza, G.F. 1992. The genus Jujuyaspis as a world reference fossil for the Cambrian-Ordovician boundary. In: Global perspectives on Ordovician Geology (Eds. B.D. Webby \& J.R. Laurie). Balkema, Rotterdam, 115-120.

Aceñolaza, F.G. \& Durand, F. 1983. Observaciones sobre la fauna graptolítica tremadociana del Famatina, La Rioja. Correlación Geológica, Tucumán, 1, 129-131.

Aceñolaza, F.G. \& Durand, F. 1984. Observaciones sobre la fauna graptolítica tremadociana del Famatina, provincia

Figura 15.Graptolitos planctónicos del Miembro Peña Negra de la Formación Volcancito, secciones de Río Volcancito (a-c) y Peña Negra (d-i). Rabdosomas comprimidos en vista lateral excepto f e i, con colonias preservadas oblicuamente. - a-c, Rhabdinopora flabelliformis acenolazai subsp. nov.: a, paratipo PIL 14488, horizonte de $3.30 \mathrm{~m}$ (x 1.6); b, paratipo PIL 14485, horizonte de $3.30 \mathrm{~m}$ (x 2,25); c, paratipo PIL 14483, base de la sección (x 2,1). - d-i, Rhabdinopora turneri sp. nov.: d, rabdosomas orientados apicalmente en un posible sinrabdosoma, paratipos PIL 14490, horizonte de $9 \mathrm{~m}$ (x 2,1); e, paratipos PIL 14489, algo distorsionados durante la compactación diagenética, horizonte de 4 m (x 2,3); f, dos colonias jóvenes, la de la izquierda mostrando la estructura cuadrirradiada preservada oblicuamente, paratipos PIL 14498, horizonte de 246 m (x 3); g, paratipo PIL 14500, horizonte de 150 m (x 4); h, grupo de rabdosomas, PIL 14491 con holotipo (abajo a la derecha) y paratipos, horizonte de $9 \mathrm{~m}$ (x 3,3); i, paratipos 14501, horizonte de $246 \mathrm{~m} \mathrm{(x} \mathrm{1,8).}$

Tremadocian graptolites from the Peña Negra Member of the Volcancito Formation, sections of Río Volcancito (a to c) and Peña Negra ( $d$ to i). Rhabdosomes in lateral view, with some obliquely preserved specimens in figs. $f$ and $i$. $-\boldsymbol{a}$-c, Rhabdinopora flabelliformis acenolazai subsp. nov.: a, Paratype PIL 14488, from the horizon of $3.30 \mathrm{~m}$ above the base of the section(x 1.6); b. Paratype PIL 14485, from the same horizon (x 2.25); $\boldsymbol{c}$, Paratipo PIL 14483, base of the section (x 2.1). - d-i, Rhabdinopora turneri sp. nov.: d, A somewhat distorted ?synrhabdosome grouping, paratypes PIL 14490, from the horizon of $9 m$ above the base of the section (x 2.1); e, Paratypes PIL 14489, distorted specimens showing loose flexuous stipes -see also Figs. $6 d$ and $6 h$, from the horizon of $4 m(x 2.3) ; f$, Two young colonies, on the left obliquely preserved showing quadriradiate structure, PIL 14498, from horizon of $246 \mathrm{~m}$ (x 3); g, Paratype PIL 14500, from horizon of 150 $m(x 4) ; \boldsymbol{h}$, Group of specimens on the beding plane, PIL 14491 with holotype down to the right and paratypes -see also Figs. 6a-b, from the horizon of $9 m$ (x 3.3); i, Paratypes 14501, from the horizon of $246 m$ (x 1.8). 

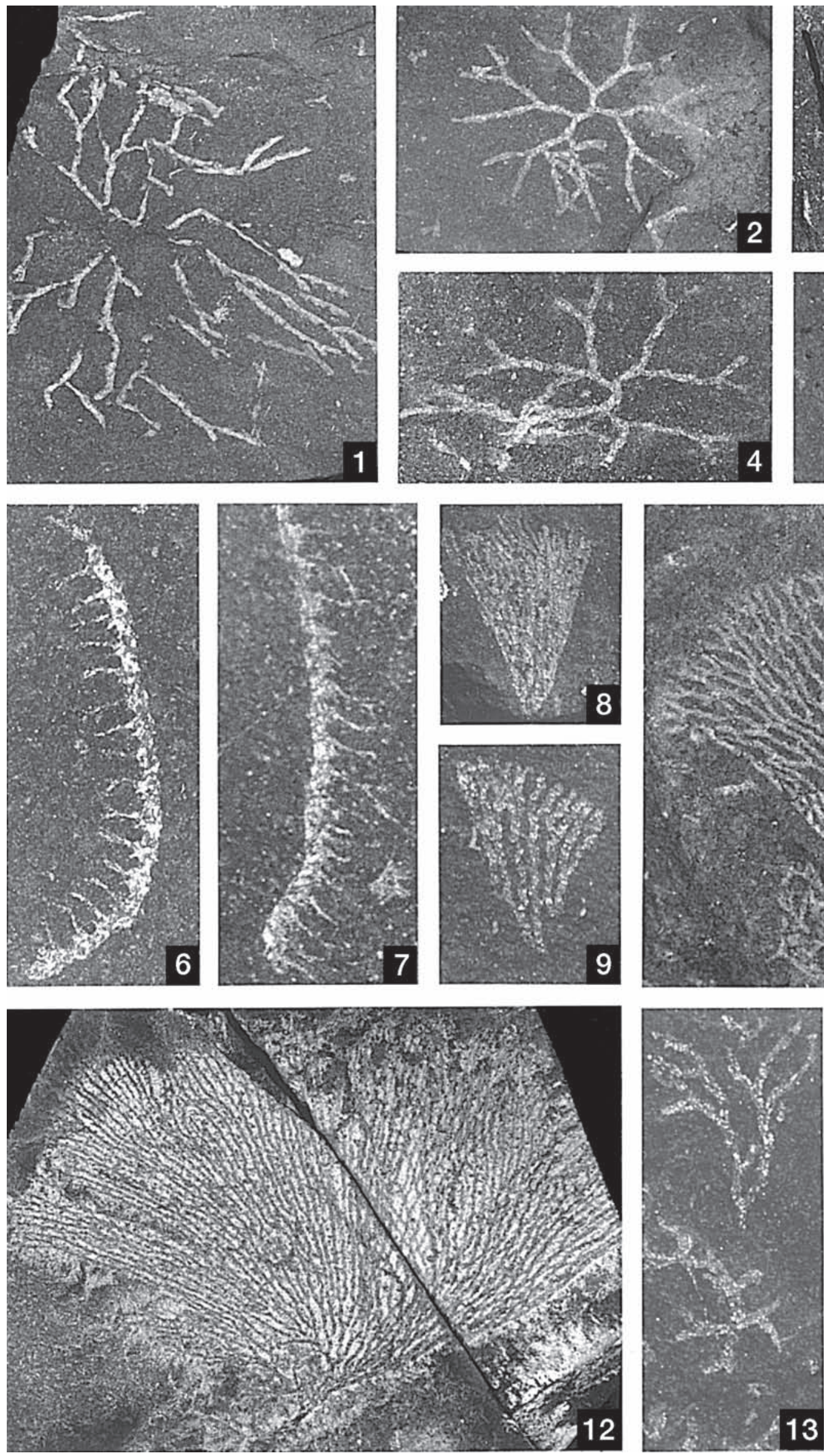
de La Rioja. Actas IX Congreso Geológico Argentino, Bariloche, 4, 267-276.

Aceñolaza, F.G. \& Esteban, S. 1996. Filocáridos (Crustacea) en el Tremadociano del Sistema de Famatina, provincia de La Rioja, Argentina. Memorias del XII Congreso Geológico Boliviano, Tarija, 1, 281-288.

Aceñolaza, F.G. \& Gutiérrez-Marco, J.C. 2000. Graptolitos de la Formación Portezuelo de las Minitas (Ordovícico Inferior) del Sistema de Famatina, La Rioja, Argentina. Boletín de la Academia Nacional de Ciencias, Córdoba, 64, 17-26.

Aceñolaza, F.G. \& Toselli, A. 1981. Geología del Noroeste Argentino. Publicación de la Facultad de Ciencias Naturales e Instituto Miguel Lillo, Universidad Nacional de Tucumán, 1287, 1-212.

Aceñolaza, F.G. \& Toselli, A. 1988. El Sistema de Famatina, Argentina: su interpretación como orógeno en el margen continental activo. Actas V Congreso Geológico Chileno, Santiago, 1, A55-A67.

Aceñolaza, F.G. \& Toselli, A.J. 2000. Argentine Precordillera: allochthonous or autochthonous Gondwanic? Zentralblatt für Geologie und Paläontologie, Teil I, 1999, 743-755.

Aceñolaza, F.G., Gorustovich, S. \& Solís, J. 1976. El Ordovícico del río La Alumbrera, Departamento Tinogasta, Provincia de Catamarca. Ameghiniana, 13, 269-288.

Aceñolaza, F.G., Miller, H. \& Toselli, A., Eds. 1996. Geología del Sistema de Famatina. Münchner Geologische Hefte, Allgemeine Geologie, A19, 1-410.

Aceñolaza, F.G., Buatois, L.A., Mángano, M.G., Esteban, S.B., Tortello, M.F. \& Aceñolaza, G.F. 1999. Cámbrico y Ordovícico del noroeste argentino. In: Geología Argentina (Ed. R. Caminos). Anales del Instituto de Geología y Recursos Minerales, Servicio Geológico Minero Argentino, 29, 169-187.

Aceñolaza, F.G., Miller, H. \& Toselli, A. 2000. The Pampean and Famatinian cycles - superposed orogenic events in west Gondwana. Zeitschrift für Angewandte Geologie, Sonderheft, 1, 337-344.

Aceñolaza, F.G., Miller, H. \& Toselli, A. 2002. ProterozoicEarly Paleozoic evolution in western South America -a discussion. Tectonophysics, 354, 121-137.

Aceñolaza, F.G., Miller, H. \& Toselli, A. 2003. Reply to the Discussion to "Proterozoic-Early Paleozoic evolution in western South America -a discussion” by Astini and Rapalini. Tectonophysics, 366, 149-150.

Aceñolaza, G.F., Tortello, M. \& Esteban, S.B. 1996. Oxygen deficient facies of Lower Paleozoic age in northwestern Argentina. Correlación Geológica, Tucumán, 12, 15-21.

Aceñolaza, G.F., Gutiérrez-Marco, J.C., Rábano, I. \& Díaz Martínez, E. 1999. Las lumaquelas de la Formación Sella (Ordovícico de la Cordillera Oriental boliviana) y su interés paleobiogeográfico. Actas del XIV Congreso Geológico Argentino, Salta, 1, 355-458.

Aceñolaza, G.F., Milana, J.P., Heredia, S. \& Simoes, M. 2003. Stratigraphical and biostratigraphical framework of the Angosto de La Quesera conglomerate complex (Cordillera Oriental of Salta): an incised valley system in the Tremadocian of NW Argentina. In: Ordovician from the Andes (Eds. G.L. Albanesi, M.S. Beresi \& S.H. Peralta). Correlación Geológica, Tucumán, 17, 365-370.

Albanesi, G.L. \& Ortega, G. 2002. Advances on conodontgraptolite biostratigraphy of the Ordovician System of Argentina. Correlación Geológica, Tucumán, 16, 143-166.

Albanesi, G.L., Esteban, S.B. \& Barnes, C.R. 1999. Conodontes del intervalo del límite Cámbrico-Ordovícico en la Formación Volcancito, Sistema de Famatina, Argentina. Temas Geológico-Mineros ITGE, Madrid, 26, 521-526.

Albanesi, G.L., Barnes, C.R. \& Hünicken, M.A. 2000a. Conodont paleobiogeography of the Iapetus Ocean in

Figura 16.Graptolitos planctónicos (a-e) y bentónicos (f-m) procedentes del Miembro Peña Negra de la Formación Volcancito en la sección de Peña Negra: Tremadociense. - a-e, Anisograptus matanensis Ruedemann, 1937: a, rabdosoma de aspecto flexuoso por distorsión dorsolateral, PIL 14511, horizonte de $105 \mathrm{~m}$ (x 2,5); b, PIL 14512, horizonte de $110 \mathrm{~m}$ (x 3,7); c, PIL 14513, horizonte de $25 \mathrm{~m}$ (x 4,4); d, PIL 14806, horizonte de $110 \mathrm{~m}$ (x 5); e, PIL 14809, horizonte de $10 \mathrm{~m}$ (x 3,7). - f-h, Airograptus? guillermoi sp. nov.: f, estipe madura aislada, en preservación lateral, mostrando espinas tecales bífidas, paratipo PIL 14813, horizonte de 167 m (x 8,7); g, otra estipe con idénticos caracteres, paratipo PIL 14814, horizonte de $246 \mathrm{~m}$ (x 10); h, rabdosoma juvenil, paratipo PIL 14812, horizonte de 105 m (x 3,9). - i-k, Dictyonema sp. nov. 1: i, fragmento proximal PIL 14817, horizonte de $27 \mathrm{~m}$ (aprox. x 5,5); j, colonia adulta PIL 14821, horizonte de $246 \mathrm{~m}$ (x 3,6); k, colonia juvenil PIL 14816, horizonte de 27 m (x 2,4). - l, Aspidograptus cuerdai sp. nov.: rabdosoma adulto PIL 14815, horizonte de $27 \mathrm{~m}$ (x 2). - m, Dendrograptus sp.: fragmento de rabdosoma (arriba) asociado con una colonia juvenil cuadrirradiada de Rhabdinopora sp. en preservación discoidal (abajo); PIL 14818, horizonte de $246 \mathrm{~m}$ (x 7,5). Planktic (figs. a to e) and benthic (figs. f to $m$ ) Tremadocian graptolites from the Peña Negra Member of the Volcancito Formation, Peña Negra section. - a-e, Anisograptus matanensis Ruedemann, 1937: a, Adult rhabdosome with distorted stipes, PIL 14511, from the horizon of $105 \mathrm{~m}$ above the base (x 2.5); b, PIL 14512, horizon of $110 \mathrm{~m}(x 3.7)$; $\boldsymbol{c}$, PIL 14513, horizon of $25 \mathrm{~m}(x 4.4) ; \boldsymbol{d}$, PIL 14806, horizon of $110 \mathrm{~m}(x \mathrm{x}) ; \boldsymbol{e}$, young stage of a typical triradiate specimen, but with long primary stipes, PIL 14809, horizon of $10 m$ (x 3.7). $-\boldsymbol{f}$-h, ?Airograptus guillermoi sp. nov.: $\boldsymbol{f}$, lateral view of mature stipe showing the bifid autothecal spines, paratype PIL 14813, horizon of $167 \mathrm{~m}(x$ 8.7); g, another stipe with the same autothecal morphology, paratype PIL 14814, horizon of $246 \mathrm{~m}$ (x 10); h, young rhabdosome, paratype PIL 14812, horizon of $105 \mathrm{~m}$ (x 3.9). - i-k, Dictyonema sp. nov. 1: $\boldsymbol{i}$, proximal fragment PIL 14817, horizon of $27 \mathrm{~m}(\mathrm{ca} . x 5.5) ; \boldsymbol{j}$, adult rhabdosome PIL 14821, horizon of $246 \mathrm{~m}$ (x 3.6); $\boldsymbol{k}$, young rhabdosome PIL 14816, horizon of $27 \mathrm{~m}$ (x 2.4). - $\boldsymbol{l}$, Aspidograptus cuerdai sp. nov.: adult rhabdosome PIL 14815, horizon of $27 m$ (x 2). - m, Dendrograptus sp.: fragment of rhabdosome (above) with a quadriradiate developmental stage of Rhabdinopora sp. in discoidal view (below), PIL 14818, horizon of $246 m$ (x 7.5). 
the Cambrian-Ordovician boundary interval. Abstracts Volume, $31^{\text {st }}$ International Geological Congress, Rio de Janeiro, Edición única en CD-ROM.

Albanesi, G.L., Esteban, S.B., Hünicken, M.A. \& Barnes, C.R. 2000b. Las biozonas de conodontes de la Formación Volcancito (Cámbrico tardío-Ordovícico temprano), Sistema de Famatina, noroeste de Argentina. Ameghiniana, 37 (4-suplemento), 5R.

Albanesi, G.L., Ortega, G. \& Zeballo, F. 2001. Late Tremadocian conodont-graptolite biostratigraphy from NW Argentine basins. The Guide Book, Abstracts \& OrdovicianSilurian correlation chart for the joint Field Meeting of IGCP 410 and IGCP 421 in Mongolia, 121-123.

Albanesi, G.L., Esteban, S.B., Ortega, G., Hünicken, M.A. \& Barnes, C.R. 2005. Bioestratigrafía y ambientes sedimentarios de las Formaciones Volcancito y Bordo Atravesado (Cámbrico Superior-Ordovícico Inferior), Sistema de Famatina, Provincia de La Rioja, Argentina. In: Geología de la Provincia de La Rioja (Precámbrico-Paleozoico Inferior) (Eds. J. Dahlquist, C. Rapela \& E. Baldo). Publicación Especial de la Asociación Geológica Argentina.

Alonso, R.N., Malanca, S. \& Sureda, R.J. 1982. Consideraciones sobre el Ordovícico en la sierra de Aguilar, Jujuy, Argentina. Revista del Instituto de Ciencias Geológicas, Jujuy, 5, 15-37.

Álvaro, J.J., Vennin, E., Moreno-Eiris, E., Perejón, A. \& Bechstädt, T. 2000. Sedimentary patterns across the LowerMiddle Cambrian transition in the Esla nappe (Cantabrian Mountains, northern Spain). Sedimentary Geology, 137, 43-61.

Astini, R.A. 1999. El Ordovícico del Sistema del Famatina. In: Relatorio del XIV Congreso Geológico Argentino, Salta (Eds. G. González Bonorino, R. Omarini \& J. Viramonte). Geología del Noroeste Argentino, 1, 152-159.

Astini, R.A. 2001a. Paleoenvironmental reconstruction and paleoclimatic implications of a perigondwanic Cambrian-Ordovician mixed carbonate-siliciclastic succession in Famatina, western Argentina. In: Abstracts Book, Official Business Meeting and Field excursion of the Subcommission on Ordovician Stratigraphy (Ed. N. Hamoumi), Rabat, 31-32.

Astini, R.A. 2001b. Las algas calcáreas Nuia y Girvanella a través de la transición cambro-ordovícica (Formación Volcancito) en el Famatina: significado paleoambiental y paleogeográfico. Ameghiniana, 38, 243-255.

Astini, R.A. 2003. Chapter 1. The Ordovician Proto-Andean basins. In: Ordovician fossils of Argentina (Ed. J.L. Benedetto). Secretaría de Ciencia y Tecnología, Universidad Nacional de Córdoba, 1-74.

Astini, R.A. \& Dávila, A.F. 2000. Event layer sedimentology in a Cambrian-Ordovician mixed platform (Volcancito Formation), Famatina System, western Argentina. Resúmenes II Congreso Latinoamericano de Sedimentología y VIII Reunión Argentina de Sedimentología, Mar del Plata, 38-39.

Astini, R.A. \& Dávila, A.F. 2004. Ordovician back arc foreland and Ocloyic thrust belt development on the western Gondwana margin as a response to Precordillera terrane accretion. Tectonics, 23, TC4008, 1-19.
Astini, R.A. \& Rapalini, A.E. 2003. "Proterozoic-Early Paleozoic evolution in western South America -a discussion" in: Tectonophysics, 354: 121-137 (2002). Tectonophysics, 366, 143-148.

Astini, R.A., Benedetto, J.L. \& Vaccari, N.E. 1995. The early Paleozoic evolution of the Argentine Precordillera as a Laurentian rifted, drifted, and collided terrane: A geodynamic model. Geological Society of America Bulletin, 107, 253-273.

Astini, R.A., Dávila, F.M. \& Carrera, M.G. 2000. Nuia y Girvanella en la transición cambro-ordovícica (Formación Volcancito) en el Famatina, La Rioja, Argentina. Ameghiniana, 37 (4-suplemento), 6R.

Astini, R.A., Dávila, F.M., Rapela, C.W., Pankhurst, R.J. \& Fanning, C.M. 2003. Ordovician back-arc clastic wedge in the Famatina Ranges: new ages and implications for reconstruction of the proto-Andean Gondwana margin. In: Ordovician from the Andes (Eds. G.L. Albanesi, M.S. Beresi \& S.H. Peralta). Correlación Geológica, Tucumán, 17, 375-380.

Baldo, E.G., Fanning, C.M., Rapela, C.W., Pankhurst, R.J., Casquet, C. \& Galindo, C. 2003. U-Pb SHRIMP dating of rhyolite volcanism in the Famatinian belt and K-bentonites in the Precordillera. In: Ordovician from the Andes (Eds. G.L. Albanesi, M.S. Beresi \& S.H. Peralta). Correlación Geológica, Tucumán, 17, 185-189.

Benedetto, J.L. 1998. Early Palaeozoic brachiopods and associated shelly faunas from western Gondwana: their bearing on the geodynamic history of the pre-Andean margin. In: The Proto-Andean Margin of Gondwana (Eds. R.J. Pankhurst \& C.W. Rapela). Geological Society, London, Special Publications, 142, 57-83.

Benedetto, J.L. 2001. Una fauna de braquiópodos arenigianos (Ordovícico temprano) en rocas volcanoclásticas de la Puna occidental de Argentina: implicaciones paleoclimáticas y paleogeográficas. Ameghiniana, 38, 131-146.

Benedetto, J.L. 2003a. Chapter 3. Paleobiogeography. In: Ordovician fossils of Argentina (Ed. J.L. Benedetto). Secretaría de Ciencia y Tecnología, Universidad Nacional de Córdoba, 91-109.

Benedetto, J.L. 2003b. Chapter 7. Brachiopods. In: Ordovician fossils of Argentina (Ed. J.L. Benedetto). Secretaría de Ciencia y Tecnología, Universidad Nacional de Córdoba, 187-271.

Benedetto, J.L., Sánchez, T.M., Carrera, M.G., Brussa, E.D. \& Salas, M.J. 1999. Paleontological constraints on successive paleogeographic positions of Precordillera terrane during the Early Paleozoic. In: Laurentia-Gondwana Connections before Pangea (Eds. V.A. Ramos \& J.D. Keppie). Geological Society of America, Special Paper, 336, 21-42.

Benedetto, J.L., Brussa, E.D. \& Pompei, J.F. 2002. El Ordovícico de la región de Susques-Huancar (Puna oriental de Jujuy): precisiones sobre su edad y significado estratigráfico. Actas del XV Congreso Geológico Argentino, El Calafate, 1, 572-577.

Bengtson, P. 1988. Open nomenclature. Palaeontology, 31, 223-227. 
Berry, W.B.N. 1960. Graptolite faunas from the Marathon region, west Texas. The University of Texas, Publication $6005,1-179$.

Berry, W.B.N. 1962. Stratigraphy, zonation, and age of Schaghticoke, Deepkill, and Normanskill Shales, Eastern New York. Geological Society of America Bulletin, 73, 695-718.

Bodenbender, G. 1911. Constitución geológica de la parte meridional de La Rioja y regiones limítrofes, República Argentina. Boletín de la Academia Nacional de Ciencias, Córdoba, 19, 5-221.

Bodenbender, G. 1912. Parte meridional de la provincia de La Rioja y regiones limítrofes. Anales del Ministerio de Agricultura, Sección Geología, Mineralogía y Minería, Buenos Aires, 7, 9-165.

Bodenbender, G. 1916. El Nevado de Famatina. Boletín de la Academia Nacional de Ciencias, Buenos Aires, 21, 100-182.

Bodenbender, G. 1922. El Nevado de Famatina. Anales del Ministerio de Agricultura, Sección Geología, Mineralogía y Minería, Buenos Aires, 16, 1-68.

Bouček, B. 1957. The dendroid graptolites of the Silurian of Bohemia. Rozpravy Ústředního Ústavu Geologického, 23, 1-294.

Braithwaite, L.F. 1976. Graptolites from the Lower Ordovician Pogonip Group of Western Utah. The Geological Society of America, Special Paper, 166, 1-106.

Brussa, A.D. 1997. Graptolitos del Arenigiano tardío-Llanvirniano de la Formación Sierra de la Invernada, Precordillera occidental sanjuanina. Parte 1. Ameghiniana, 34, 357-372.

Buatois, L.A., Moya, M.C., Mángano, M.G., Malanca, S., Albanesi, G.L. \& Ortega, G. 2003. Paleoenvironmental and sequence stratigraphic framework of the CambrianOrdovician transition in the Angosto del Moreno Area, Northwest Argentina. In: Ordovician from the Andes (Eds. G.L. Albanesi, M.S. Beresi \& S.H. Peralta). Correlación Geológica, Tucumán, 17, 397-401.

Buggisch, W., Bordonaro, O.L., Cañas, F., Gosen, W. v., Keller, M., Krumm, S., Lehnert, O. \& Loske, W. 2000. Sedimentary and structural evolution of the Argentine Precordillera - A key to the history of an exotic terrane. Zeitschrift für Angewandte Geologie, Sonderheft, 1, 355362.

Bulman, O.M.B. 1927. A monograph of British dendroid graptolites. Part 1. Palaeontographical Society Monographs (for 1925), 1-28.

Bulman, O.M.B. 1931. South American graptolites with special reference to the Nordenskjöld Collection. Arkiv för Zoologi, 22A (3), 1-111.

Bulman, O.M.B. 1933. On the graptolites prepared by Holm. VI. Structural characters of some Dictyonema and Desmograptus species from the Ordovician and Silurian rocks of Sweden and the East Baltic region. Arkiv för Zoologi, 26A (5), 1-52.

Bulman, O.M.B. 1934. A monograph of British dendroid graptolites. Part 3. Palaeontographical Society Monographs (for 1932), xxxiii-lx, 65-92.
Bulman, O.M.B. 1938. Graptolithina. In: Handbuch der Paläozoologie -Band 2D (Ed. O.H. Schindewolf). Gebrüder Borntraeger, Berlin, D1-D92.

Bulman, O.M.B. 1941. Some Dichograptids of the Tremadocian and Lower Ordovician. Annals and Magazine of Natural History [11], 7, 100-121.

Bulman, O.M.B. 1950. Graptolites from the Dictyonema Shales of Quebec. Quaterly Journal of the Geological Society of London, 106, 63-99.

Bulman, O.M.B. 1954. The graptolite fauna of the Dictyonema Shales of the Oslo region. Norsk Geologisk Tidsskrift, 33, $1-40$.

Bulman, O.M.B. 1966. Dictyonema from the Tremadocian of Estonia and Norway. Geological Magazine, 103, 407-413.

Bulman, O.M.B. 1970a. A new Dictyonema Fauna from the Salmien of the Stavelot Massif (with a preface by F. Geukens). Bulletin de la Société belge de Géologie, Paléontologie et Hydrogéologie, 79, 213-224.

Bulman, O.M.B. 1970b. Graptolithina, with sections of Enteropneusta and Pterobranchia. In: Treatise on Invertebrate Paleontology, vol. V (2nd. ed) (Ed. R.C. Teichert). The Geological Society of America and the University of Kansas Press, Lawrence, xxxii + 163 pág.

Bulman, O.M.B. 1971. Some species of Bryograptus and Pseudobryograptus from Northwest Europe. Geological Magazine, 108, 361-371.

Bulman, O.M.B. \& Rickards, R.B. 1966. A revision of Wiman's dendroid and tuboid graptolites. Bulletin of the Geological Institutions of the University of Uppsala, 43, 1-72.

Bulman, O.M.B. \& Rushton, A.W.A. 1973. Tremadoc faunas from boreholes in central England. Bulletin of the Geological Survey of Great Britain, 43, 1-40.

Casquet, C., Baldo, E.G., Pankhurst, R.J., Rapela, C.W., Galindo, C., Fanning, C.M. \& Saavedra, J. 2001. Involvement of the Argentine Precordillera terrane in the Famatinian mobile belt: U-Pb SHRIMP and metamorphic evidence from the Sierra de Pie de Palo. Geology, 29, 703-706.

Chapman, A.J., Durman, P.N. \& Rickards, R.B. 1996. A provisional classification of the graptolite Order Dendroidea. Paläontologisches Zeitschrift, 70, 189-202.

Chen, J.-y., Zhou, Z.-y., Zou, X.-p., Lin, Y.-k., Yang, X.-c., Li, Z.-k., Qi, D.-1., Wang, S.-h., Xu, H.-z. \& Zhu, X.d. 1980a. Outline of Ordovician deposits and faunas in Shandung, N. Anhui and N. Jiangsu, E. China. Memoirs of the Nanjing Institute of Geology and Palaeontology, 16, 159-195 (en chino).

Chen, J.-y., Zhou, Z.-y., Zou, X.-p., Lin, Y.-k., Yang, X.-c., Wang, Q.-c., Qi, J.-k., Wang, Q.-Z. \& Lu, X.-1. 1980b. Ordovician sediments and faunas in the Taihang mountains, north China. Memoirs of the Nanjing Institute of Geology and Palaeontology, 16, 111-152 (en chino).

Cooper, R.A. 1979. Sequences and correlation of Tremadoc graptolite assemblages. Alcheringa, 3, 7-19.

Cooper, R.A. 1998. Towards a general model for the depth ecology of graptolites. Temas Geológico-Mineros ITGE, 23, 161-163. 
Cooper, R.A. 1999. Ecostratigraphy, zonation and global correlation of earliest Ordovician planktic graptolites. Lethaia, 32, 1-16.

Cooper, R.A. \& Lindholm, K. 1990. A precise worldwide correlation of early Ordovician graptolite sequences. Geological Magazine, 127, 497-525.

Cooper, R.A. \& Stewart, I. 1979. The Tremadoc graptolite sequence of Lancefield, Victoria. Palaeontology, 22, 767-797.

Cooper, R.A., Maletz, J., Wang, H.-f. \& Erdtmann, B.-D. 1998. Taxonomy and evolution of earliest Ordovician graptoloids. Norsk Geologisk Tidsskrift, 78, 3-32.

Cooper, R.A., Nowlan, G.S. \& Williams, S.H. 2001. Global Stratotype Section and Point for base of the Ordovician System. Episodes, 24, 19-28.

Cooper, R.A., Maletz, J., Taylor, L. \& Zalasiewicz, J.A. 2004. Graptolites: Patterns of diversity across paleolatitudes. In: The Great Ordovician Biodiversification Event (Eds. B.D. Webby, F. Paris, M. Droser \& I.G. Percival). Columbia University Press, New York, 281-293.

Cuerda, A., Cingolani, C.A. \& Varela, R. 1983. Las graptofaunas de la Formación Los Sombreros, Ordovícico inferior, de la vertiente oriental de la Sierra del Tontal, Precordillera de San Juan. Ameghiniana, 20, 239-260.

Cuerda, A.J., Caballé, M., Cingolani, C. \& Alfaro M. 1998. Ordovician (Caradoc) dendroids and their stratigraphic relationships, northeastern Argentine Precordillera. Temas Geológico-Mineros ITGE, 23, 164-169.

Cuerda, A.J., Caballé, M. \& Alfaro, M. 2004. Bioestratigrafía de la Formación Las Vacas (Ordovícico - Precordillera Argentina) basada en graptofaunas. Relaciones con el diastrofismo guandacólico. Ameghiniana, 41, 25-44.

Destombes, J., Hollard, H \& Willefert, S. 1985. Lower Palaeozoic rocks of Morocco. In: Lower Palaeozoic rocks of the world, vol. 4 (Ed. C.H. Holland). John Wiley \& sons, New York, 91-336.

Egenhoff, S.O., Maletz, J. \& Erdtmann, B.-D. 2004. Lower Ordovician graptolite biozonation and lithofacies of southern Bolivia: relevance for palaeogeographic interpretations. Geological Magazine, 141, 287-299.

Eichwald, E. 1840. Über das silurische Schichtensystem in Esthland. St. Petersburg, 210 pp.

Erdtmann, B.-D. 1982a. Palaeobiogeography and environments of planktic dictyonemid graptolites during the earliest Ordovician. In: The Cambrian-Ordovician boundary: sections, fossil distributions, and correlations (Eds. M.G. Bassett \& W.T. Dean). National Museum of Wales, Geological Series, 3, 9-27.

Erdtmann, B.-D. 1982b. A reorganization and proposed phylogenetic classification of planktic Tremadoc (early Ordovician) dendroid graptolites. Norsk Geologisk Tidsskrift, 62, 121-144.

Erdtmann, B.-D. 1986. Comments on some earliest Ordovician (Salmien) graptolites from Solwaster, Massif de Stavelot, Belgian Ardennes. Aardkundige Mededelingen, 3, 75-88.

Erdtmann, B.-D. 1988a. Graptolite-based correlation of earliest Ordovician in eastern North American marginal sequences with coeval succesions in northern China and Oslo, Norway. Bulletin of the New York State Museum, 462, 33-42.

Erdtmann, B.-D. 1988b. The earliest Ordovician nematophorid graptolites: taxonomy and correlation. Geological Magazine, 125, 327-348.

Erdtmann, B.-D. 2001. The "middle" Tremadoc Peltocare Event (PRE): A possible cause for the first major crisis in planktic graptolite evolutionary history. Paleobios, 21, $2^{\text {nd }}$ Supplement, 3-4.

Erdtmann, B.-D. \& Botsford, J.W. 1986. A new early Tremadoc (La1) graptolite faunule from western Newfoundland: its Australian affinity and biofacies relations. Canadian Journal of Earth Sciences, 23, 766-773.

Erdtmann, B.-D. \& Comeau, D.J. 1980. A new Anisograptus faunule from the Goodwin Formation (Tremadoc, Early Ordovician) of central Nevada and the Cambrian-Ordovician boundary. Journal of Paleontology, 54, 719-727.

Erdtmann, B.-D., Kley, J., Müller, J. \& Jacobshagen, V. 1995. Ordovician basin dynamics and new graptolite data from the Tarija Region, Eastern Cordillera, South Bolivia. In: Ordovician Odyssey (Eds. J.D. Cooper, M.L. Droser \& S.C. Finney). The Pacific Section Society for Sedimentary Geology, Fullerton, Book 77, 69-73.

Esteban, S.B. 1992. Presencia de Plesioparabolina sp. (Trilobita) en la Formación Volcancito (Tremadociano), quebrada del Portezuelo de La Alumbrera, Sistema de Famatina, Argentina. Correlación Geológica, Tucumán, 9, 57-61.

Esteban, S.B. 1993. Litofacies de plataforma en la Formación Volcancito (Tremadociano), flanco oriental de la sierra de Famatina, La Rioja, Argentina. Actas XII Congreso Geológico Argentino y II Congreso de Exploración de Hidrocarburos, Mendoza, 1, 116-120.

Esteban, S.B. 1994. Oxygen-deficient facies in the Early Ordovician of the Famatina System, La Rioja province, NW Argentina. Abstracts 14th International Sedimentological Congress, Recife, A-10.

Esteban, S.B. 1996a. El Tremadociano del Sistema de Famatina, Argentina. Correlación Geológica, Tucumán, 12, 261-262.

Esteban, S.B. 1996b. Los primeros trilobites ciclopígidos en el Ordovícico de Argentina (Formación Volcancito, Sistema de Famatina). Ameghiniana, 33, 57-64.

Esteban, S.B. 1999a. Estratigrafía, Geología Sedimentaria y Paleontología del Ordovícico basal del Sistema de Famatina. Tesis Doctoral, Universidad Nacional de Tucumán, 1-189 (inédita).

Esteban, S.B. 1999b. Cyclopygid trilobites and associated facies from the Ordovician of the Famatina basin (Northwestern Argentina): Paleogeographic and evolutionary implications. Acta Universitatis Carolinae, Geologica, 43, 377-379.

Esteban, S.B. 2001. Estructuras biogénicas en facies de grano fino del Tremadociano Superior (Sistema de Famatina, La Rioja, Argentina). Resúmenes IV Reunión Argentina de Icnología y II Reunión de Icnología del Mercosur, Tucumán, 40.

Esteban, S.B. 2002. The Early Ordovician in the Sistema de Famatina: Stratigraphic and geotectonic framework. 
In: Aspects of the Ordovician System in Argentina (Ed. F.G. Aceñolaza). Correlación Geológica, Tucumán, 16, 27-40.

Esteban, S.B. 2003. Biogenic and physical sedimentary structures in latest Cambrian-earliest Ordovician mudrock facies (Famatina Range, Northwestern Argentina). Geologica Acta, 1, 85-94.

Esteban, S.B. \& Gutiérrez-Marco, J.C. 1997. Graptolitos del Tremadoc del Sistema de Famatina (Argentina). In: XIII Jornadas de Paleontología \& V Reunión Internacional del Proyecto 351 PICG (Eds. A. Grandal d'Anglade, J.C. Gutiérrez-Marco, J.C. \& L. Santos Fidalgo), La Coruña, 59-63.

Esteban, S.B. \& Rigby, J.K. 1998. Hexactinellid sponges from the Lower Tremadocian Volcancito Formation, Famatina Range, Northwestern Argentina. Brigham Young University, Geology Studies, 43, 1-7.

Esteban, S.B. \& Zimmermann, U. 2002. Tremadocian successions at the border of Gondwana (northwestern Argentina): Iniciation of the evolution of retro-arc basins? Abstracts $16^{\text {th }}$ International Sedimentological Congress, South Africa, 94-95.

Esteban, S.B., Tortello, M.F., Mángano, M.G., Buatois, L. A. \& Aceñolaza, F.G. 1999. Bioestratigrafía del Paleozoico inferior del Sistema del Famatina. In: Relatorio del XIV Congreso Geológico Argentino, Salta (Eds. G. González Bonorino, R. Omarini \& J. Viramonte). Geología del Noroeste Argentino, 1, 217-223.

Fanning, C.M., Pankhurst, R.J., Rapela, C.N., Baldo, E.G., Casquet, C. \& Galindo, C. 2004. K-bentonites in the Argentine Precordillera contemporaneous with rhyolite volcanism in the Famatinian Arc. Journal of the Geological Society, London, 161, 747-756.

Feng, H. \& Erdtmann, B.-D. 1999. The early Tremadoc graptolite sequence in the Wuning area, South China and its international correlation. Acta Universitatis Carolinae, Geologica, 43, 21-24.

Fernández Fernández, A. \& Moro Benito, M.C. 1996. Presencia de Girvanella y trazas fósiles en los ironstones ordovícicos y metasedimentos encajantes de la provincia de Zamora (España). Geogaceta, 19, 87-90.

Finney, S., Gleason, J., Gehrels, G., Peralta, S. \& Aceñolaza, G. 2003a. Early Gondwanan Connection for the Argentine Precordillera Terrane. Earth and Planetary Science Letters, 205, 349-359.

Finney, S., Gleason, J., Gehrels, G., Peralta, S. \& Vervoort, J.D. 2003b. U/Pb geochronology of detrital zircons from Upper Ordovician Las Vacas, La Cantera, and Empozada formations, NW Argentina. In: Ordovician from the Andes (Eds. G.L. Albanesi, M.S. Beresi \& S.H. Peralta). Correlación Geológica, Tucumán, 17, 191-196.

Finney, S.C., Gleason, J.D., Gehrels, G.E., Peralta, S. \& Aceñolaza, G. 2004. Corrigendum to "Early Gondwanan Connection for the Argentine Precordillera Terrane". Earth and Planetary Science Letters, 219, 413.

Finney, S.C., Peralta, S., Gehrels, G. \& Marsaglia, K. 2005. The Early Paleozoic history of the Cuyania (greater Precordillera) terrane of western Argentina: evidence from geochronology of detrital zircons from Middle Cambrian sandstones. Geologica Acta, en prensa.

Fortey, R.A. 1984. Global earlier Ordovician transgressions and regressions and their biological implications. In: Aspects of the Ordovician System (Ed. D.L. Bruton). Palaeontological Contributions of the University of Oslo, 295, 37-50.

Fortey, R.A. \& Cooper, R.A. 1986. A phylogenetic classification of the graptoloids. Palaeontology, 29, 631-654.

Fortey, R.A. \& Owens, R.M. 1978. Early Ordovician (Arenig) stratigraphy and faunas of the Carmarthen district, southwest Wales. Bulletin of the British Museum (Natural History), Geology, 30, 225-294.

Fortey, R.A., Landing, E. \& Skevington, D. 1982. CambrianOrdovician boundary sections in the Cow Head Group, western Newfoundland. In: The Cambrian-Ordovician boundary: sections, fossil distributions, and correlations (Eds. M.G. Bassett \& W.T. Dean). National Museum of Wales, Geological Series, 3, 95-129.

Fortey, R.A., Harper, D.A.T., Ingham, J.K., Owen, A.W. \& Rushton, A.W.A. 1995. A revision of Ordovician series and stages from the historical type area. Geological Magazine, 132, 15-30.

Galindo, C., Casquet, C., Rapela, C., Pankhurst, R.J., Baldo, E. \& Saavedra, J. 2004. Sr, C and O isotope geochemistry and stratigraphy of Precambrian and Lower Paleozoic carbonate sequences from the western Sierras Pampeanas of Argentina: Tectonic implications. Precambrian Research, 131, 55-71.

Ganis, G.R., Williams, S.H. \& Repetski, J.E. 2001. New biostratigraphic information from the western part of the Hamburg klippe, Pennsylvania, and its significance for interpreting the depositional and tectonic history of the klippe. Geological Society of America Bulletin, 113, 109-128.

Gradstein, F.M \& Ogg, J.G. 2004. Geologic Time Scale 2004 - why, how, and where next!. Lethaia, 37, 175-181.

Gradstein, F.M., Finney, S.C., Lane, R \& Ogg, J.G. 2003. ICS on stage. Lethaia, 36, 371-378.

González Barry, C. \& Alonso, R. 1984. Nuevos graptolites del Tremadociano superior del norte de Argentina. Memorias del III Congreso Latinoamericano de Paleontología, México, 62-67.

Gurley, R.R. 1896. North American Graptolites, part 1. Journal of Geology, 4, 63-102.

Gutiérrez-Marco, J.C. \& Esteban, S.B. 2003. Reappraisal of the Tremadocian graptolite sequence of the Famatina System, NW Argentina. In: Proceedings of the $7^{\text {th }}$ International Graptolite Conference (Eds. G. Ortega \& G.F. Aceñolaza). Correlación Geológica, Tucumán, 18, 39-44.

Gutiérrez-Marco, J.C. \& Esteban, S.B. 2004. Los graptolitos del Paleozoico Inferior de la sierra de Famatina. In: Simposio Bodenbender (Eds. F.G. Aceñolaza, G.F. Aceñolaza, M. Hünicken \& A.J. Toselli). INSUGEO Miscelánea, 13, 35.

Gutiérrez-Marco, J.C. \& Lenz, A.C. 1998. Graptolite synrhabdosomes: biological or taphonomic entities? Paleobiology, 24, 37-48.

Gutiérrez-Marco, J.C., Carlotto, V., Cárdenas, J., Finney, S.C., 
Rábano, I., Villas, E. \& Herrera, Z. 2004. Paleontología y rasgos paleobiogeográficos del Ordovícico del sur de Perú. In: Resúmenes Extendidos XII Congreso Peruano de Geología (Eds. J. Dávila, V. Carlotto \& A. Chalco). Sociedad Geológica del Perú, Publicación Especial 6, 455-458.

Hall, J. 1862. Report of the superintendent of the Geological Survey, exhibiting the progress of the work. January 1, 1861 (including descriptions of new species of fossils from the investigations of the survey). Wisconsin Geological Survey, Madison, 1-52.

Harrington, H.J. \& Leanza, A.F. 1957. Ordovician trilobites of Argentina. Department of Geology, University of Kansas, Special Publication, 1, 1-276.

Hernández Sampelayo, P. 1915. Fósiles de Galicia. Nota sobre la fauna paleozoica de la provincia de Lugo. Boletín del Instituto Geológico de España, 36, 277-303.

Huff, W.D., Bergström, S.M., Kolata, D.R., Cingolani, C. \& Astini, R.A. 1998. Ordovician K-bentonites in the Argentine Precordillera: relations to Gondwana margin evolution. In: The Proto-Andean Margin of Gondwana (Eds. R.J. Pankhurst \& C.W. Rapela). Special Publication of the Geological Society, London, 142, 107-126.

Huff, W.D., Bergström, S.M., Kolata, D.R., Cingolani, C., Krekeler, M.P. \& Prokopenko, M. 2003. Ordovician Kbentonites in the Argentine Precordillera and their relation to Laurentian volcanism. In: Ordovician from the Andes (Eds. G.L. Albanesi, M.S. Beresi \& S.H. Peralta). Correlación Geológica, Tucumán, 17, 197-202.

Hughes, C.P. 1980. A brief review of the Ordovician faunas of northern South America. Actas II Congreso Argentino de Paleontología y Bioestratigrafía, y I Congreso Latinoamericano de Geología, Buenos Aires 1978, 1, 11-22.

IUGS. 2004. International Stratigraphic Chart (produced by J.G. Ogg). International Commission on Stratigraphy. www.stratigraphy.org/cheu.pdf; A Geological Time Scale 2004 (produced by F.M. Gradstein and 38 coll.). Geological Survey of Canada, Miscellaneous Report 86.

Jackson, D.E. \& Lenz, A.C. 2000. Some graptolites from the late Tremadoc and early Arenig of Yukon, Canada. Canadian Journal of Earth Sciences, 37, 1177-1193.

Jin, Y-q. \& Wang, X-f. 1977. The discovery of graptolites in the Baishuxi Formation of the Early Ordovician in central Hunan and the multiramous graptolites in the Qiaotingzi Formation. Professional Papers of Stratigraphy and Palaeontology, Beijing, 3, 74-85 (en chino).

Keller, M. 1999. Argentine Precordillera: Sedimentary and plate tectonic history of a Laurentian crustal fragment in South America. Geological Society of America, Special Paper, 341, 1-131.

Koukharsky, M., Torres Claro, R., Etcheverría, M., Vaccari, N. \& Waisfeld, B. 1996. Episodios volcánicos del Tremadociano y del Arenigiano en Vega Pinato, Puna salteña, Argentina. Actas XIII Congreso Geológico Argentino y III Congreso de Exploración de Hidrocarburos, Buenos Aires, 5, 535-542.

Landing, E. 1993. Cambrian-Ordovician boundary in the Taconic allochthon, eastern New York, and its interregional correlation. Journal of Paleontology, 67, 1-19.
Lavandaio, E. 1971. Hallazgo de graptolites arenigianos en el Ordovícico de la sierra del Famatina, La Rioja, Rep. Argentina. Revista de la Asociación Geológica Argentina, 26, 527.

Lavandaio, E. 1973. Geología del sector Cerro Tolar-Cuchilla Negra, Sierra del Famatina, La Rioja, Argentina. Actas $V$ Congreso Geológico Argentino, Buenos Aires, 4, 41-54.

Legrand, P. 1973. Resultats récents sur le problème de la limite Cambrien-Ordovicien au Sahara Algerien Septentrional. Bulletin de la Société d'Histoire Naturel d'Afrique du Nord, 64, 159-180.

Lemon, R.R.H. \& Cranswick, J.S. 1956. Graptolites from Huacar, Peru. Publicaciones del Museo de Historia Natural "Javier Prado" [C -Geología], 5, 1-32.

Lenz, A.C. \& Kozlowska-Dawidziuk, A. 2002. Upper Homerian (upper Wenlock, Silurian) graptolites from Artic Canada. Journal of Paleontology, 76, 321-346.

Lin, Y.-k. 1983. Upper Cambrian dendroid graptolites from the Taizihe valley, Liaoning. Acta Palaeontologica Sinica, 22, 262-277.

Lin, Y.-k. 1992. Dendroid graptolites from Changshan Formation (Late Cambrian) of Xiyushan Mountain, Tangshan, Hebei. Acta Palaeontologica Sinica, 31, 100-107.

Linnemann, U., Elicki, O. \& Gaitzsch, B. 2003. Die Stratigraphie des Saxothuringikums. Geologica Saxonica, 4849, 29-70.

Malanca, S. 2002. Trilobites del límite Cámbrico-Ordovícico en El Angosto del Moreno, Cordillera Oriental argentina. Resúmenes VIII Congreso Argentino de Paleontología y Bioestratigrafía, Corrientes, 87-88.

Malanca, S., Monteros, J.A. \& Moya, M.C. 1998. Nuevos datos paleontológicos de la Formación Las Vicuñas (Tremadoc temprano), Puna occidental argentina. Resúmenes VII Congreso Argentino de Paleontología y Bioestratigrafía, Bahía Blanca, 90.

Maletz, J. \& Egenhoff, S.O. 2001. Late Tremadoc to early Arenig graptolite faunas of southern Bolivia and their implications for a worldwide biozonation. Lethaia, $\mathbf{3 4}$, 47-62.

Maletz, J. \& Egenhoff, S.O. 2003. Lower to Middle Ordovician graptolite biostratigraphy of southern Bolivia. Revista Técnica de YPFB, 21, 103-115.

Maletz, J. \& Ortega, G. 1995. Ordovician graptolites of South America: Palaeogeographic implications. In: Ordovician Odyssey (Eds. J.D. Cooper, M.L. Droser \& S.C. Finney). The Pacific Section Society for Sedimentary Geology, Fullerton, book 77, 189-192.

Maletz, J., Egenhoff, S.O. \& Erdtmann, B.-D. 1999. Late Tremadoc to early Arenig graptolite succession of southern Bolivia. Acta Universitatis Carolinae, Geologica, 43, 29-32.

Mángano, M.G. \& Buatois, L.A. 1996. Shallow marine event sedimentation in a volcanic arc-related setting: the Ordovician Suri Formation, Famatina Range, northwest Argentina. Sedimentary Geology, 105, 63-90.

Mángano, M.G., Astini, R.A., Buatois, L.A. \& Dávila, F. 2002. The Ordovician System in the Famatina Belt: Depositional and Tectonic evolution. In: Aspects of the 
Ordovician System in Argentina (Ed. F.G. Aceñolaza). Correlación Geológica, Tucumán, 16, 295-312.

Mannheim, R. 1993. Génesis de las volcanitas eopaleozoicas del Sistema del Famatina, Noroeste de Argentina. Actas XII Congreso Geológico Argentino y II Congreso de Exploración de Hidrocarburos, Mendoza, 4, 147-155.

Matthews, S.C. 1973. Notes on open nomenclature and on synonymy lists. Palaeontology, 16, 713-719.

McCormick, T. \& Fortey, R.A. 1999. The most widely distributed trilobite species: Ordovician Carolinites genacinaca. Journal of Paleontology, 73, 202-218.

Miller, J.F. \& Stitt, J.H. 1995. Stratigraphic position and significance of Jujuyaspis and Iapetognathus in the Wilberns Formation, Texas. In: Ordovician Odyssey (Eds. J.D. Cooper, M.L. Droser \& S.C. Finney). Pacific Section Society for Sedimentary Geology, Fullerton, book 77, 105-108.

Miller, S.A. 1889. North American Geology and Paleontology. Western Methodist Book Concern, Cincinnati, 1-664.

Monteros, J.A. 1999. Anisograptus delicatulus Cooper \& Stewart en la Sierra de Mojotoro, Cordillera Oriental Argentina. Implicancias bioestratigráficas. Actas XIV Congreso Geológico Argentino, Salta, 1, 50-51.

Moya, M.C. \& Albanesi, G.L. 2000. New stratigraphic section to define the Cambrian-Ordovician boundary in Eastern Cordillera, northwest Argentina. In: Cambrian from the southern edge (Eds. G.F. Aceñolaza \& S. Peralta). Instituto Superior de Correlación Geológica, Tucumán, Miscelánea 6, 114-116.

Moya, M. C., Malanca, S., Monteros, J.A. \& Cuerda, A. 1994. Bioestratigrafía del Ordovícico inferior en la Cordillera Oriental argentina basada en graptolites. Revista Española de Paleontología, 9, 91-104.

Moya, M.C., Monteros, J.A. \& Monaldi, C.R. 1998. Graptolite dating of a Lower Ordovician unconformity in the Argentinian Andes. Temas Geológico-Mineros ITGE, 23, 227-230.

Moya, M.C., Malanca, S. \& Monteros, J.A. 2003a. The Cambrian-Tremadocian units of the Santa Victoria Group (northwestern Argentina): a new correlation scheme. In: Ordovician from the Andes (Eds. G.L. Albanesi, M.S. Beresi \& S.H. Peralta). Correlación Geológica, Tucumán, 17, 105-111.

Moya, M.C., Malanca, S., Monteros, J.A., Albanesi, G.L., Ortega, G. \& Buatois, L.A. 2003b. Late Cambrian -Tremadocian faunas and events from Angosto del Moreno Section, Eastern Cordillera, Argentina. In: Ordovician from the Andes (Eds. G.L. Albanesi, M.S. Beresi \& S.H. Peralta). Correlación Geológica, Tucumán, 17, 439-444.

Moya, M.C., Monteros, J.A., Malanca, S. \& Albanesi, G.L. 2003c. The Mojotoro Range, Eastern Cordillera, Salta Province. In: Ordovician and Silurian of the Cordillera Oriental and Sierras Subandinas, NW Argentina. Field Trip Guide (Eds. M.C. Moya, G. Ortega, J.A. Monteros, S. Malanca, G.L. Albanesi, L.A. Buatois \& F.J.Zeballo, F.J.). Instituto Superior de Correlación Geológica, Tucumán, Miscelánea 11, 17-22 y 59-64.
Moya, M.C., Malanca, S., Monteros, J.A., Albanesi, G.L., Ortega, G. \& Buatois, L.A. 2003d. The Angosto del Moreno area, Eastern Cordillera, Jujuy Province. In: Ordovician and Silurian of the Cordillera Oriental and Sierras Subandinas, NW Argentina. Field Trip Guide (Eds. M.C. Moya, G. Ortega, J.A. Monteros, S. Malanca, G.L. Albanesi, L.A. Buatois \& F.J.Zeballo, F.J.). Instituto Superior de Correlación Geológica, Tucumán, Miscelánea 11, 29-35 y 70-79.

Moya, M.C., Monteros, J.A., Malanca, S., Ortega, G. \& Albanesi, G.L. 2003e. Quebrada del Toro and Angosto de La Quesera, Eastern Cordillera, Salta Province. In: Ordovician and Silurian of the Cordillera Oriental and Sierras Subandinas, NW Argentina. Field Trip Guide (Eds. M.C. Moya, G. Ortega, J.A. Monteros, S. Malanca, G.L. Albanesi, L.A. Buatois \& F.J.Zeballo, F.J.). Instituto Superior de Correlación Geológica, Tucumán, Miscelánea 11, 47-49 y 89-91.

$\mathrm{Mu}$, A.T. 1953. A preliminary study on the graptolites in the Taitzeho Valley, Liaotung. Acta Palaeontologica Sinica, 1, 23-35 (en chino).

$\mathrm{Mu}$, A.T. 1955. The new materials of the dendroid graptolites of China. Palaeontologia Sinica, 138 (5 of the New Series B), 1-62 (en chino).

Mu, E.-z., Ge, M.-y., Chen, X., Ni, Y.-n. \& Lin, Y.-k. 1979. Lower Ordovician graptolites of Southwest China. Palaeontologia Sinica, 156 (13 of the New Series B), 1-156 (en chino).

Mu, E.-z., Li, J.-j., Ge, M.-y., Lin, Y.-k. \& Ni, Y.-n. 2002. The fossil Graptolites of China. Science press, Beijing, i-xiv, 1-1205 (en chino).

Obut, A.M. 1964. Podtip Stomochordata. Stomokhor dovye. In: Osnovy paleontologii: Echinodermata, Hemichordata, Pogonophora $i$ Chaetognatha (Ed. Y.A. Orlov). Nedra Press, Moskva, 279-337 (en ruso).

Obut, A.M. \& Sennikov, N.V. 1984. Graptolites and zonal subdivisions of the Lower Ordovician of the Gorny Altai. In: Lower Ordovician Stratigraphy and Fauna of Mountain Altai (Eds. E.I. Mjagkova \& A.G. Yadrenkina). Nauka, Moscow, 53-106 (en ruso).

Ogg, J.G. 2004. Status of divisions of the International Geologic Time Scale. Lethaia, 37, 183-1999.

Ortega, G. 1987. Las graptofaunas y los conodontes de la Formación Los Azules, Cerro Viejo, Zona de Huaco, Departamento de Jáchal, San Juan. Tesis doctoral, Universidad Nacional de Córdoba, Argentina (inédita).

Ortega, G. \& Albanesi, G.L. 2002. Bioestratigrafía de graptolitos y conodontes del tremadociano tardío de la Cordillera Oriental argentina. Actas del XV Congreso Geológico Argentino, El Calafate, 1, 542-547.

Ortega, G. \& Rao, R.I. 1995. Nuevos hallazgos de graptolitos (Ordovícico Inferior) en la sierra de Cajas, Departamento Humahuaca, provincia de Jujuy, Argentina. Boletín de la Academia Nacional de Ciencias, Córdoba, 60, 293-316.

Ortega, G. \& Suárez-Soruco, R. 1994. Graptofaunas del Ordovícico inferior (Tremadociano-Arenigiano temprano) en el área de Culpina, Departamento de Chuquisaca, sur de Bolivia. Revista Técnica de YPFB, 15, 217-244. 
Ortega, G., Albanesi, G.L. \& Rao, R.I. 1998. Lower Ordovician graptolites and conodonts from Cajas range and Parcha area, Eastern Cordillera, northern Argentina. Temas Geológico-Mineros ITGE, 23, 236-240.

Pankhurst, R.J. \& Rapela, C.W. (Eds.) 1998. The Proto-Andean Margin of Gondwana. Geological Society, London, Special Publications, 142, 383 pp.

Peralta, S.H. 1986. Graptofaunas del Llanvirniano inferior (Ordovícico) y Ludlowiano inferior (Silúrico) en la Formación Rinconada, Precordillera Oriental de San Juan. Actas IV Congreso Argentino de Paleontología y Bioestratigrafía, Mendoza, 1, 59-66.

Perejón, A., Fröhler, M., Bechstädt, T., Moreno-Eiris, E. \& Boni, M. 2000. Archaeocyathan assemblages from the Gonessa Group, Lower Cambrian (Sardinia, Italy) and their sedimentologic context. Bolletino della Società Paleontologica Italiana, 39, 257-291.

Rábano, I. 1983. The Ordovician trilobite Hungioides Kobayashi, 1936 (Asaphina, Dikelokephalinidae) from Spain. Geobios, 16, 431-441.

Rao, R.I. 1999. Los conodontes Cambro-Ordovícicos de la Sierra de Cajas y del Espinazo del Diablo, Cordillera Oriental, República Argentina. Revista Española de Micropaleontología, 31, 23-51.

Ramos, V.A. 1999. Rasgos estructurales del territorio argentino. 1. Evolución tectónica de la Argentina. In: Geología Argentina (Ed. R. Caminos). Anales del Instituto de Geología y Recursos Minerales, Servicio Geológico Minero Argentino, 29, 715-784.

Ramos, V.A. 2000. The Southern Central Andes. In: Tectonic Evolution of South America. (Eds. U.G. Cordani, E.J. Milani, A. Thomaz Filho \& D.A. Campos). $31^{\text {st }}$ International Geological Congress, Brazil, 561-604.

Ramos, V.A. \& Keppie, J.D., Eds. 1999. Laurentia-Gondwana Connections before Pangea. Geological Society of America, Special Paper, 336, 1-276.

Rapela, C.W., Coira, B., Toselli, A.J. \& Saavedra, J. 1992. The Lower Paleozoic magmatism of southern Gondwana and the evolution of Famatinian orogen. International Geology Review, 34, 1081-1142.

Rapela, C.W., Pankhurst, R.J., Casquet, C., Baldo, E., Saavedra, J. \& Galindo, C. 1998. Early evolution of the Proto-Andean margin of South America. Geology, 26, 707-710.

Rickards, R.B. \& Wright, A.J. 1997. Graptolites of the Barnby Hills Shale (Silurian, Ludlow), New South Wales, Australia. Proceedings of the Yorkshire Geological Society, 51, 209-227.

Rickards, R.B., Baillie, P.W. \& Jago, J.B. 1990. An Upper Cambrian (Idamean) dendroid assemblage from near Smithton, northwestern Tasmania. Alcheringa, 14, 207 232.

Rickards, R.B., Packham, G.H., Wright, A.J. \& Williamson, P.L. 1995. Wenlock and Ludlow graptolite faunas and biostratigraphy of the Quarry Creek district, New South Wales. Memoir of the Association of Australasian Palaeontologists, 17, 1-68.

Rickards, R.B., Hamedi, M.A. \& Wright, A.J. 2001. A new assemblage of graptolites, rhabdopleuran hemichordates and chitinous hydroids from the late Arenig (Ordovician) of the Banestan area, east-central Iran. Alcheringa, 25, 169-190.

Ross, R.J. \& Berry, W.B.N. 1963. Ordovician graptolites of the Basin Ranges in California, Nevada, Utah, and Idaho. United States Geological Survey Bulletin, 1134, i-v, 1-177.

Rubiolo, D., Cisterna, C., Villeneuve, M. \& Hickson, C. 2002. Edad U-Pb del granito de Las Angosturas en la Sierra de Narváez (Sistema de Famatina, provincia de Catamarca). Actas del XV Congreso Geológico Argentino, El Calafate, $\mathbf{1}, 359-362$.

Ruedemann, R. 1904. Graptolites of New York. Part 1. Graptolites of the Lower Beds. New York State Museum, Memoir 7, 455-803.

Ruedemann, R. 1916. Paleontologic contributions from New York State Museum, 1. New York State Museum, Bulletin 189, 7-98.

Ruedemann, R. 1947. Graptolites of North America. Geological Society of America, Memoir 19, 1-652.

Salter, J.W. 1858. On Graptopora, a New Genus of Polyzoa, allied to the graptolites. Proceedings of the American Association for Advancement of Science, 11 (for 1857), 63-66.

Salter, J.W. 1866. The geology of north Wales. Geological Survey of Great Britain, 3, 239-381.

Sennikov, N.V. 1994. Siberian graptolite associations from Cambrian-Ordovician boundary beds. In: Graptolite Research Today (Eds. X. Chen, B.-D. Erdtmann \& Y.-n. Ni). Nanjing University Press, 159-163.

Shergold, J.H. 2000. The Early Ordovician trilobite genus Jujuyaspis in Australia. In: Cambrian from the southern edge (Eds. G.F. Aceñolaza \& S. Peralta). Instituto Superior de Correlación Geológica, Tucumán, Miscelánea $\mathbf{6}$, 128-130.

Sherwin, L. \& Rickards, B. 2002. Late Silurian (Pridoli) graptolites from the Wallace Shale, New South Wales. Alcheringa, 26, 87-101.

Skevington, D. 1963. Graptolites from the Ontikan limestones (Ordovician) of Öland, Sweden. I: Dendroidea, Tuboidea, Camaroidea, and Stolonoidea. Bulletin of the Geological Institutions of the University of Uppsala, 42, 1-62.

Sobolevskaya, R.F. 1971. New Ordovician graptolites of the Omulev Mountains. Paleontological Journal, 5, 76-81 (pág. 82-87 en la versión rusa original en Paleontologicheskii Zhurnal).

Sobolevskaya, R.F. \& Koren', T.N. 1997. Graptoliti Ordovika i Silura Novoi Zemli. In: Atlas zonalnij kompleksov vedyshij grup ranepaleozoiskoi fauni severa Rocii. Graptoliti, trilobiti (Ed. T.N. Koren'). VSEGEI, Sankt-Petersburg, 5-99, 134-175, 200-204 (en ruso).

Sour, F. \& Buitrón, B.E. 1987. Los graptolitos del Tremadociano de Ixtaltepec, Oaxaca. Consideraciones sobre el límite Cámbrico-Ordovícico en la región. Revista de la Sociedad Mexicana de Paleontología, 1, 380-395.

Spjeldnaes, N. 1986. Astogenetic development of some lower Ordovician graptolites from Norway. In: Palaeoecology and Biostratigraphy of Graptolites (Eds. C.P. Hughes \& 
R.B. Rickards). Geological Society Special Publication, London, 20, 97-102.

Spincer, B.R. 1998. Oolitized fragments of filamentous calcimicrobes and the pseudofossil affinity of Nuia Maslov from the Upper Cambrian rocks of central Texas. Journal of Paleontology, 72, 577-584.

Steinmann, G. 1929. Geologie von Perú, mit Beiträgen von R. Stappenbeck, F. Sieberg \& C. Lissón. Carls Winters Universitätsbuchhandlung, Heidelberg, 1-448.

Stelzner, A. 1872. Beiträge zur Geologie und Paläontologie der Argentinischen Republik. Geologische Teil. Cassel, Berlin, 275 pp. (Traducción española en Actas de la Academia Nacional de Ciencias, Córdoba, 8, 1-228, año 1923).

Sureda, R.J. \& Omarini, R.H. 1999. Evolución geológica y nomenclatura pre-Gondwánica en el noroeste de Argentina (1800-160 Ma). Acta Geologica Hispanica, 34, 197-225.

Thomas, W.A. \& Astini, R.A. 1996. The Argentine Precordillera: A traveler from the Ouachita embayment of North American Laurentia. Science, 273, 752-757.

Thomas, W.A. \& Astini, R.A. 2003. Ordovician accretion of the Argentine Precordillera terrane to Gondwana: A review. Journal of South American Earth Sciences, 16, 67-79.

Thomas, W.A., Astini, R.A. \& Bayona, G. 2002. Ordovician collision of the Argentine Precordillera with Gondwana, independent of Laurentian Taconic orogeny. Tectonophysics, 345, 131-152.

Thomas, W.A., Astini, R.A., Mueller, P.A., Gehrels, G.E. \& Wooden, J.L. 2004. Transfer of the Argentine Precordillera terrane from Laurentia: Constraints from detrital-zircon geochronology. Geology, 32, 965-968.

Toro, B.A. 1997. Asociaciones de graptolitos del Arenig de la localidad tipo de la Formación La Alumbrera, Sistema de Famatina, Argentina. Revista Española de Paleontología, 12, 43-51.

Toro, B.A. \& Brussa, E.D. 2003. Chapter 11. Graptolites. In: Ordovician fossils of Argentina (Ed. J.L. Benedetto). Secretaría de Ciencia y Tecnología, Universidad Nacional de Córdoba, 441-505.

Tortello, M.F. 2003. Biostratigraphic significance of the latest Cambrian-earliest Ordovician agnostoid trilobites from Northwestern Argentina. Geologica Acta, 1, 61-72.

Tortello, M.F. \& Esteban, S.B. 1995. Un trilobite agnóstido en el Ordovícico de la región de Bordo Atravesado (Cuesta de Miranda), Provincia de La Rioja, Argentina. Actas del VI Congreso Argentino de Paleontología y Bioestratigrafía, Trelew, 271-275.

Tortello, M.F. \& Esteban, S.B. 1997. Significado bioestratigráfico de una asociación de trilobites del tramo basal de la Formación Volcancito (Sistema de Famatina, La Rioja, Argentina). Ameghiniana, 34, 265-270.

Tortello, M.F. \& Esteban, S.B. 1998. La transición Cámbrico-Ordovícica en la Formación Volcancito (Sistema de Famatina, La Rioja, Argentina). Resúmenes del VII Congreso Argentino de Paleontología y Bioestratigrafía, Bahía Blanca, 93.
Tortello, M.F. \& Esteban, S.B. 1999. La transición Cámbrico-Ordovícico en la Formación Volcancito (sierra de Famatina, La Rioja, Argentina). Ameghiniana, 36, 371-387.

Tortello, M.F. \& Esteban, S.B. 2003a. Occurrence of the Early Ordovician trilobite Jujuyaspis keideli Kobayashi in the Despensa Formation, Aguilar Range, Northwestern Argentina. In: Ordovician from the Andes (Eds. G.L. Albanesi, M.S. Beresi \& S.H. Peralta). Correlación Geológica, Tucumán, 17, 333-335.

Tortello, M.F. \& Esteban, S.B. 2003b. Lower Ordovician stratigraphy and trilobite faunas from the southern Famatina Range, La Rioja, Argentina. Special Papers in Palaeontology, 70, 213-239.

Tortello, M.F., Esteban, S.B. \& Lech, R.R. 1996. Paleontología del Sistema de Famatina. Münchner Geologische Hefte, Allgemeine Geologie, A19, 125-136.

Tortello, M.F., Esteban, S.B. \& Aceñolaza, G.F. 2002. Trilobites from the base of the Ordovician System in Argentina. In: Aspects of the Ordovician System in Argentina (Ed. F.G. Aceñolaza). Correlación Geológica, Tucumán, 16, 131-142.

Toselli, G. 1975. Contribución al conocimiento geológico de la región de Volcancito, Sierra de Famatina, provincia de La Rioja. Tesis Doctoral, Universidad Nacional de Córdoba, 1-170 (inédita).

Toselli, G. 1977. El Paleozoico Inferior y Medio de la región de Volcancito, Sierra de Famatina, provincia de La Rioja. Acta Geológica Lilloana, 14, 83-104.

Turner, J.C.M. 1960. Faunas graptolíticas de América del Sur. Revista de la Asociación Geológica Argentina, 14, $5-180$

Turner, J.C.M. 1964. Descripción geológica de la Hoja 15c Vinchina (Provincia de La Rioja). Boletín Dirección Nacional de Geología y Minería, Buenos Aires, 100, 1-81.

Vaccari, N.E. 1995. Early Ordovician trilobite biogeography of Precordillera and Famatina, western Argentina: preliminary results. In: Ordovician Odyssey (Eds. J.D. Cooper, M.L. Droser \& S.C. Finney). Pacific Section Society for Sedimentary Geology, Fullerton, book 77, 193-196.

Wang, H.-f., Cooper, R.A. \& Erdtmann, B.-D. 1998. Restudy on the earliest Ordovician graptolites from the Dayangcha section in Jilin. Acta Palaeontologica Sinica, 37, 212-234.

Wang, X.-f. 2000. The Tremadoc (Ordovician) graptolite diversification events. Palaeontology Down Under 2000, Geological Society of Australia, Abstracts, 61, 124-125.

Wang, X.-f. \& Erdtmann, B.-D. 1987. Zonation and correlation of the earliest Ordovician graptolites from Hunjiang, Jilin province, China. Bulletin of the Geological Society of Denmark, 35, 245-257.

Wang, X.-f. \& Wang, C.-s. 2001. Tremadocian (Ordovician) graptolite diversification events in China. Alcheringa, 25, 155-168.

Wang, X.-f., Jin, Y.-j., Wu, Z.-t., Fu, H.-y., Li, Z.-c. \& Ma, K.-k. 1977. Graptolithina. In: Handbook of Palaeontology of Central-South China, Pt. 1, Early Paleozoic Era (Ed. Hubei Institute of Geological Science). Geological Press, Beijing, 266-371 (en chino). 
Webby, B.D., 1998. Steps toward a global standard for Ordovician stratigraphy. Newsletters on Stratigraphy, 36, 1-33.

Webby, B.D., Cooper, R.A., Bergström, S.M. \& Paris, F. 2004. Stratigraphic framework and time slices. In: The Great Ordovician Biodiversification Event (Eds. B.D. Webby, F. Paris, M. Droser \& I.G. Percival), Columbia University Press, New York, 41-47.

Wilde, P., Quinby-Hunt, M.S., Berry, W.B.N. \& Orth, C.J. 1989. Palaeo-oceanography and biogeography in the Tremadoc (Ordovician) Iapetus Ocean and the origin of the chemostratigraphy of Dictyonema flabelliforme black shales. Geological Magazine, 126, 19-27.

Williams, S.H. \& Stevens, R.K. 1991. Late Tremadoc graptolites from western Newfoundland. Palaeontology, 34, $1-47$.

Xiao, C.-X. \& Zhong, G.-p. 1988. Some dendroid graptolites of Shihtzupu Formation from Shiqian, Guizhou. Acta Palaeontologica Sinica, 27, 213-217 (en chino).

Yin, G.-z., Gong, L.-z., Cai, Y. \& Jiao, H.-1. 1984. On the Cambrian-Ordovician boundary in Guizhou of China. In: Scientific Papers on Geology for International Exchange -prepared for the $27^{\text {th }}$ International Geological Congress. Geological publishing House, Beijing, 25-34.

Yu, J.-h., Liu, H.-b. \& Fang, Y.-t. 1985. Dendroids from the Xinchangian Stage (Early Ordovician) of the Xiushui Drainage Basin, Jiangxi Province. Acta Palaeontologica Sinica, 24, 18-28 (en chino).

Zhang, Y. \& Erdtmann, B.-D. 2004a. Tremadocian (Ordovician) biostratigraphy and graptolites at Dayangcha (Baishan, Jilin, NE China). Paläontologische Zeitschrift, 78, 323-354.

Zhang, Y. \& Erdtmann, B.-D. 2004b. Astogenetic aspects of the dendroid graptolite Airograptus (Late Cambrian-Early
Ordovician) and their phylogenetic implications. Lethaia, 37, 457-465.

Zhang, Y., Erdtmann, B.-D. \& Feng, H. 2003. Tremadocian graptolite biostratigraphy of China and its international correlation. In: Proceedings of the $7^{\text {th }}$ International Graptolite Conference (Eds. G. Ortega \& G.F. Aceñolaza). Correlación Geológica, Tucumán, 18, 105-113.

Zhang, Y., Erdtmann, B.-D. \& Feng, H. 2004. Tremadocian (Early Ordovician) graptolite biostratigraphy of China. Newsletters on Stratigraphy, 40, 155-182.

Zhou, Z.-y., Dean, W.T. \& Luo, H.-1. 1998. Early Ordovician trilobites from Dali, west Yunnan, China, and their palaeogeographical significance. Palaeontology, 41, 429-460.

Zhou, Z.-y., Wang, Z.-h., Zhang, J.-m., Lin, Y.-k. \& Zhang, J.-1. 1984. Cambrian-Ordovician boundary sections and the proposed candidates for stratotype in North and Northeast China. In: Stratigraphy and Palaeontology of Systemic Boundaries in China. Vol. 2, Cambrian-Ordovician Boundary. Anhui Science and Technology Publishing House, 1-57.

Zimmermann, U. \& Esteban, S.B. 2002. Provenance and facies of the Volcancito Formation, Famatina Range (Northwestern Argentina). Actas XV Congreso Geológico Argentino, El Calafate, 1, 786-791.

Zimmermann, U., Bahlburg, H. \& Esteban, S.B. 2003. Depositional history of the Ordovician Famatina Basin (western Gondwana; NW Argentina). In: Ordovician from the Andes (Eds. G.L. Albanesi, M.S. Beresi \& S.H. Peralta). Correlación Geológica, Tucumán, 17, 487-493.

Manuscrito recibido: 6 de Julio, 2004 Manuscrito aceptado: 28 de Febrero, 2005 